\title{
Article
}

\section{Offering an Invisible Hand: The Rise of the Personal Choice Model for Rationing Public Benefits}

\author{
David A. Super ${ }^{\dagger}$
}

\section{CONTENTS}

I. INTRODUCTION

II. TRANSFORMING THE RATIONING OF PUBLIC BENEFITS

A. The Declining Importance of Formal Eligibility Rules

B. An Overview of the Managed Choice Alternative to Formal Eligibility Rules.

1. Possible Responses to Shortcomings in Formal Eligibility Rules

2. Differential Responses to Informal Rationing Systems .........830

3. Quantifying the Impact of Informal Rationing

C. Formal, Informal, and Hybrid Rationing Systems 836

1. Establishing and Modifying Informal Rationing Systems

2. The Visibility of Rationing Systems

$\dagger$ Visiting Professor of Law, Washington \& Lee University Law School. The comments of Anne Alstott, Helen Hershkoff, Jon Michaels, Wendell Primus, and Isaac Shapiro, and the tireless research of Melanie Coleman and Meri $O$. Triades, greatly strengthened this Article. The author is deeply indebted to Kelly Dunbar of The Yale Law Journal for his invaluable editorial guidance. The author is grateful to the Frances Lewis Law Center at Washington \& Lee University Law School for its generous support of this research. 
3. Absolute or Probabilistic Control of Program Participation.

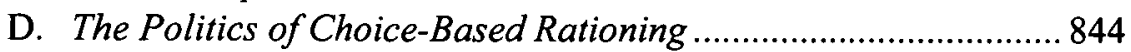

1. The Appeal of Choice-Based Rationing ................................ 844

2. The Decentralization of Decisionmaking on Informal Rationing.

E. The Efficiency, Equity, and Authenticity of Choice-Based Rationing

III. How Principles of Choice AfFect the Design of Programs' SUBSTANTIVE ELIGIBILITY RULES

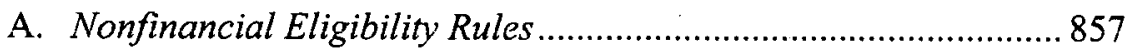

1. Requirements To "Earn" Eligibility ..................................857

2. Linkages to Receipt of Other Public Benefits ...................... 859

B. Replacing Means-Testing with the Invisible Hand ......................8 861

1. Income Eligibility and Claimant Choice ............................... 862

2. Resource Eligibility and Claimant Choice ............................8 864

IV. LAW AND ADVOCACY IN RESPONSE TO CHOICE-BASED RATIONING STRATEGIES

A. The Declining Importance of Formal Modes of Legal Advocacy in the Choice-Based Public Benefits System 868

1. The Proliferation of Sources of Public Benefits Law 869

2. The Limitations of Fair Hearings as Responses to Choice-Based Rationing Techniques.

3. The Demise of Public Benefits Litigation. 874

4. The Decline of the Attorney-Client Relationship as the Paradigm for Public Benefits Advocacy 876

B. Advocacy in the New Public Benefits Environment .....................880

1. A Nonadversarial Alternative to Fair Hearings....................882

2. Managing Program Administrators' Incentives.................... 883

3. The Value of Incentive-Based Public Benefits Advocacy...... 888 


\section{INTRODUCTION}

\section{As the Personal Responsibility and Work Opportunity Reconciliation} Act (PRWORA) of $1996^{l}$ was in debate, both supporters and opponents focused on what changes it would make in formal eligibility rules for means-tested programs. The legislation's champions emphasized its new work requirements that were widely popular with the general public, but generally avoided talking about reductions in benefits. The message they sought to convey was that assistance would remain available to those who demonstrated their willingness to try to help themselves through work. ${ }^{2}$

Opponents, in turn, tried to portray the legislation as hardhearted and predicted that states would impose eligibility rules denying assistance to numerous innocent families. ${ }^{3}$ True, the legislation itself contained few explicit restrictions on eligibility for cash assistance that were vulnerable to political attack. Its opponents, however, forecast a "race to the bottom" in which states would restrict eligibility rules to avoid attracting migrants from

1. Pub. L. No. 104-193, 110 Stat. 2105 (codified as amended primarily in scattered sections of 7 and 42 U.S.C.).

2. Typical were the comments of Republican Senator Rick Santorum, who promised that recipients would receive "education and training that is meaningful" and promised that "if you cannot find a job in the private sector, if you cannot get a job on your own, the State will assist you getting that job. If you cannot find a private-sector job, the State will assist you in getting a public-sector job." 142 CONG. REC. 18,486 (1996) (statement of Sen. Santorum). He went on to assure the public that low-income families could count on a "[f]ederal safety net system that is there to provide for every aspect... of the 50 or more programs that there are to take care of every possible need a child in America has." Id. In a similar vein, House Ways and Means Committee Chairman Bill Archer described the Temporary Assistance to Needy Families (TANF) block grant as simply being a more "efficient" way to aid low-income families. 141 CONG. REC. 8491 (1995) (statement of Rep. Archer).

3. See, e.g., Note, Devolving Welfare Programs to the States: A Public Choice Perspective, 109 HARV. L. REV. 1984 (1996). According to former Clinton Administration subcabinet officer and distinguished legal scholar Peter Edelman,

[A]ny decent nation has to provide a safety net of assistance for its children. Flawed as it was, the previous system had that safety net. Benefits varied widely, but everywhere in America a family coming to a welfare office could get help if they met the federal requirements. This had been true for sixty years. Now no state had any federally defined obligation to help needy children.

PETER EDELMAN, SEARCHING FOR AMERICA's HEART 140 (2001). Similarly, social historian Charles Noble wrote of PRWORA:

The changes were historic. AFDC was converted to a block grant, ending its entitlement status. A tough work requirement was imposed: the law required states to place at least $25 \%$ of cash welfare recipients into jobs or work programs by 1997 , and $50 \%$ by 2002 . Adults who failed to find work within two years were to be denied all federal funds. No one could receive federal cash assistance for more than five years. States could deny welfare benefits to women who had additional children while on welfare, and to unmarried persons under eighteen. Federal funds were denied to unmarried parents under eighteen who did not live with an adult and attend school. Legal immigrants' access to any form of public assistance was radically limited. In one fell swoop, the nation had given up its commitment to income maintenance as a "right." Charles noble, Welfare as We Knew it: a Political History of the AMERican WELFARE STATE 128 (1997). 
less generous neighbors. ${ }^{4}$ The change from a program with federal matching funds to a fixed block grant would increase states' financial incentives to restrict eligibility for means-tested programs.

Both PRWORA's supporters and its opponents focused singlemindedly on formal eligibility rules. Yet formal, explicitly substantive rules are only one way in which the government rations public benefits. Systems that lead to procedural denials of substantively eligible claimants, that discourage claimants from seeking or continuing to receive benefits, or that give third parties influence over whether a claimant will receive benefits also have a rationing effect. The importance of such informal rationing systems had been growing for some time, but the 1996 welfare law moved them to the center of public welfare policy. Personal choice-and its manipulation-have replaced formal rules as the dominant theme in public benefits law.

The widespread embrace of the personal choice model represents a sea change in American public benefits law. Under this model, states have sought to restructure both their formal and informal rationing systems so that a claimant's failure to receive benefits can be attributed to the claimant's own choices rather than to those of the state. Instead of explicitly declaring a claimant ineligible for benefits, the state agency may act more subtly to influence the process through which claimants make choices. Alternatively, it may establish rules that interpret claimants' ambiguous actions as choices. Such attempts to influence claimants' choices may result from deliberate state policy decisions, but they also may result from the independent actions of local administrators and eligibility workers responding to perceived signals or incentives to reduce caseloads.

This personal choice model of public benefits law differs fundamentally from any that came before it. Appreciating the importance of this new model for rationing public benefits requires some historical perspective. Public benefit programs for low-income people in this country have gone through four major periods. During the first and by far the longest period, these programs were almost exclusively local creations. This period began in the early days of the Republic and lasted until the Great Depression. ${ }^{5}$

4. See Edelman, supra note 3, at 146; Anne L. Alstott, Tax Policy and Feminism: Competing Goals and Institutional Choices, 96 COLUM. L. REV. 2001, 2078 (1996) (noting critics' fear that states would engage in a "race to the bottom").

5. See, e.g., Michael B. Katz, In the Shadow of THE POORHouse: A Social History of WELFARE IN AMERICA 3-109 (1986) (describing variations in local practice, as well as essential continuities, over the course of this period); FRANCES FOX PIVEN \& RICHARD A. ClOWARD, Regulating the POOR: THE FUnCTIONS OF PUBliC Welfare 23-38 (Vintage Books 2d ed. 1993) (1971) (interpreting the policies of this period, both here and abroad, as efforts to discipline the work force); DAVID J. ROTHMAN, THE DISCOVERY OF THE ASYLUM: SOCIAL ORDER AND DISORDER IN THE NEW REPUBLIC 237-64 (1971) (placing the "poor house era" in the context of a larger preoccupation with institutions as remedies, first therapeutic and then custodial, to myriad social problems); WALTER I. TRATTNER, FROM POOR LAW TO WELFARE STATE: A HISTORY OF 
Although commonly referred to as the "poorhouse era," the cost and administrative demands of maintaining institutions for all people in need of public aid quickly proved insuperable. Thus, the vast majority of families receiving aid were not sent to the poorhouse. ${ }^{7}$ In theory, however, aid provided in the community ("outdoor relief") was seen as an alternative to institutionalization. ${ }^{8}$ The poorhouse remained a potent symbol of the moral opprobrium associated with receipt of public aid and a deterrent to those who might consider seeking public assistance. ${ }^{9}$ In this period, local officials had virtually unlimited discretion about what, if anything, to do for (or about) destitute families. The guiding philosophy of the era was that poverty was a manifestation of immorality.

The poorhouse had fallen into general disuse by the Civil War, but the highly localized and nonprofessional character of the system continued until local governments' financial ability to relieve the poor collapsed during the Great Depression. ${ }^{10}$ Responding to this collapse, and to advocacy by social workers, President Roosevelt and Congress federalized a significant part of the financing of poor relief." This new system preserved a great deal of local discretion, but administration of programs soon passed from general government officials (such as township trustees) to professional social workers. These social workers sought to remedy the poverty of low-income families the way they might try to remedy alcoholism or other antisocial behavior. Nonetheless, the moral condemnation of low-income people became less universal; for example, in Edwards v. California, the Supreme Court explicitly rejected the notion that immorality and poverty could be equated. ${ }^{12}$ The guiding principle of this era was the exercise of social workers' professional judgment.

The turmoil of the $1960 \mathrm{~s}$, and changes within the social work profession, made this model unsustainable. ${ }^{13}$ The welfare rolls exploded in response to migration from the rural South to northern and western cities,

SOCIAL WELFARE IN AMERICA 47-272 (6th ed. 1994) (describing the role of social workers and other professionals in spurring this country to move beyond institutionalization). To be sure, this country's treatment of low-income persons varied and evolved enormously over this period. In particular, belief in the promise of institutional responses to poverty blossomed during the Jacksonian era but largely faded within a few years. Shifting attitudes toward urbanization and immigration over this period also affected the treatment of low-income people. Nonetheless, enough features remained constant-devolution of broad, subjective discretion to local officials and the treatment of poverty as a symptom of moral failure - to justify treating this span of years as a single period for purposes of comparison with the current regime.

6. See, e.g., KATZ, supra note 5, at 3-109 (contrasting the theory and practice of the poorhouse era across more than a century).

7. Id. at 3 .

8. Id. at 54-55.

9. Id. at 33-34.

10. See id. at 219-22; PIVEN \& ClOWARD, supra note 5, at 57-61.

11. See KATZ, supra note 5, at 217-39; TRATTNER, supra note 5, at 275-99.

12. 314 U.S. 160,177 (1941).

13. See TRATTNER, supra note 5 , at $337-46$. 
the banning of overt racial discrimination, and welfare rights advocacy. ${ }^{14}$ States and localities struggling under the costs of this expansion decided that they could not afford to continue to hire enough licensed social workers to give them the small caseloads required for them to practice their profession. A few years later, a new legalistic model arose, spurred by two factors: first, President Johnson's funding of legal services, programs as part of the War on Poverty; and second, the Supreme Court's recognition of statutory and procedural due process claims asserted by claimants for public benefits in King v. Smith ${ }^{15}$ and Goldberg v. Kelly, ${ }^{16}$ respectively. Social workers were largely removed from programs' administration, policymaking was further centralized, and in place of professional judgment came a complex set of statutory and regulatory rules that at least purported to be objective. The dominant figure in this era, replacing the township trustee and the social worker, was the lawyer. The guiding principle of this era was constraining discretion through uniform rules. In place of the poorhouse or the social worker's clipboard, the physical symbol of the era might be a volume of the Federal Supplement or perhaps of the Code of Federal Regulations.

The legalistic era of public benefit programs ended with the restrictions on federally financed legal services Congress enacted in $1995^{17}$ and the elimination of the legal entitlement to cash assistance the following year in PRWORA. As in the earlier transitions, however, the collapse or debilitation of the old regime became apparent well before it was clear what new system would take its place. This Article describes and analyzes the evolving principles of this new order of public benefit programs. It finds that while some of the trappings of the old regime linger-notably formal eligibility rules - the new regime has increasingly marginalized them in favor of a heavy practical and rhetorical emphasis on claimants' choices. The primary focus of public policy increasingly is to manipulate those choices. Rather than be guided by the actions of lawyers (or the social workers or township trustees of eras past), the professionals we now venerate are economists, even if relatively few of them may actually be involved in program management. Persons wishing to affect policy thus must adopt the analytic methods and tools of economists, modifying rules to adjust claimants' incentives rather than to reach a particular outcome directly. This Article concludes that while greater reliance on claimants'

14. See PIVEN \& CloWARD, supra note 5, at 183-98; see also LAWRENCE M. MEAD, THE NEW POLITICS OF POVERTY 28 (1992).

15. 392 U.S. 309 (1968).

16. 397 U.S. 254 (1970).

17. The final restrictions are found in 42 U.S.C. $\$ 2996 \mathrm{f}(\mathrm{b})$. Continuing appropriations acts had begun to impose these restrictions in October 1995. See, e.g., Act of Sept. 30, 1995, Pub. L. No. 104-31, §101(b), 109 Stat. 278, 279 (requiring the Legal Services Corporation to follow restrictions in the then-pending bill until final legislation could be authorized). 
genuine choices can both improve the distribution of benefits and leave claimants with more autonomy, such choice-based rationing systems raise serious concerns of equity, efficiency, and democratic legitimacy.

The stakes involved are substantial. In each of the two years following the start of the most recent recession in March 2001, states' assistance caseloads under the Temporary Assistance for Needy Families (TANF) block grant declined about $2 \%$ from their already historically low levels. ${ }^{18}$ By contrast, in the first two years after the previous recession began in July 1990, Aid to Families with Dependent Children (AFDC) caseloads rose $11 \%$ and $7 \% .^{19}$ Over the two years following March 2001 , the number of people participating in the food stamp program, which has been restructured much less than cash assistance programs, increased $11 \%$ and $9 \%{ }^{20}$ As far as those relying upon media accounts are likely to be aware, however, cash assistance programs' eligibility rules still offer aid to those in need. ${ }^{21}$ It is of course possible that these changes can be accounted for by families that are making free and voluntary choices not to receive aid for which they are eligible. Nonetheless, it seems important to investigate the possibility that some other, hidden process is working to deny aid to increasing numbers of families at the very time when the economic downturn is making employment less available. ${ }^{22}$ The consequences

18. Elise Richer et al., Ctr. for law \& Soc. Policy, Welfare Caseloads in 27 STATES DECLINE IN FIRST QUARTER OF 2003, at 1-2 (2003), http://www.clasp.org/DMS/ Documents/1058538793.25/caseload_2003_Q1.pdf.

19. These figures are derived from the author's tabulations of data from the Department of Health and Human Services (HHS). See Dep't of Health \& Human Servs., Flash Data Reports (June 2003) (on file with author). The AFDC caseload was 4,037,976 in July $1990 ; 4,499,870$ in July 1991; and 4,815,463 in July 1992 . By contrast, $2,114,414$ families were receiving assistance at the beginning of the current recession. Id. Thus, even with a much higher number of families already receiving aid, AFDC responded to a substantial increase in need while TANF actually reduced the number of families it helped as need rose.

20. I have tabulated these figures based on data available online. See Food \& Nutrition Serv., U.S. Dep't of Agric., Food Stamp Program Monthly Data (Nov. 25, 2003), at http://www.fns.usda.gov/pd/fsmonthly.htm. The number of food stamp recipients was $17,249,899$ in March 2001; 19,216,647 in March 2002; and 21,019,190 in March 2003. Id. The food stamp increases in the first two years following July 1990 were $14 \%$ percent and $11 \%$ percent. See Food \& Nutrition Serv., U.S. Dep't of Agric., Key Data Reports (June 2003) (on file with author).

21. But see Sharon ParrotT \& NINA WU, CTR. ON BUdget \& POlicy PRIORITIES, STATES ARE CUTTING TANF AND CHILD CARE PROGRAMS 1 (2003), http://www.cbpp.org/6-3-03tanf.pdf (finding that many states have in fact reduced these programs in response to the recession). These cuts, however, can hardly explain shrinking cash assistance caseloads. This is particularly true since most of the cuts have affected childcare subsidies, which generally are not included in caseload figures, and since caseload declines are by no means confined to the states that have narrowed eligibility.

22. There is some indication that recessions hit those with the least skills disproportionately hard, as workers displaced from higher-paying jobs are able to displace them from the low-skilled employment market. See, e.g., WILlIAM JULIUS WILSON, WHEN WORK DISAPPEARS: THE WORLD OF THE NEW URBAN POOR 25-26, 34-38 (1996). Conversely, a significant part of the reason that low-skilled welfare recipients were able to find jobs in the mid- and late 1990s was that ultralow unemployment rates made employers despair of finding any more skilled applicants for their low-paying positions. HARRY J. HOLZER ET AL., EMPLOYERS IN THE BOOM: HOW DID 
of extreme poverty for the health, ${ }^{23}$ education, ${ }^{24}$ social adjustment, ${ }^{25}$ and long-term well-being ${ }^{26}$ of the children in these families are too great for an anomaly of this kind to be ignored.

This Article examines the implications of the pervasive emphasis on incentives and choices in public benefits law: the creation of a new system of informal rationing that has eclipsed the importance of formal eligibility rules, sharp changes in those formal eligibility rules themselves that transcend traditional ideological labels, and a fundamental change in the nature of advocacy over public benefits issues. Many of the principles considered here apply across a wide range of programs. The Article's primary focus, however, is on means-tested programs providing subsistence benefits to low-income families-particularly cash assistance and, to a much lesser extent, food stamps, Medicaid, and childcare subsidies. Part II explores the basic choices involved in rationing public benefits, contrasting formal and informal systems. It then addresses the factors that are likely to go into a potential claimant's decision on whether to apply for, or to continue to receive, a public benefit. It finds that a combination of ideological, political, and practical considerations have increasingly driven policymakers to rely upon informal rationing systems that seek to present individuals' failure to receive benefits as the result of their own choices rather than of the state's policy decisions.

Part III analyzes the ways in which the increasing emphasis on claimants' choices has reshaped substantive eligibility rules, sometimes resolving longstanding problems in programs' structures and sometimes creating new problems. Designing rules for economic beings expected to make rational choices is a very different task from selecting which supposedly passive individuals should receive aid.

Part IV argues that the modes of advocacy traditionally applied to eligibility-based rationing systems are unlikely to prove effective in

THE HIRING OF UNSKILLED WORKERS CHANGE DURING THE 1990S?, at 4-5, 18-19 (2003), http://www.urban.org/UploadedPDF/410780_BoomPaper.pdf. With unemployment rates now hovering around six percent, News Release, Bureau of Labor Statistics, U.S. Department of Labor, The Employment Situation: October 2003, at 1 (Nov. 7, 2003), it seems likely to be quite some time before those conditions return.

23. See Sanders Korenman \& Jane E. Miller, Effects of Long-Term Poverty on Physical Health of Children in the National Longitudinal Survey of Youth, in CONSEQUENCES OF GROWING UP POOR 70, $92-98$ (Greg J. Duncan \& Jeanne Brooks-Gunn eds., 1997).

24. See Judith R. Smith et al., Consequences of Living in Poverty for Young Children's Cognitive and Verbal Ability and Early School Achievement, in CONSEQUENCES OF GROWING UP POOR, supra note 23, at 132, 146-56, 164-66.

25. See Rand D. Conger et al., Family Economic Hardship and Adolescent Adjustment: Mediating and Moderating Processes, in CONSEQUENCES OF GROWING UP POOR, supra note 23, at $288,305-10$.

26. See Greg J. Duncan \& Jeanne Brooks-Gunn, Income Effects Across the Life Span: Integration and Interpretation, in CONSEQUENCES OF GROWING UP POOR, supra note 23, at 596, 596-610. 
choice-based systems. It suggests that only by changing program administrators' incentives can advocates hope to change the incentives that those administrators in turn create for claimants. Finally, Part V offers some concluding observations about the ways in which analysis of public benefits law should integrate analysis of formal and informal rationing systems.

\section{TRANSForming The RATIONING OF PUBLIC BENEFITS}

This Part describes and analyzes the rationing of public benefits through influencing and imputing claimants' choices, and contrasts this approach to its predecessor. From the mid-1960s to the mid-1990s, public benefits law meant a system of highly formalized eligibility rules. Programs' strengths and weaknesses could be gleaned from a careful study of statutes and regulations. The 1996 welfare law changed this dramatically. It swept away the longstanding system of federal rules, but it did not require states to replace that system with a similarly formal one of their own. States, to be sure, did make their own rules, but these often contained only a fraction of the policy that was applied to claimants and, even in those areas they did cover, were typically far less outcome-determinative than the federal and federally directed state rules that had preceded them. The importance of this change has largely been lost amid talk of work requirements and time limits.

This Part charts the transformation of the very nature of public benefits law. Section A examines the evidence that a new form of rationing has superseded that of formal eligibility rules. Section B explores the implications of trying to ration benefits by influencing eligible claimants' decisions to apply. Section $\mathrm{C}$ analyzes how the various forms of rationing systems-formal, informal, and hybrids of the two-resemble and differ from one another in their operation. Section D identifies the political issues peculiar to informal rationing systems. And Section E considers under what circumstances informal rationing may be inefficient or inequitable.

\section{A. The Declining Importance of Formal Eligibility Rules}

The national AFDC caseload peaked in March 1994 at a little over five million families. ${ }^{27}$ Cash assistance caseloads then began a steep decline that has continued to this day. ${ }^{28}$ The replacement of AFDC with the TANF block grant in 1996 accelerated the decline, and the recession of 2001 slowed it, but the shrinkage has continued essentially uninterrupted for nine full years. By March 2003, only two million families were receiving cash 
assistance - an unprecedented decline of more than sixty percent from 1994 levels. ${ }^{29}$ Moreover, about a third of the remaining cases contain only children, ${ }^{30}$ who may have few alternatives to receiving public assistance: Among families with an adult member, then, the decline in cash assistance receipt has been even more dramatic.

At least until the last year, very little of this decline reflected tightened eligibility rules; the predicted "race to the bottom" among states' formal eligibility rules ${ }^{31}$ did not occur. Some of the decline in caseload was the predictable result of a strong economy. A great deal of the decline, however, reflects a rapid drop, from eighty-five percent to about half, in the share of eligible families that actually receive cash assistance. ${ }^{32}$ That eligible families continue to leave the cash assistance rolls even with dubious employment opportunities in a slack economy ${ }^{33}$ suggests that some powerful new dynamic is at play. These declining caseloads have been so enthusiastically received that relatively little research has been done to understand why they are taking place. New studies, however, confirm that at least forty percent of eligible nonparticipants are staying away because of repellent characteristics of the program. ${ }^{34}$ Some of these results stem from deliberate policy choices; others may have developed incidentally, although few officials are likely to want to remedy them in a political environment that measures success by caseload decline. The following Sections analyze informal rationing - the deterrence of eligible claimants-as a policy alternative to stricter eligibility rules.

29. See RICHER ET AL., supra note 18, at 4 (providing data to support these figures).

30. Office of Planning, Research \& Evaluation, Dep't of Health \& Human Servs., Table I-3: Temporary Assistance for Needy Families-Active Cases: Percent Distribution of TANF Families by Number of Adult Recipients, October 1999-September 2000, at hitp://www.acf.dhhs.gov/ programs/opre/characteristics/fy2000/103.htm (last visited Nov. 14, 2003).

31. See supra note 4 and accompanying text.

32. See Sheila R. Zedlewski, LeFt Behind or Staying AWAy? Eligible Parents Who REMAIN OFF TANF 1 (Urban Inst., Assessing the New Federalism Series No. B-51, 2002), http://www.urban.org/UploadedPDF/310571_B51.pdf.

33. In 1999, the last robust year of the 1990 s expansion, about half of all families leaving welfare were employed. See PAMELA LOPREST, FEWER WELFARE LEAVERS EMPLOYED IN WEAK ECONOMY 2 fig.1 (Urban Inst., Snapshots of Am.'s Families Series No. 5, 2003), http://www.urban.org/UploadedPDF/310837_snapshots3_no5.pdf. By 2002, that share was down to forty-two percent. See id.

34. See Sheila R. Zedlewsi et al., Families Coping Without Earnings or GOVERNMENT CASH ASSISTANCE 8-12 (Urban Inst., Assessing the New Federalism Series Occasional Paper No. 64, 2003), http://www.urban.org/UploadedPDF/410634_OP64.pdf. Indeed, another twenty-three percent of eligible nonparticipants cited pride as their prime reason for staying away. See id. at 12-13. The sense that receiving cash assistance when in dire circumstances is degrading certainly can be exacerbated or minimized by the way the program is operated. 


\section{B. An Overview of the Managed Choice Alternative to Formal Eligibility Rules}

Advocates for low-income people long have complained about malfunctioning bureaucracies and the "barriers" they place in the paths of eligible claimants seeking benefits for which they qualify. Described merely as the result of ineptitude or indifference, these procedural limitations on claimants' access to benefits seemed to call for, and in fact received, little rigorous analysis. Programs' eligibility determination procedures, however, are an important part of their systems for rationing benefits. At the simplest level, the stringency with which the government tests applications for benefits reflects the relative degree of society's concern about avoiding payments to ineligibles, as compared with its desire to provide benefits to those in need. Over the last decade, however, informal rationing through eligibility determination procedures has taken on a far greater role in state-administered public benefit programs.

This Section provides a more rigorous examination of these rationing methods. Subsection 1 provides a simple model to show the potential advantages of choice-based rationing over the formal eligibility rules that dominated public benefits law from the mid-1960s to the mid-1990s. From there, Subsection 2 shows how the impact of informal rationing is likely to differ across subgroups of claimants. Finally, Subsection 3 provides a quantitative example of how seemingly modest changes in eligibility determination procedures can drastically alter potential claimants' decisions to apply for, or continue to receive, benefits.

\section{Possible Responses to Shortcomings in Formal Eligibility Rules}

Any sweeping condemnation of the concept of informal rationing of public benefits would be misplaced. In principle, giving claimants' choices a greater role in rationing public benefits has much to commend it. The potential advantages of this method are evident when one considers a hypothetical state in which four families (call them $A, B, C$, and $D$ ) are living at seventy percent of the poverty line and another four families ( $W$, $X, Y$, and $Z$ ) are living at ninety percent of the poverty line. For some combination of fiscal, political, and philosophical reasons, the state is only willing to allocate enough resources to provide a meaningful level of benefits to four families. The obvious response is to set the income eligibility limit between seventy percent and ninety percent of poverty and serve families $A$ through $D$.

But suppose family $A$ is living in a well-insulated house it owns free and clear, in an area with low property taxes, and has a substantial vegetable garden. Perhaps the adults in family $A$ have standing offers of 
employment from a relative but prefer to enjoy their leisure time. Suppose also that family $W$ has a seriously ill child whose health requires family members to keep their poorly insulated apartment quite warm. Family $W$ is paying fairly high rent and cannot afford to move to a cheaper area because it needs to be close to the hospital where the child is being treated. The child's extensive needs and frequent crises have caused the family largely to exhaust its "favor bank" with friends and neighbors, forcing it to pay every time it needs spot childcare. One can imagine that the adults in family $W$ may be unable to increase their hours of work because of their responsibilities to care for their sick child, and may have few prospects for changing to more lucrative jobs because they depend on their current employers' flexibility in letting them miss time at short notice when the child has a crisis. In sum, family $W$ may be living much less well than the nominally poorer family $A$ and may need public aid far more.

Conventional modern eligibility-based systems of rationing offer three possible solutions, none of them terribly appealing. First, the state can allow for this possibility and give benefits to all eight families. To do that, it will have to reduce the amount of those benefits to the point that they cannot meaningfully accomplish their intended purpose. ${ }^{35}$ Resources spent on families $X, Y$, and $Z$ clearly would be better targeted on families $B, C$, and $D$. Second, the state can attempt to write eligibility rules that capture the differences in circumstances that make family $A$ less needy than family $W$. To do that, however, the state will have to make the program substantially more intrusive into the personal affairs of all eight families. It will have to expand its bureaucracy to ask these questions and to guard against families dissembling in their answers. Even then, it might well fail to identify, or correctly quantify, all of the significant ways in which families $A$ and $W$ differ from more typical families at their respective income levels. Finally, the state simply can continue to distribute the benefits only on the basis of income and accept the inefficient result that family $A$ is served instead of the needier family $W^{36}$ The obvious inadequacies of each of these

35. Eliminating the functional sufficiency of these benefits can defeat the purpose of the program, undermine its political support, and create economic inefficiencies. See David A. Super, The Political Economy of Entitlement, 104 COLUM. L. REV. (forthcoming Apr. 2004).

36. The social work model of distributing benefits that dominated AFDC into the 1960s offered a fourth option: having a skilled professional interview all of the families and make an expert determination about which four need benefits the most (or, perhaps, whether the needs of a fifth or sixth family are great enough to justify providing less-than-adequate benefits to all families). This model collapsed in the face of philosophical objections on both left and right: Liberals decried its paternalism and potential to ration benefits according to caseworkers' prejudices, and conservatives regarded social workers as too indulgent of low-income families. See Matthew Diller, The Revolution in Welfare Administration: Rules, Discretion, and Entrepreneurial Government, 75 N.Y.U. L. REV. 1121, 1137-38 (2000). The cost of social workers also assured this model's demise. Even if social workers still staffed local welfare offices, in practice the professional evaluation model brings with it much of the intrusiveness and at least as much vulnerability to manipulation and fraud as the system of fine-tuned eligibility rules in the 
approaches make it quite natural to seek a better way of matching available benefits to need.

Gauging the strength of claimants' desire for the benefit is one possible solution. Assuming that family $A$ is not unduly greedy and that family $W$ is not unusually proud or despondent, the variations in their need should roughly correspond to variations in their desire for the benefit. If the state could accurately measure the strength of this desire, it could correctly decide to award the benefit to family $W$ over family $A$. This is what pricing systems do in the private market. Exploring ways to apply similar techniques to distribute public benefits seems quite reasonable.

Finding techniques that work in public benefit programs, however, is not easy. In an idealized world of perfect markets, in which all claimants and potential claimants have perfect information and bear no transaction costs to access benefits, creating a market for a public benefit would be impossible. As long as the benefit has any value, all eight families will prefer having it to not. The actions of those with the greatest need will be indistinguishable from those of families with lesser need, even assuming that need translates perfectly into desire. On the other hand, in the real world, where markets fall well short of perfect, the state can try to test the relative strengths of the families' desire for aid by increasing the costs of learning about the benefit or by reducing its value. ${ }^{37}$ Claimants with less desire may casually overestimate the hurdles they face and give up. These less needy claimants may value their time and dignity more than their more impoverished neighbors. Those neighbors' severe need, on the other hand, may discipline them to accurately evaluate the burdens of applying.

Another strategy a state might use to distinguish among potential claimants with varying degrees of desire for a benefit is to restrict the availability of information about the program. The state might reason that those with the strongest desires for the benefit will try hardest to learn of its existence. At a minimum, a state could refrain from conducting outreach. It might then expect the families with the greatest need to make more-and more determined-inquiries and thus be more likely to learn of the program's existence. It may be, however, that the less needy families would still want help enough that they, as well as the neediest ones, would make

second alternative above. See id. at 1195-96 (criticizing the post-PRWORA TANF administration for reviving the highly discretionary methods that existed until the 1960s in an administrative structure that was staffed by nonprofessionals who had no professional code of conduct to guide them).

37. As discussed below, potential claimants' different tolerances for risk and different rates for discounting future expectations of wealth also may affect how they react to various possible kinds of disincentives. See also KATHRYN EDIN \& LAURA LEIN, MAKING ENDS MEET: How Single MOTHERS SURVIVE WELFARE AND LOW-WAGE WORK 67-69 (1997) (quoting welfare recipients as citing the risks of a layoff and destitution while awaiting the resumption of welfare benefits as reasons for not seeking work). 
sufficiently urgent inquiries to learn of the program. Merely keeping a low profile, therefore, might prove an insufficient mechanism to ration the available benefits. If so, the state could create more formidable information barriers, perhaps by keeping many other social services agencies unaware of the program's existence. It could write a confusing application form or have no form at all, forcing claimants either to judge for themselves or to make even more energetic inquiries to learn what the state requires to determine their eligibility. ${ }^{38}$ It could even disseminate misinformation about the program, discouraging all but the most desperate from applying.

Another strategy for inducing potential claimants to sort themselves by degree of need or desire for the benefit would be to degrade that benefit's value. This could be done in any one of several ways. Most obviously, the state could reduce what it spends on the benefit, perhaps requiring recipients to make payments of their own. By itself, this might not reveal much about the families' relative desire since it is easy to quantify and would affect all families equally. It might, however, magnify the effects of some additional, indirect methods of reducing the attractiveness of the benefit that may be perceived differently by claimants of varying degrees of need.

The state could reduce the value of the benefit indirectly in at least five ways. First, it could increase the transaction costs of applying for it or of continuing to receive it. For example, the agency might require more visits to its offices, keep claimants waiting longer when they do visit, or force them to spend more time filling out forms or collecting proof of eligibility. It could require them to document a certain number of attempts to find employment, consuming considerable time as well as childcare and transportation resources to obtain the necessary signatures. It could add demanding procedural requirements that a significant percentage of claimants would fail to meet. It could even hire incompetent eligibility workers, or overburden competent ones, and provide incentives to deny borderline applications. To preserve the appearance of fairness, the state might allow families to press their claims through time-consuming-and

38. Although this possibility may seem absurd in the modern world of bureaucratic public benefit program administration, this is essentially the way township relief and similar programs operated for decades prior to state governments' assumption of responsibility for operating assistance programs. Township relief and similar programs continue to operate in a number of rural states and often are the only form of cash assistance available to childless adults. See, e.g., Foster v. Ctr. Township, 527 F. Supp. 377 (N.D. Ind.) (interpreting rules governing the interaction between such programs and the food stamp program), aff'd, 673 F.2d 1334 (7th Cir. 1981) (unpublished table decision); Dupler v. City of Portland, 421 F. Supp. 1314 (D. Me. 1976) (same); KATZ, supra note 5, at 283-85 (describing the demise of most general assistance programs in the late twentieth century). 
often confusing-administrative hearings, while remaining reasonably confident that few would do so. ${ }^{39}$

A second way in which the state could reduce the value of the benefit is to enhance the stigma of receiving the benefit, either by making it better known who gets it or by inducing public hostility toward those who do. Even if privacy laws prevent the agency from publishing the names of claimants, its eligibility determination process could require them to bring notes from people likely to be important to them. To the same end, the state could require recipients to show some garish, readily recognizable card to access the benefit. Alternatively, it could publicize incidents of fraud and post signs widely encouraging the public to be on the lookout for fraudulent recipients. It could even try to accomplish both purposes at once by sending fraud investigators out to contact applicants' neighbors, landlords, or children's schools. Most simply, eligibility workers could display their scorn each time the family applied or was authorized to receive benefits. The most desperate families might feel they had to endure this stigma to avoid total destitution, but any families that could flee the program likely would.

A third indirect method of making the benefit less attractive without affecting its nominal value is to constrain its use. At a minimum, this would mean providing the benefit in kind rather than as cash. The state could go further. If it were a medical benefit, the state also could limit beneficiaries to inept doctors or heartless managed care plans. If the benefit were a housing subsidy, the state could require recipients to live in undesirable areas with poor housing stocks, limited transportation, bad schools, and few jobs. If it were food assistance, the state could allow recipients to obtain only certain foods, perhaps ones that are unlikely to appeal to children or to some ethnic groups. Less desperate families might value the benefit less if they had different priorities for additional consumption or if they thought they could afford more desirable goods or services. The neediest families probably could not have afforded much better anyway and might acquiesce in the inferior benefits.

A fourth way to reduce the benefit's value indirectly is an eligibility procedure that induces claimants to make errors resulting in denial or

39. An extreme case of an eligibility determination process increasing a claimant's costs, and thus reducing the net value of the benefit, is the major refundable tax credits: the earned income tax credit and the new broadly refundable child credit in the 2001 tax reduction law. See 26 U.S.C. $\S 32$ (2000); Economic Growth and Tax Relief Reconciliation Act of 2001, Pub. L. No. 107-16, $\S 201$ (c)(1), 115 Stat. 38, 45-47 (amending 26 U.S.C. $\S 24(d)(1)$ ). Both have extremely complex eligibility rules, requiring claimants to provide extensive information to the Internal Revenue Service. Neither, however, provides eligibility workers to inform potential claimants of what is required or to help them complete the necessary forms. As a result, many low-income workers effectively have little choice but to pay a significant portion of their benefits to tax preparation firms, which effectively function as private eligibility workers. 
termination of their benefits. A rule conditioning benefits on a claimant's performance of a particular action by a certain date may cause numerous defaults if requirements or deadlines are poorly explained or if the action is not readily within the claimant's ability to perform: Confusing forms are a common example of such a barrier. Similarly, eligible claimants may cease to pursue benefits if they understand the administering agency to have told them that they do not qualify. Furthermore, cumbersome procedures may cause the administering agency to deny or terminate benefits incorrectly. Some procedural defaults will result in the claimant not receiving benefits at all; others will increase the cost of participating by forcing the claimant to repeat parts of the eligibility determination process.

A final indirect method of reducing a benefit's value is to offer rewards to those who abstain from using the benefit or penalties for those who do claim it. The state could allow each family to receive only a certain number of months of the benefit in the parent's lifetime. Families whose current need is more moderate may be more likely to "bank" months of benefits; desperate families may not feel they can afford to do so. The state could offer an alternative benefit-one that is easier to obtain and less stigmatized, such as a single lump-sum payment-to those agreeing to forego the main program. The state also could impose severe penalties for procedural transgressions and do so in such an imprecise or careless way that any recipient is at some risk of suffering those penalties. These penalties could range from extended periods of disqualification from receiving the benefit-periods when any future increase in need would be irrelevant-to criminal prosecution for presumed fraud. The less desperate families may feel both that they have more to lose and that they need not take this risk; their needier neighbors again may be more inclined to take the chance if the alternative is lacking food, shelter, or medical care for their children or not having the childcare or transportation they require to find a job that could provide lasting improvement in their family's financial situation.

\section{Differential Responses to Informal Rationing Systems}

The more desperate families, $B, C, D$, and $W$, could be expected to endure these burdens because they have nowhere else to turn. ${ }^{40}$ The others may drop away as they perceive the transaction costs to approach or equal

40. On the other hand, the more desperate families' lack of resources may disadvantage them in complying with these requirements. See infra Section II.E. Indeed, their very desperation may prevent them from assessing accurately the prospects of gaining the benefits in question. 
the value of the benefit. ${ }^{41}$ This is possible because the marginal utility produced by each additional dollar of income (or benefits whose value can be translated into income) declines as income rises. If the benefit is food assistance, it may mean the difference between a monotonous diet and a more balanced one for the less desperate families but may be crucial to helping their more desperate neighbors have enough food to eat through the month. If the benefit is housing assistance, it may allow one group of families to move out of dilapidated or overcrowded conditions while offering the other the means to avoid homelessness.

Families dropping away because state policies have reduced the value of the benefit can do so in one of four ways. Some will hear of the onerous eligibility determination process and not apply. Others will begin the process but then withdraw their applications when they realize what is required of them. Still others will intentionally or unintentionally fail to fulfill one of the procedural requirements and be denied on that basis. Finally, some will begin to receive benefits but will default on a procedural requirement of continued participation.

Which of these four patterns of disenrollment occurs is likely to depend upon which methods of discouraging participation an agency employs. Administrative hurdles that are announced at the time of application-or that are contained in the application form itself-may reduce the rate at which potential claimants apply. Particularly heavy burdens for those seeking to qualify initially may cause many claimants to withdraw their applications or to default on procedural requirements. These burdens are likely to disproportionately affect those with short-term needs for benefits as well as those with relatively modest needs; they may have less effect on those who expect their need to be chronic. ${ }^{42}$ On the other hand, procedures that burden recipients by requiring frequent reports or reapplications may particularly discourage those with modest but chronic need, including those hoping to combine low-wage work with public benefit receipt.

Procedures that raise the cost of establishing or reestablishing eligibility also discriminate against persons for whom the activities required to participate are particularly costly or whose circumstances the eligibility determination system is most likely to misjudge. Thus, if the state agency requires claimants to produce ten pieces of paper, an urban claimant living within easy walking distance of the office and the places where that verification may be obtained may elect to participate even if his need is

41. At some point, the members of family $A$ may decide that claiming the benefit is an option inferior to accepting their relative's job. This does not, of course, necessarily mean that they will take the job offer: They may still prefer leisure time to increased consumption.

42. Indeed, making the initial application process too difficult could discourage recipients from leaving the program for uncertain prospects of employment: They may fear that, once off the program, they will have difficulty returning. See EDIN \& LEIN, supra note 37, at 67-69. 
modest, while a claimant in more severe need who faces greater obstacles to obtaining that verification - a handicap, a work schedule, a child whose chronic health problems require numerous doctors' visits, or a lack of access to transportation ${ }^{43}$ - may drop away.

\section{Quantifying the Impact of Informal Rationing}

Although the discussion above considers discouragements to participation in qualitative terms, quantitative examination of some examples shows that seemingly modest burdens can readily cumulate to have powerful effects on low-income claimants.

A crucial point in analyzing procedural issues in public benefits law is that each required point of contact with the state agency has two potential adverse consequences, or costs, ${ }^{44}$ to the claimant: the direct costs of making the contact, which may include lost wages, transportation costs, childcare, or money for postage or pay telephones, and the risk of a denial or termination of benefits. ${ }^{45}$ Each of these factors can sharply alter a claimant's analysis of the costs and benefits of applying for assistance. When combined with stigma, invasions of privacy, and the psychic costs of interacting with the public welfare system, these costs can cause a potential claimant to decide rationally not to seek benefits with a large nominal value for which she or he is substantively eligible.

Consider a simple example in which a working claimant is deciding whether to apply for $\$ 200$ per month in food stamps. Superficially, those benefits are worth $\$ 2400$ over the course of the next year. Assume that the claimant has a $40 \%$ chance of denial upon her or his initial application, a $30 \%$ chance of denial upon any subsequent recertification that she or he is required to undergo during the course of the year, and a $10 \%$ chance of an adverse outcome-either termination of benefits or, much worse, an accusation of fraud-each time she or he is required to report a change in

43. Transportation can be a problem for low-income people who lack reliable vehicles in rural or spread-out suburban areas. See HEIDI GOLDBERG, CTR. ON BUDGET \& POLICY PRIORITIES, STATE AND COUNTY SUPPORTED CAR OWNERSHIP PROGRAMS CAN HELP LOW-INCOME FAMILIES SECURE AND KEEP JOBS 1 (2001), http://www.cbpp.org/11-8-01 wel.pdf. Even in urban areas, low-income people who live near transit lines may find that some places they need to visit are difficult to reach without a car. $I d$. at 6 .

44. The risk of a denial or termination could as easily be seen as a diminution of the benefit of the program rather than as an affirmative cost. The difference between these two characterizations has little consequence for this analysis.

45. In practice, these costs partially converge. Unless the agency imposes a fixed period of ineligibility, the consequence of an improper denial is that the claimant must reenter the claims determination process, possibly without benefits, until his reapplication is approved. If the process is slow and imposes high direct costs, the risk of erroneous denials is higher because they will have more severe consequences. 
income to the agency. ${ }^{46}$ Assume further that the worker's wages fluctuate enough that they vary by $\$ 25$ or more from the prior month's level an average of once every three months. For full certification or recertification interviews, assume that the claimant must lose a full day's pay of $\$ 41.20$ (eight hours times the $\$ 5.15$ minimum hourly wage) and must pay $\$ 3$ for transportation but no additional childcare costs. ${ }^{47}$ Assume that required reports cost the equivalent of one hour's lost wages.

If the state requires claimants to apply for recertification every three months ${ }^{48}$ and to report changes in earnings of $\$ 25$ or more, ${ }^{49}$ the claimant will have an $86.5 \%$ chance of being denied initially or terminated before the end of the year. ${ }^{50}$ Her or his expected reward for applying therefore will be not $\$ 2400$ but $\$ 792.38 .^{51}$ In addition, she or he will face expected

46. For simplicity, this analysis assumes that the costs and consequences of a fraud accusation are identical to being terminated from the program. In fact, they are surely more severe.

47. This estimate of the cost of applying likely is conservative. Two USDA studies have addressed this question, using somewhat different methodologies. A 1990 survey of 706 applicants in five counties found average out-of-pocket costs of $\$ 10.40$. A successful application required an average of 1.8 personal visits to the food stamp office, with a mean cost of $\$ 1.75$ per round trip. More than half had to pay out of pocket for required documentation. Although the average time spent was only 4.8 hours, it seems likely that losing this large a block of time would force the applicant to take at least one full day off from work. See SUSAN BARTLETT ET AL., U.S. DEP'T OF AGRIC., THE FOOD STAMP APPLICATION PROCESS: OFFICE OPERATIONS AND CLIENT EXPERIENCES 31-69 (1992), http://www.nal.usda.gov/foodstamp/FOODSTAMPREPORTS/ FSP-193.PDF. Indeed, many low-skilled jobs require employees to work for a whole shift or not at all, making it likely that many lost two full days from work. A 1996 survey found average outof-pocket costs were $\$ 10.31$ for new applicants and $\$ 5.84$ for recipients seeking recertification. The average time required was 4.8 hours for new applications and 2.3 hours for recertification. This largely reflected an average of 2.3 trips to food stamp offices or other places (perhaps sources of verification) for each new applicant and 1.4 trips for each recipient seeking to renew his or her benefits. See MiCHAEL PONZA ET AL., U.S. DEP'T OF AGRIC., CUSTOMER SERVICE IN THE FOOD STAMP PROGRAM 38-47 (1999), http://www.fns.usda.gov/oane/MENU/Published/ FSP/FILES/ProgramOperations/fspcust.pdf.

48. Three-month certification periods were becoming increasingly common prior to 2000 , when the USDA promulgated rules making the minimum certification period six months for most households. Compare 7 C.F.R. $\S 273,10(\mathrm{f})(4)(2000)$, with id. $\S 273.10(\mathrm{f})(3)(\mathrm{i})(2003)$.

49. Until recently, this was the threshold for reporting changes in the food stamp program. See id. $\$ 273.12$ (a)(1)(i) (2002) (amended 2003); id. § 273.12(a)(1)(vii) (2003) (allowing states to dispense with most change-reporting obligations for six months). States' cash assistance and Medicaid rules typically also require reports for changes above this longstanding $\$ 25$ threshold. See id. \$ 435.916(b) (2002); LIZ SCHOTT ET AL., CTR. ON BUdGeT \& POlicy PRIORITIES, COORDINATING MEDICAID AND FOOD STAMPS 13 (2001).

50. The odds of remaining on the program throughout the year are the $60 \%$ chance of initial approval multiplied by the $70 \%$ chance of surviving a recertification on each of three occasions and the $90 \%$ chance of surviving each of the four required reports. I assume that the first change in income sufficient to trigger the reporting requirement occurs in the third month of benefits, and that each subsequent change in income occurs three months thereafter.

51. This is the sum of the actuarial value of each month's benefits, which is computed by multiplying $\$ 200$ by the chance the claimant will still be receiving benefits in a given month. 
participation costs of just under $\$ 100 .^{52}$ The net benefit of applying therefore would be $\$ 692.76$, not even $30 \%$ of the face value of the benefits.

If the state instead reverts to the system prevalent during the $1980 \mathrm{~s}$, by requiring monthly reports with annual recertification interviews, the claimant's chances of being dropped from the program fall to about $79 \%{ }^{53}$ The gross expectation of benefits would rise to $\$ 943.43$ over the course of the year. The claimant's net advantage from applying would be $\$ 879.10$. While significantly better, that is still just $37 \%$ of the nominal value of the program.

Adopting quarterly reporting with six-month certification periods, as the USDA's July 14, 1999 initiative would permit, a state could improve the likelihood that the claimant would be receiving food stamps in the final month of the year to $34 \%$ and raise her or his expectation from applying to $\$ 1042$, about $43 \%$ of the face value of the potential benefits. ${ }^{54}$ Adopting twelve-month certification periods and semiannual reporting, as the USDA's November 2000 rules allow, gives the claimant a better than $50 \%$ chance of receiving food stamps for twelve months and a more than $\$ 1320$ annual expectation from applying, about $55 \%$ of the potential benefits the program could offer. At this point, some $93 \%$ of both the cost of participating and the actuarial loss of benefits due to a denial is attributable to the initial application.

If it wishes to do so, a state agency often can ameliorate direct costs by reducing the intensity of the contact. For example, telephone contacts may take less time than in-person visits. ${ }^{55}$ Substituting the submission of a paper report for an office visit can allow functionally literate claimants to provide the required information on their own time. ${ }^{56}$ Agencies also can reduce direct costs by improving the efficiency and flexibility of their operations. For example, they can reduce claimants' waiting time by offering and keeping fixed appointments and can reduce the need for repeated trips by

52. This figure is reduced because the high likelihood that the claimant will be removed from the program fairly early in the year reduces the number of recertifications she or he may have to attend and the number of reports she or he may need to submit.

53. The claimant will have a $60 \%$ chance of surviving the initial application and a $90 \%$ chance of surviving each of the ten monthly reports due before the twelfth month's benefits are issued. Consistent with federal regulations, I assume that payments for a given month are conditioned upon having filed a report in the previous month that describes circumstances of two months earlier. For example, benefits in March are conditioned on providing a report in early February that describes household circumstances in January.

54. I assume that the costs and risks associated with recertification subsume those of any reports due in the same month.

55. See 7 C.F.R. \& 273.2(e)(1)-(2) (2003) (allowing food stamp offices to limit interviews to once every twelve months and directing the substitution of a telephone contact for an in-person interview in cases of hardship).

56. See id. $\S 273.12(a)(1)$ (vii) (allowing food stamp offices to substitute a simple written report after six months' receipt of benefits for the interview and recertification that previously was common). 
scheduling those appointments at a time when the eligibility worker will have all information necessary to conduct a definitive interview.

Reducing the risk of denials, on the other hand, is more problematic. The traditional strategy of claimants' advocates has been to correct denials after the fact through the fair hearing process. For a variety of reasons, that strategy has little promise. ${ }^{57}$

An alternative strategy is to try to reduce the likelihood that contacts with the agency will result in a denial or termination of benefits. Different approaches are appropriate for different kinds of contacts. In general, these can include changing agencies' or individual eligibility workers' incentives to deny claimants, improving eligibility workers' competence and the reliability of agencies' automated systems, simplifying requirements and agencies' communications about those requirements, and reducing the burden of those requirements. A common approach to verification requirements, for example, has been to limit the number of items a claimant must verify or to increase the range of items she or he may produce to meet the requirement.

For the most part, measuring the factors that influence an eligible potential claimant's decision to seek benefits is quite difficult. One partial exception may be the value of the benefit. Cash assistance benefits continue to lose value to inflation. Recent developments have reduced the value of the Medicaid and food stamp benefits packages as well. The spread of managed care unquestionably has changed the value of Medicaid for many beneficiaries, although it is difficult to quantify that change in the aggregate. In addition, some states have narrowed the Medicaid benefit package to meet budgetary constraints. ${ }^{58}$ Fiscal concerns also have kept

57. First, fair hearings are virtually useless where a claimant was denied in technical compliance with the agency's own rules. For example, if a broken-down city bus prevents the claimant from arriving at an interview and the program's rules make no provision for rescheduling, a fair hearing officer is not expected to reopen the claimant's application. If the claimant misunderstood the eligibility worker or an agency form and missed a deadline, the hearing officer is unlikely to reverse the termination of benefits. Occasionally a hearing officer may feel empowered to give the claimant a second chance to comply with a procedural rule or an eligibility worker may default, allowing the claimant's appeal to be upheld. Given the low likelihood of such an outcome, however, the expected benefits of a fair hearing may be more than offset by the claimant's costs of attending the hearing.

Second, only a tiny number of claimants request such hearings. See infra text accompanying note 168 . And third, the overwhelming majority of all requests for relief through hearings are denied in their entirety. See infra note 167 and accompanying text. Given the complexity of benefit programs' rules, the share of unrepresented claimants losing their appeals is undoubtedly much higher. With funding reductions and substantive prohibitions reducing the availability of legal services advocates for public benefits claimants, a system that cannot work well for unrepresented claimants is of dubious value.

58. See leighton Ku et al., Ctr. on Budget \& Policy Priorities, Proposed State MEDICAID CUTS WOULd JeOPARDIZE HEALTH INSURANCE COVERAGE FOR ONE MILLION PEOPLE 4-9 (2003), http://www.cbpp.org/12-23-02health.pdf; VERNON SMITH ET AL., THE HENRY J. KAISER FAMILY FOUND., MEDICAID SPENDING GROWTH: A 50-STATE UPDATE FOR FISCAL YEAR 2003, at 9 (2003), http://www.kff.org/content/2003/4082/4082.pdf. 
Medicaid's provider reimbursement rates low in many states, which may reduce the number of providers, particularly high-quality providers, willing to treat patients with Medicaid coverage.

Similarly, the value of food stamp benefits was reduced substantially by PRWORA's across-the-board cuts: Reductions in food stamp benefit levels accounted for about $60 \%$ of PRWORA's food stamp savings, which in turn accounted for about half of PRWORA's estimated total savings. Some $\$ 5.4$ billion, almost one-fifth of the law's estimated food stamp savings, came from low-income working households. ${ }^{59}$ Taking just two of the larger cuts into account, a low-income working household that would have received a food stamp benefit of $\$ 224$ per month in 2003 under prior law is now eligible for only $\$ 200$ per month, a reduction of $11 \%{ }^{60}$ These reductions in benefits certainly are a factor in current recipients' calculations of the costs and benefits of complying with reporting and recertification requirements necessary to continue receiving benefits.

\section{Formal, Informal, and Hybrid Rationing Systems}

Appreciating the sensitivity of claimants' participation decisions creates new opportunities to ration public benefits. In order to receive a public benefit, at least three things must take place: First, the claimant must decide to request that the benefit be provided (or continue to be provided). Second, the administering agency must determine that the claimant has complied with the procedural requirements for obtaining that benefit. Finally, the state agency must determine that the individual meets the substantive eligibility requirements for that benefit. Policymakers may change the rationing of public benefits by influencing any of these three decisions.

Traditionally, legal and policy analysis of public benefit programs has focused overwhelmingly on the third of these steps - substantive eligibility requirements. Increasingly, however, policy is being made through manipulating the other two: dissuading potential claimants from entering or remaining in a program or increasing the likelihood that the claimant will be rejected for procedural reasons. These methods of rationing may go wholly unrecognized: A program's administrators may characterize the resulting procedural denials as the results of claimants' choices not to comply with the program's rules. Even if they are recognized, the nature and scope of policymaking may remain obscure; the same procedural rules may deter some potential claimants and induce procedural defaults by others. Thus, it often makes sense to consider together those rationing

59. CTR. ON Budget \& POliCy PRIORITIES, THE DEPTH OF THE FOOD STAMP CUTS IN THE FINAL WELFARE BILL 2 (1996), http://www.cbpp.org/DEPTH9.HTM.

60. DAVID A. SUPER, CTR. ON BUDGET \& POLICY PRIORITIES, WORK AND THE FOOD STAMP PROGRAM 20 (2003), http://www.cbpp.org/9-30-03fs.pdf. 
mechanisms that explicitly rely upon claimants' choices and those that increase the rate of procedural denials. ${ }^{61}$ On the other hand, some policies might help ration benefits in both formal and informal ways. A time limit is such a hybrid: It both denies eligibility to claimants who have exhausted the permitted number of months of benefits and discourages still-eligible claimants from using up their remaining allocations.

Formal rationing systems that manipulate eligibility rules, informal rationing devices that rely on procedural rules or changing individual choices, and hybrids of the two have many similarities. The severity of each type of system can be adjusted to achieve the desired degree of impact on participation, although eligibility rules may lend themselves to more precise calibration. Each type of system is amenable to centralized or decentralized application and to rule-based or highly discretionary administration. ${ }^{62}$ In theory, both formal and informal systems can operate either competitively-providing benefits to a predetermined number of claimants based on the relative strengths of their applications or by forgiving the least severe procedural transgressions - or as open-ended entitlements provided to all individuals who meet some absolute standard. ${ }^{63}$

Since some eligibility rules and some eligibility determination procedures are inevitable in any means-tested program, policymakers generally have options to tighten or relax rationing through either approach. Indeed, some of the most sophisticated and perceptive thinking about informal rationing over the past decade has been done by Medicaid administrators and advocates seeking to reduce informal impediments to benefits. In such instances administrators have presumably doubted the quality or voluntariness of applicants' choices not to pursue benefits.

The three respects in which formal and informal rationing systems differ most dramatically are the manner in which they may be established, their visibility, and whether they seek to operate absolutely or probabilistically. Each of these differences has important consequences for

61. To be sure, unless benefits are to be forced upon persons not making application for them, some individual choices are an inevitable part of any system for rationing public benefits. As discussed previously in Section II.B, however, a wide range of public policies can influence those choices.

62. For example, the state can limit participation formally with an income eligibility rule or by empowering eligibility workers to deny benefits based on subjective criteria such as the "suitable home" requirement that flourished prior to King v. Smith, 392 U.S. 309 (1968). The state can ration benefits informally by setting a fixed number of job search contacts each claimant must make or by empowering eligibility workers to exercise discretion over what type of verification to require from a claimant or when to require a claimant to appear for an interview.

63. Although competitive systems are common when relatively small numbers of entities are competing for government contracts or grants, they are difficult to design for mass public benefit programs because of the difficulty of harmonizing standards across many reviewers. In addition, competitive systems typically require postponing decisions until all candidates can be evaluated, Such delay would interfere with many public benefit programs' abilities to meet claimants' immediate needs. 
the democratic legitimacy of the resulting rationing. The following Subsections address these differences in order.

\section{Establishing and Modifying Informal Rationing Systems}

Informal rationing systems differ from formal systems in the multiplicity of ways in which they can be established. Since some formal eligibility rules, such as time limits, can deter individual participation, informal or choice-based rationing obviously can be established through formal, overt public policy choices. Legislatures and senior program administrators also can establish or modify procedural barriers or disincentives to participate. In addition, these senior policymakers can convey to lower-level administrative staff the desire to have informal limits imposed, tightened, or relaxed. ${ }^{64}$ Where eligibility rules are set by statute and administrators lack the legislature's support, manipulation of informal rationing systems may be the main vehicle available for expanding or shrinking a program. ${ }^{65}$

Perhaps more importantly, far more junior officials, ones with no role in setting eligibility rules, can have major roles in setting the conditions under which a potential claimant chooses whether to participate in a program. They may do so through the exercise of officially designated authority - by designating the interval between required eligibility reviews, for example. ${ }^{66}$ But local managers, supervisors, and individual eligibility workers also can-and perhaps more commonly do-change those conditions through largely invisible modifications in the way they do their jobs: the staff assigniments they make, the information they do or do not dispense, the level of scrutiny they give applications, their willingness to make exceptions or accommodations, or their attentiveness in answering their telephones and clearing filled voicemail systems. Since much of this authority is difficult for state officials to oversee and effectively impossible

64. The methods by which senior officials can signal their subordinates are many and varied. See generally Diller, supra note 36 , at $1173-76$ (describing the methods by which state administrators have prompted local staffs to enforce work-related requirements in TANF-funded cash assistance programs); David A. Super, Working for Food: The Food Stamp Program as Model for a New Anti-Poverty Agenda, 79 N.Y.U. L. REV. (forthcoming June 2004) (on file with author) (describing efforts to shift the food stamp program's orientation from cash assistance recipients to low-wage workers).

65. The Clinton Administration found itself in this position when it sought to expand Medicaid and food stamp benefits for working poor families after 1996. See generally Super, supra note 64. Similarly, the Reagan Administration made some efforts to shrink means-tested programs through informal methods after the congressional elections of 1982 made it difficult to narrow eligibility legislatively. See, e.g., Food Stamp Program, 51 Fed. Reg. 7202, 7206 (Feb. 28, 1986) (codified at 7 C.F.R. $\$ 273.2$ (2003)) (expanding the range of intrusive verification procedures permissible in the food stamp program).

66. See, e.g., 7 C.F.R. $\S 273.10(f)$ (giving eligibility workers broad discretion to set the length of the certification periods for successful food stamp applicants). 
to rescind, these local agency employees' role as de facto policymakers is assured.

Nominally, the degree of state and local control over means-tested benefit programs differs dramatically between those receiving TANF funding - over which state control is virtually total-and the food stamp program, which is subject to hundreds of pages of federal regulations; the extent of federal control over Medicaid is somewhere in the middle. But in fact, state and local officials have numerous opportunities to influence claimants' choices-and the likelihood of procedural denials and abandoned applications - under all three programs. Medicaid rules assume an eligibility process more than they prescribe one. ${ }^{67}$ Even under the supposedly prescriptive food stamp program, states and local offices have wide flexibility to schedule appointments, ${ }^{68}$ decide how much verification claimants must produce, ${ }^{69}$ impose work requirements, ${ }^{70}$ specify reporting requirements between full eligibility determinations, ${ }^{71}$ and set the interval between those determinations. ${ }^{72}$ Thus, the most important question about state and local governments' informal rationing of these benefits is not whether they can do it, but rather why they might wish to do so.

\section{The Visibility of Rationing Systems}

A second distinguishing feature of informal rationing systems is their invisibility to those not directly involved in their administration. Part of this invisibility is simply a product of the decentralized manner in which they are imposed: Policymakers, analysts, and the news media are far more likely to understand and remember a single set of rules set by a central authority than they are to be able to integrate bits and scraps of information about a plethora of locally designed policies. An advocate of open politics and informed democratic participation in policymaking may condemn the very invisibility that makes these strategies appeal to some legislators and administrators. With eligibility rules increasingly poor proxies for a program's actual performance, measuring its coverage and effectiveness becomes problematic.

At least as important in keeping such rules invisible, however, is the fundamentally different way in which they act upon claimants. Eligibility rules' role in constraining participation in a program is obvious. Since procedural rules exist in part to allow agencies to apply substantive

67. See 42 C.F.R. $\S \S 435.901-.920$.

68. See 7 C.F.R. $\S \S 273.2(\mathrm{e}), 273.14(\mathrm{~b})(3)$.

69. See id. $\$ 273.2(\mathrm{f})(2)-(3)$.

70. See id. $\$ 273.7$.

71. See id. \$ 273.12(a).

72. See id. \& 273.10(f). 
eligibility rules, most will assume that whatever burdens they impose on claimants are inevitable. ${ }^{73}$ Only the most sophisticated observers are likely to recognize the additional role of procedural rules as independent rationing devices and to understand that they can be relaxed or tightened considerably.

Most policymakers' and analysts' lack of familiarity with the brutal realities of many low-income people's lives $^{74}$ also can cause them to overlook the importance of informal rationing devices even when they recognize those devices' existence. Even if an analyst is aware of a procedure or of a policy that affects potential claimants' inclination to participate, she may fail to recognize it as a rationing device. For example, when an agency asks a claimant for copious proof of her income, most observers are likely to see only an attempt to conform the reality of who receives benefits to the terms of the program's income eligibility rules; those income-eligible claimants who will be denied benefits for lack of verification will largely be ignored. . Still less obvious will be the impact such policies have on potential claimants' decisions to seek benefits: Few who have not experienced poverty are likely to think of the harried working mother who fears losing her employer's respect and confidence if she seeks his signature on a wage verification form.

The relative invisibility of informal rationing devices has several consequences. Policymakers wishing to articulate one agenda and pursue another can adjust the stringency of informal rationing devices with little danger of being called on the inconsistency. At the same time it was publicly espousing fiscal discipline, the Clinton Administration made numerous changes in Medicaid and food stamp procedures to reduce claimants' costs of participation and the risk of procedural denials. Its Office of Management and Budget (OMB) adopted the convenient position that changes allowing more already-eligible people to participate should not be regarded as increasing the programs' costs because they were only bringing in participants whom Congress already had decided to serve when it enacted the programs' substantive eligibility rules. ${ }^{75}$ Conversely, as the recent economic downturn has squeezed states' budgets, many have dropped policies adopted a few years earlier to ease procedural burdens on

73. See, e.g., U.S. GEN. ACCOUNTING OFFICE, NO. GAO/RCED-89-4, FOOD STAMP PROGRAM: ADMINISTRATIVE HINDRANCES TO PARTICIPATION 14-18, 21-25 (1988).

74. See, e.g., Goldberg v. Kelly, 397 U.S. 254, 264 (1970) (noting how the pressures on lowincome individuals can impair their abilities to advocate for themselves in the public welfare system, particularly if they have no ongoing source of income).

75. See, e.g., Food Stamp Program: Noncitizen Eligibility and Certification Provisions, 65 Fed. Reg. 70,134, 70,142-43 (Nov. 21, 2000) (estimating the costs of two food stamp regulatory changes that reduce the costs to households of receiving food stamps, and eliminate procedural denials, without considering increased participation by substantively eligible households). 
claimants for Medicaid. State policymakers apparently have reasoned that these changes will go largely unnoticed, or can be explained away in technical terms, while changing formal eligibility rules would be understood as a retreat from efforts to reduce the ranks of the uninsured. Yet the source of savings under both sets of policies is essentially the same: fewer people receiving Medicaid coverage.

The relative invisibility of indirect methods can also allow policymakers to ration benefits for a broader array of purposes than they could readily hope to justify publicly. The upheavals of the mid-1990s did stretch the range of politically acceptable objectives for eligibility rules, at least for a while. Traditionally, however, policymakers have had to justify most eligibility rules under one of only a small handful of rubrics. Most substantive eligibility rules are explained either as measuring need for a benefit or worthiness to receive it. Once a basic need- or worthiness-based rationing system is established, arguments about equity, reliability, simplicity, or cost may lead to some fine-tuning. At some point, however, restrictions on substantive eligibility without substantive justification can expose policymakers' failure to fulfill their own stated programmatic objectives. Discouraging participation may be a safer way to achieve the same savings.

Even agencies that are unconcerned about benefit costs-perhaps because some other level of government pays them-can nonetheless seek to ration benefits as a way of preserving administrative resources. The public may be unsympathetic to "bureaucrats" denying benefits to concededly needy and worthy claimants "just to save themselves work," but some administrators may feel that their staffing is so inadequate that they have little choice. In a similar vein, administrators may feel they must limit the number of "difficult" or "error-prone" cases they serve. And, of course, the obscurity of informal rationing methods can help accomplish racist or other invidious agendas. ${ }^{76}$

The relative invisibility of choice-based rationing also can allow interventions whose ends have widespread political support but that could not readily be implemented through eligibility rules without seeming too heavy-handed. For example, when PRWORA eliminated King v. Smith's prohibition on state-created social and behavioral eligibility conditions, ${ }^{77}$ it opened the door to a broad range of interventions to accomplish its stated goals of promoting marriage and discouraging out-of-wedlock births. Yet

76. See, e.g., Susan T. Gooden, All Things Not Being Equal: Differences in Caseworker Support Toward Black and White Welfare Clients, 4 HARV. J. AFR.-AM. PUB. POL'Y 23 (1998) (finding dramatic differences between the extent of supportive services offered to white and African-American claimants).

77. Personal Responsibility and Work Opportunity Reconciliation Act of 1996, Pub. L. No. 104-193, $\S 103(\mathrm{a})(1), 110$ Stat. 2105, 2112-13 (codified at 42 U.S.C. $\S 601(\mathrm{~b})(2000)$ ) (disavowing the individual legal entitlements that provided the basis for King v. Smith). 
although states clearly could have reinstated the "man in the house," "substitute father," or "suitable home" rules, none appears to have given serious thought to doing so. Apparently the country had changed enough in the intervening three decades that such overt interventions were no longer politically palatable. Indeed, although those rules would likely reduce cash assistance's roll as a subsidy to single-parent families, even the writings of the Heritage Foundation's Robert Rector, one of the most fervent advocates of making marriage a centerpiece of public welfare policy, avoid advocating reinstating the pre-King rules. ${ }^{78}$ Instead, conservatives can advocate giving states incentives to provide benefits to fewer unmarried claimants and expect that states in turn will find informal, and hence uncontroversial, ways of achieving that outcome. ${ }^{79}$

Curiously, hybrid rationing systems may be even less transparent than purely informal ones. This is because they may leave the public misled rather than merely ignorant. For example, if the public is told that relatively few families were terminated under a state's time limit, it may assume that the time limit had been set at a high enough level to avoid doing much harm. In fact, many families may have left the roles early, experiencing severe hardship, to avoid exhausting their months of eligibility completely.

\section{Absolute or Probabilistic Control of Program Participation}

In theory, eligibility rules determine precisely who will and will not receive benefits, while the impact of choice-based systems depends on the aggregate effect of individual claimants' responses to incentive systems. It thus would appear that formal systems can target limited resources more precisely than can informal systems. As the example set out in Subsection

78. See, e.g., ROBERT E. RECTOR ET AL., THE HERITAGE Found., "MARRIAGE Plus": Sabotaging the President's EFforts To Promote Healthy Marriage 1, 4-5, 7 (2003), $\mathrm{http} / / \mathrm{www}$.heritage.org/Research/Welfare/BG1677.cfm (repeatedly insisting that marriage promotion programs should be voluntary); ROBERT E. RECTOR, THE HERITAGE FOUND., YET ANOTHER SHAM WELFARE REFORM: EXAMINING THE NGA PLAN (1996), $\mathrm{http} / /$ www.heritage.org/Research/Welfare/BG1075.cfm (arguing for giving states incentives to promote marriage rather than having the federal government exert direct pressure on claimants).

79. Although not prominent in public discussions of marriage promotion, a particularly inflexible regime of required cooperation in paternity establishment can have this effect. Since husbands' paternity generally is presumed, these policies by definition apply only to women who had children while unmarried. Limiting the number of putative fathers a woman may name before becoming subject to a lifetime disqualification and requiring extensive information about the whereabouts of putative fathers in order to deem the woman to be cooperating will deny benefits to some of the unmarried mothers discussed at great length in the PRWORA's preamble, 42 U.S.C. $\$ 601$ note (Congressional Findings), without explicitly punishing their sexual behavior or childbearing. Perhaps for nonemotive budgetary reasons, a number of states have been moving to impose these sorts of policies. See, e.g., Smyth v. Carter, 168 F.R.D. 28, 32-33 (W.D. Va. 1996) (enjoining the state from terminating cash assistance to mothers who attest to their inability to identify their children's fathers, often because of past substance abuse or a large number of past sexual partners); Doston v. Duffy, 732 F. Supp. 857, $871-73$ (N.D. Ill. 1988) (same). 
II.B.1 showed, however, in practice most eligibility rules only crudely approximate the policymakers' specific intentions for administrative reasons. ${ }^{80}$ Thus, it is difficult to generalize about which type of system has the more precise impact.

Informal rationing systems' probabilistic impact, however, creates significant challenges for policymakers, analysts, and the courts. Even if it is certain that a practice will deter or prevent some eligible people from receiving a benefit, it is not certain which particular individuals will be so affected. With political, analytical, and legal discussions all traditionally tending to start from the individual, this requires some difficult adaptation.

Critics of an eligibility rule typically seek to rally political opposition by pointing to a seemingly needy and worthy person whom it would reject. In opposing informal rationing systems, they can inveigh generally against "heartless" or "incompetent" bureaucracy, but humanizing the argument with an individual "victim" is difficult. At best, they will find someone who lost benefits due to what they hope will be regarded as excusable neglect. Even if they find someone with an appealing story, however, that story may take longer to tell than policymakers, journalists, or members of the general public are willing to listen. And it will usually be true that, with sufficient advocacy assistance, any particular claimant could have surmounted the obstacles. $^{81}$

More generally, policies that act probabilistically challenge some of our basic assumptions about human nature. We think of a racist as someone who wants to give nothing to people of color, and we think of an opponent of granting public benefits to a particular population as someone who wants to deny the benefits to everyone in that population. Our public and political discourse lacks the tools to describe and counteract the racist who is satisfied with reducing but not eliminating the benefits going to those in disfavored groups or the program opponent who is content with a ten- or

80. For example, policymakers may wish to take into account the contributions a low-income family receives from relatives in determining the family's need for benefits. In practice, identifying and quantifying these contributions, which typically are made in cash or in kind, is administratively impossible. Policymakers may try to deny benefits to some of these families by requiring that the incomes and resources of close relatives that live together be considered jointly in applying a means test. Even if eligibility workers implement this rule perfectly, they will deny benefits to some genuinely desperate families whose relatives live with them, but refuse to support them. This rule will also fail to affect families being supported by relatives living next door, across town, or even across the country.

81. Indeed, advocates face significant ethical issues highlighting the case of a particular claimant. In many instances, they could fairly easily obtain benefits for that claimant. Arguing that a particular family is in dire need of aid while failing to help it get that aid seems hypocritical and heartless. Providing that help, however, would destroy that family's effectiveness as an example of the putative unfairness of the policy at issue. Convincing the public that a problem that individual advocacy can remedy nonetheless deserves systematic attention requires making a statistical case that the number of such problems outstrips available advocacy resources-a most difficult argument to win and one that must be made with data rather than with sympathetic claimants. 
twenty-percent reduction in participation. Specifically in the public benefits arena, any administrative requirements will manifestly have some adverse impact on participation, but some such requirements are inevitable. Few reliable tools are available to identify those requirements that are having substantially more impact on participation than is reasonably necessary. Predicting the impact of a policy requires not only understanding its terms and the burdens under which claimants must work, but also the signals and incentives perceived by eligibility workers. A work requirement in the hands of an eligibility worker taught to seek compliance will operate very differently from a nominally identical requirement applied by one seeking to reduce his or her caseload.

\section{The Politics of Choice-Based Rationing}

As described above, choice-based rationing can be quite elusive. The very existence of these interventions, much less their purposes and impact, can be difficult to discern. This Section analyzes the political forces driving the rise of informal rationing. Its goal is both to understand the strength of the appeal of this kind of rationing and to assess the diverse incentives and motives of many senior and junior officials who may be imposing or adjusting these rationing systems.

The rise of choice-based rationing of public benefits affects both the substance of political struggles over public benefit programs and the locations where those struggles take place. Subsection 1 considers the varied political impulses that have provided the impetus for informal rationing. Subsection 2 then shows that a much wider and more diverse array of actors can control informal rationing than could establish or modify formal eligibility rules.

\section{The Appeal of Choice-Based Rationing}

The rise of informal rationing as the nominal force in organizing public benefit programs reflects a confluence of factors. Some conservatives clearly sought to increase the burden of the eligibility determination process to discourage receipt of public benefits. ${ }^{82}$ It would be a mistake, however, to view informal rationing as the conservative agenda triumphant. First,

82. According to two American Enterprise Institute commentators, job search requirements, behavioral rules, and other new requirements-what they refer to as the "hassle" factor-

raise what economists would call the "cost" of being on welfare. By a rough calculation

that assumes recipients value their time at the minimum wage, these kinds of requirements can reduce the advantage of being on welfare versus working by about 50 percent. In very low-benefit states, the advantage can fall to zero.

Douglas J. Besharov \& Peter Germanis, Am. Enter. Inst., Welfare Reform-Four Years Later, PUB. INT., Summer 2000, at 17, 22. 
were conservatives in a position to dictate the terms of the new public benefits regime by themselves, they likely would not select informal rationing as the theme. Some would prefer the complete abolition of these programs; ${ }^{83}$ others would prefer a regime in which benefits were strictly conditioned on work. ${ }^{84}$ As instrumental as they were in destroying the old order, however, conservatives have not been in a position to set the terms of the new system unilaterally. Indeed, leading conservatives have acknowledged that while polls show voters "want adult welfare recipients to work" they also still "want the government to assist needy families.",85 The reasons informal rationing has come to dominate the public benefits landscape in fact are much more complex.

To the extent that choice-based rationing's roots are philosophical, they extend far beyond the narrow right-wing core that piloted PRWORA to enactment. Both our economic and legal systems place a high premium on individual choice. It is the foundation of the market economy. Our legal system would become almost instantly mired if parties could not be held to the consequences of choices to waive rights in contracts or in legal proceedings. We also accept that coerced or foolish choices can sometimes be valid. Only in the most extreme cases will we find a contract to be unenforceable because of the parties' unequal bargaining power. We allow the use of plea bargains despite understanding that they are motivated by the desire to avoid more serious penalties rather than by a desire to do penance for a wrong. And on the basis of a few poorly chosen words we will find suspects to have waived the fundamental rights in the Fourth, Fifth, and Sixth Amendments. Thus, although choice-based rationing has rarely been discussed in the context of public benefits law, such rationing has a long history in American law, and it is quite natural for policymakers to consider it. ${ }^{86}$

83. See, e.g., ChARLES MURRAY, LOSING GROUND 227-28 (1984) (arguing for the abolition of most or all means-tested family assistance programs above the local level to create stronger work incentives).

84. See, e.g., RON HASKINS, WELFARE IN A SOCIETY OF PERMANENT WORK 9-10 (Northwestern Univ./Univ. of Chi. Joint Ctr. for Poverty Research, Working Paper No. 145, 1999), http://www.jcpr.org/wpfiles/Haskins_wp.pdf; MEAD, supra note 14, at 233-34; RECTOR, supra note 78 , at 5-6.

85. Implementation of Welfare Reform Work Requirements and Time Limits: Hearing Before the Subcomm. on Human Res. of the House Comm. on Ways and Means, 107th Cong. (2002), 2002 WL 388673 [hereinafter Hearing] (testimony of Douglas J. Besharov, Resident Scholar, American Enterprise Institute) (quoting New York University professor and fellow conservative Lawrence M. Mead).

86. In numerous other areas of public law, policymakers have turned to choice-based rationing strategies when changing explicit legal rules was constitutionally or politically infeasible. After the Supreme Court prevented states from enacting formal prohibitions on abortion, antiabortion legislators sought to limit the number of abortions by influencing women's choices. See Planned Parenthood v. Casey, 505 U.S. 833, 877 (1992) (plurality opinion) (accepting some such efforts while finding that others unduly burdened women's choices); Michael C. Dorf, Incidental Burdens on Fundamental Rights, 109 HARV. L. REV. 1176, 1224-26 
Some may see stringent procedural requirements as having intrinsic value: The process of navigating procedural barriers legitimizes the claimant's receipt of the benefit. In this vision, which need not be motivated by animus for low-income people, having to surmount some eligibility barriers reminds the claimant that the benefit is a gratuity. Alternatively, compliance with procedural requirements can be seen as a form of consideration for the benefit ultimately received.

Choice-based rationing also can appeal to the deep-seated American suspicion of bureaucracy. At least superficially, it appears to reduce the heavy hand of state bureaucracy and to give low-income families more say in determining their own fates. Indeed, the basic premises that make informal rationing plausible-in particular, an active, volitional claimant-have been popularized by the left. To be sure, the content of choice-based rationing is far removed from the left's prescription of expanded options, positive incentives, and political empowerment. Nonetheless, choice-based rationing might never have arisen had it not been for the more dynamic image of public benefits claimants advanced by the welfare rights movement ${ }^{87}$ and liberal efforts to "make work pay" by expanding benefits for low-wage workers. ${ }^{88}$

The rise of choice-based rationing, however, has been driven more by pragmatic state administrators than by social theorists of any stripe. With

(1996) (describing waiting periods as a device to induce more careful deliberations). The 104th Congress, a few months before enacting PRWORA, applied an aggressive informal rationing strategy to prisoners. Rather than explicitly authorizing brutality or oppressive conditions in prisons, it imposed huge financial and procedural burdens on prisoners seeking redress from federal courts. See Prison Litigation Reform Act of 1995, Pub. L. No. 104-134, $\$ \S 801-810$, 110 Stat. 1321, 1321-66 to -77 (1996) (codified in scattered sections of $11,18,28$, and 42 U.S.C.). As a result, prisoners' petitions fell by thirty-six percent between 1996 and 1998 with no significant change in the underlying substantive law. See James E. Robertson, Prison Reform, a Faustian Bargain, 37 CRIM. L. BULL. 195, 195 n.2 (1997). In the Antiterrorism and Effective Death Penalty Act of 1996, Congress also sharply reduced state prisoners' access to relief through writs of habeas corpus without explicitly denying the right to file writs after a prior unsuccessful attempt. Pub. L. No. 104-132, § 106(b), 110 Stat. 1214, 1220-21 (codified at 28 U.S.C. $\S 2244$ (b) (2000)). A host of procedural rules made denials of first petitions more likely, and an even greater array of hurdles allowed procedural denials of most successor writs. Id. Yet when innocent prisoners denied relief under this regime occasionally gained media attention, officials could insist that the writ was still available and that any substantive injustice was chargeable to the prisoner's own procedural defaults. See Kenneth Williams, The Antiterrorism and Effective Death Penalty Act: What's Wrong with It and How To Fix It, 33 CONN. L. REV. 919, 942 (2001) ("By enacting Section 2244(b)(2), Congress has created the illusion that the federal courts are willing to consider successor petitions in cases of innocence, while ensuring at the same time that no inmate will be able to satisfy its stringent demands."). On the other hand, in Miranda v. Arizona the Court sought to increase the likelihood that suspects would invoke their right against self-incrimination by requiring that they be informed of that right. 384 U.S. 436 (1966). Influencing suspects' choices in this way can be seen as an alternative to stiffening the underlying substantive right.

87. See, e.g., FranCES FoX PIVEN \& RiChaRd A. Cloward, POOR PEOPLE's MOVEMENTS: WHY THEY SUCCEED, HOW THEY FAIL 264-361 (1977).

88. See, e.g., DAVID T. EllwOOd, POOR SUPPORT: POVERTY IN THE AMERICAN FAMILY 104-21 (1988). 
the traditional tools of formal rationing largely unavailable to many policymakers feeling intense pressure to constrain receipt of means-tested benefits, various forms of informal rationing have been adopted.

In particular, state policymakers - under intense media and scholarly scrutiny before and particularly after PRWORA's enactment-have found choice-based rationing systems to have two appealing political consequences. First, they are far less visible than formal eligibility rules. ${ }^{89}$ Caseloads appear to drop as if guided by an invisible hand; most observers are likely to believe that the invisible hand derives from reduced need and families' greater ability to sustain themselves without cash assistance..$^{90}$ Reporters and researchers may not recognize that rationing is taking place or, even if they do, they will have difficulty explaining it to policymakers and the general public. ${ }^{91}$ Second, even if these systems' role is understood, the component of choice is likely to legitimate them in the eyes of many. The public may have qualms about pulling the rug out from under needy people with no alternatives, but it certainly is in no mood to force benefits on people who seem to have chosen another path. ${ }^{92}$

The architecture of particular programs also may encourage policymakers to prefer choice-based rationing systems. The vast majority of states, for example, are meeting TANF's work requirements with the help of the caseload reduction credit, which reduces states' required work participation rate in lockstep with their reductions in welfare caseloads. ${ }^{93}$ In

89. See Diller, supra note 36, at 1208-09; Michael Lipsky, Bureaucratic Disentitlement in Social Welfare Prograns, 58 SOC. SERV. REV. 3, 5 (1984); cf. Ruth Conniff, Radical Plan Would Squeeze the Poor, ST. LOUIS POST-DISPATCH, June 4, 1996, at 13B (criticizing a proposal to tighten formal eligibility nules); George Hesselberg, Just Look at What a State We're in, WIS. ST. J., Feb. 6, 1996, at IC (calling Govemor Thompson's claim to have reduced welfare caseloads thirty-three percent a "fudge" because "most of that decline came by jiggling the eligibility and the basic benefit requirements").

90. See, e.g., Engler's Legacy: A Timeline, DET. NEwS, Dec. 30, 2002, at 6A (charting retiring Michigan Governor John Engler's accomplishments over his twelve-year term in part by declines in welfare receipt); Sheila McCarthy, Welfare-to-Work Effort Is Called Success as Caseload Drops 50\%, BUFF. NEWS, Dec. 29, 1998, at 5B (treating caseload decline as the key measure of the success of changes in welfare policy with little critical examination of how those changes were achieved).

91. Less honorably, of course, this invisibility may appeal to those wishing to pursue rationing agendas that could not win widespread political acceptance, such as easing administrative burdens or permitting racial discrimination.

92. Administrators whose thinking has not fully made the transition from AFDC also may reason that informal rationing techniques may be resistant to legal challenge since they do not absolutely bar anyone from receiving benefits. These techniques thus may more reliably achieve the desired savings than some legally suspect eligibility rules. In reality, however, absent any (unlikely) state constitutional provisions to the contrary, states' legal ability to curtail eligibility for TANF is almost plenary. See 42 U.S.C. $\$ 617$ (2000) (prohibiting federal officials from interfering with states' choices absent a specific federal mandate); see also Helen Hershkoff, Positive Rights and State Constitutions: The Limits of Federal Rationality Review, 112 HARV. L. REV. 1132 (1999) (proposing state constitutional theories to limit this near-plenary authority).

93. For the prescribed formula for calculating the participation rate, see 42 U.S.C. $\S 607(\mathrm{~b})(3)(\mathrm{A})$. 
calculating the credit, however, states may not include caseload reductions resulting from changes in federal or state eligibility rules. ${ }^{94}$ Thus, the TANF statute gives a strong preference to caseload reductions through informal means.

TANF, the Child Care and Development Block Grant, and other programs funded by fixed block grants in general have incentives to control costs fairly rigidly. Some block grants may have limited ability to carry funds forward from year to year (or to borrow from future years in the event of a cost overrun); state administrators therefore may need to adjust participation levels several times a year. Changing formal eligibility rules may require time-consuming reprogramming of the state's computer system, amendment of its manuals, and retraining of its eligibility staff. Adjusting the stringency of informal rationing approaches-releasing outreach materials if enrollment is below expectations or telling local offices to verify eligibility rigorously - may be a faster way of ensuring that participation tracks available funding.

State and local officials' incentive structures in other programs, such as Medicaid and food stamps, are more complex. On the one hand, such programs provide important benefits to the state. Medicaid, for example, is the federal government's largest grant-in-aid program to states. On the other hand, Medicaid is also one of the largest and fastest growing components of states' budgets. ${ }^{95}$ Although both formal and informal rationing methods can achieve savings, prior expansions of Medicaid eligibility received so much public attention that they may be politically difficult to rescind. Accordingly, states have been inclined to take less visible routes, such as reducing the value of the Medicaid benefit package (leaving beneficiaries still "insured," just less so) and reestablishing burdensome eligibility determination procedures they previously had abolished to encourage potential claimants to apply for coverage. ${ }^{96}$ Similarly, food stamps are federally funded, but the threat of quality control penalties may deter states from granting benefits.

\section{The Decentralization of Decisionmaking on Informal Rationing}

In analyzing informal rationing systems, it is necessary to consider the motives of a much wider range of actors than it is for formal eligibility rules. For example, state officials' incentives to issue food stamp benefits,

94. Id. $\S 607(\mathrm{~b})(3)(\mathrm{B})$.

95. Medicaid costs typically consume about one-quarter of states' budgets. See, e.g., SMITH ET AL., supra note 58, at 4-9.

96. See id. at 12; Amy Goldstein, States' Budget Woes Fuel Medicaid Cuts, WASH. POST, Oct. 11, 2002, at A1 (quoting Delaware's Medicaid director as saying that "[i]t's nuts to go out there and drag people in if you can't even serve them or deal with them"). 
which the federal government fully funds, and cash assistance benefits, which come entirely from moneys within the state's control, are quite different. Yet local officials generally pay for none of these benefits; $;{ }^{97}$ as a result, they may be similarly eager or reluctant to provide each. They may have no fiscal motive to withhold benefits, but they nonetheless may have strong administrative or philosophical reasons to want to provide or withhold benefits to some or all claimants.

As discussed above, much of the impetus for informal rationing has been an imbalance between broadly accepted goals for cash assistance and other means-tested programs - caseload reduction, error reduction, and cost avoidance-and an unwillingness of politically accountable policymakers to adopt explicit rules sufficient to accomplish those goals fully. Thus, the locus of policymaking has passed to a considerable degree from senior state officials-governors, legislators, and political appointees-to lower-level managers on the state and local level. These relatively junior officials are tasked with achieving the state's goals but denied many of the formal policymaking tools required to meet them. The result has been a great increase in informal rationing.

Although legislatures theoretically retain the most power in these systems, their visibility can sharply constrain their ability to exercise that power in clear, directive ways. Conversely, although local administrators remain nominally subordinate both to state political officers and to the civil servants in state agencies' policywriting units, the relative invisibility of local offices provides them with the greatest latitude to exercise discretion and to vary the severity of informal rationing regimes.

Senior state officials naturally retain an interest in the operation of their programs and may be reluctant to cede control to the whims of their local subordinates. They may try to provide incentives for local officials to follow the course they favor. Thus, analysis of informal rationing systems may require exploring multiple layers of incentives. ${ }^{98}$ The more difficult it is to understand why a program is operating as it is, the more likely

97. Roughly a third of the states require local governments to contribute to the costs of cash assistance benefits, Medicaid, or both. STAFF OF HOUSE COMM. ON WAYS \& MEANS, 103D CONG., OVERVIEW OF ENTITLEMENT PROGRAMS: 1994 GREEN BOOK 383, 386-87 (Comm. Print 1994). This obviously could cause county managers to differentiate between benefits they help fund and those paid entirely by the state or federal governments. These managers, however, occupy but one tier in the bureaucracy. In any case, all of the benefits that lower-level managers, supervisors, and eligibility workers distribute are funded at a level of government higher than where they are sitting.

98. Of course, several layers of incentives and choices are possible within the government. The legislature may threaten the welfare commissioner's personnel and travel funds to encourage efforts to expand or limit participation; the commissioner may manipulate the incentives of regional overseers who do the same for county managers who in turn signal branch managers what expectations they should impose on unit supervisors and eligibility workers. 
researchers and reporters will miss a step and fail to grasp the importance of what is happening.

Unlike eligibility rules, informal rationing systems also can be created by accident or by inaction. ${ }^{99}$ Procedural barriers to eligibility and disincentives to seek benefits can easily result from inadvertent failures to consider the problems claimants face or from the failure to address those problems once realized. Many rules that would pose no difficulties to middle-income people with stable jobs and residences, adequate transportation, and multiple options for short-term childcare can be devastating for low-income people lacking some of those advantages. Yet it can be most difficult to persuade middle-income policymakers that they, their predecessors, or their counterparts elsewhere in government have narrowed access to benefits without any evidence that this was intended. ${ }^{100}$

This can complicate analysis of informal rationing considerably. Not only must policymakers or researchers recognize that a policy or practice is affecting participation, but they also must consider whether it is deliberate or the result of negligence or ineptitude. The possibility that no one intended to tighten or loosen rationing of the benefit can deflect outsiders from the search for someone who did: Neither public law nor our political process deals especially well with policies that mimic unintended consequences. $^{101}$

\section{E. The Efficiency, Equity, and Authenticity of Choice-Based Rationing}

Given that powerful political forces are likely to rely on choice-based rationing for the foreseeable future, it is incumbent on us to assess its

99. To be sure, many eligibility rules have consequences of an unintended nature or intensity, and a few may be misdrafted. It is difficult, however, to create an eligibility rule altogether by accident.

100. Moreover, many of the same philosophical, political, and administrative factors that can cause some officials to tighten informal rationing, see supra Subsection II.D.1, can also induce others not to search too closely for evidence that their subordinates may be seeking to constrain participation in this way. For a cogent discussion of other ways in which devolution can interfere with the transparent and efficient administration of public benefit programs, see Jon D. Michaels, Deforming Welfare: How the Dominant Narratives of Devolution and Privatization Subverted Federal Welfare Reform, 34 SETON HALL L. REV. (forthcoming Jan. 2004).

101. See, e.g., Jefferson v. Hackney, 406 U.S. 535, 545-51 (1972) (finding no cognizable equal protection issue where substantial differences between the public assistance benefit levels paid to predominately white and predominately African-American and Latino groups could not be shown to result from intentional racial discrimination). In trying to bring political pressure to bear on complex systems such as public benefit administration, the biggest challenge often is getting the public or nonexpert legislators to understand what policy is at issue. This difficulty commonly is overcome by describing the policymaker's intended result without explaining the mechanics of how she or he intended to get there. For example, in late 1994, liberals persuaded the public that House Republicans wanted to put low-income children into orphanages not by explaining how that might be done-inevitably a complex chain of events, if it was to happen at all-but rather primarily because the Republican's speaker-apparent, Newt Gingrich, made the mistake of saying that it might not be a bad idea. 
virtues and deficiencies. It is easy to caricature many strategies for changing potential claimants' incentives to pursue a benefit. On those rare occasions when politicians or the news media address them, they commonly treat these policies as the results of bureaucratic ineptitude or heartlessness. Liberal commentators often do much the same. ${ }^{102}$ Yet the choice often is not between informal rationing and none at all, but rather between these techniques and additional formal eligibility restrictions. Presumably, a legislature or agency decides to ration benefits because it believes that more people are receiving assistance than is fiscally, politically, or ideologically acceptable. If an agency is forced to remove administrative impediments to participation, it is unlikely to abandon its determination to reduce its caseload. Thus, a more realistic assessment would recognize these systems' significant appeal, as well as their shortcomings, and compare them with the advantages and disadvantages of the rule-based methods of rationing that dominated the three decades before the 1996 welfare law and those of the social work model that preceded it. One may disagree with informal rationing policies, but intelligent policymakers could adopt them for coherent reasons.

This Section seeks to identify criteria for judging informal rationing systems. In particular, it considers efficiency concerns, equity and distributional problems with some informal rationing systems, and questions about the quality of the putative choices upon which these systems rely.

Analyzing the efficiency of informal rationing systems can be quite complex. This analysis must encompass waste, or loss of value, of the limited funds provided for means-tested benefits, the mistargeting of those funds on claimants in less severe need, administrative costs, and the costs of the perverse incentives some informal rationing systems create.

The efficiency of a formal eligibility rule customarily is judged by comparing how much it improves the targeting of benefits (under whatever norms the political process has selected) with the cost to the agency of administering the rule. In informal rationing systems, however, many costs are displaced to private actors, particularly claimants. Rationing methods that lower the value of a benefit other than by directly reducing the depth of the subsidy are inefficient in that the state is destroying some of the value that it is paying to create: The state is paying to create a benefit of a certain value and then destroying a part of that value to make the benefit less

102. See, e.g., EllwoOd, supra note 88, at $141-42$ (criticizing the burdens of the welfare application process as a work disincentive); Anna Lou Dehavenon, Charles Dickens Meets Franz Kafka: The Maladministration of New York City's Public Assistance Programs, 17 N.Y.U. REV. L. \& SOC. CHANGE 231, 247-50 (1989-1990) (blaming inefficiency and skewed incentives for the high rate of administrative terminations of eligible recipients' benefits in New York City). 
attractive. Such an action is, in effect; a benefit reduction without the fiscal advantage to the state. ${ }^{103}$

Systems for deterring participation also may change claimants' relationships with third parties in ways that produce similar inefficiencies. Systems that give third parties influence over a claimant's chances of obtaining benefits may compel the claimant to offer the third party an inducement to cooperate. ${ }^{104}$ For example, a landlord may insist that a claimant become current on her rent before signing a verification form. If the claimant was planning instead to move and take advantage of her judgment-proof status, that will reduce the effective value of the benefit she is seeking. Similarly, a worker may feel that she can only ask her employer for a finite number of favors. If one of those favors must be spent on doing the paperwork necessary for her to receive advance payment of the earned income tax credit, ${ }^{105}$ she may feel unable to ask for as much time off to attend parent-teacher conferences or take her children to the doctor. Most simply, if obtaining or retaining a benefit requires multiple office visits, extensive document collection, job searches, or other activities demanding substantial transportation or childcare resources, claimants who pursue benefits are likely to become indebted to, or exhaust the good will of, those who provide those resources. This may leave the claimant less free to turn to the same people for help when seeking or starting employment and may make it difficult for the claimant to refuse their requests for favors that may interfere with the claimant's plans to enhance her independence.

Informal rationing also is likely to entail substantially greater administrative costs than tighter formal eligibility rules. Some of these strategies may increase administrative costs for the state: Someone, for example, must review claimants' verification, even if that function takes substantially less time than it took the claimant to gather it. Officials responsible for setting and adhering to budgets may fret that estimating how many claimants will be deterred from applying is far harder than determining how many a given eligibility change will render ineligible. If participation is higher than is desired, administrators may be uncertain how to calibrate the signals they send to their line employees to achieve the desired degree of additional rigor. If an agency requires several iterations to arrive at an informal rationing regime producing the desired level of caseload reduction, it must incur the not inconsiderable administrative costs

103. This action not only deters participation by many of those with lesser need, but also reduces the value of assistance to those in greater need who feel compelled to absorb these costs to get benefits.

104. To the extent that third parties are willing to assist the claimant without extracting rent, the rationing system is imposing costs on them rather than the claimant. This remains an inefficiency of the system.

105. See 26 U.S.C. $\S \S 32,3507$ (2000). 
of changing its systems and retraining its workers each time it makes an adjustment.

Informal rationing may also produce an inefficient targeting of benefits. Such rationing may make it more or less likely that a given type of eligible claimant will participate, but it almost certainly will fall far short of assuring a perfect fit between need and the provision of benefits. A potential claimant with less need may happen to be neighbors with an eligibility worker; a desperate family may have a close relative who was convicted of fraud based on an innocent misunderstanding and overestimate the risk of being accused. One family may be particularly greedy, another unusually stoic. And although need and desire for assistance may be factors in potential claimants' choices whether to participate, other factors may well prove even more important for many families.

Moreover, policies that discourage receipt of public benefits may create incentives, or promote behaviors, that many policymakers would regard as perverse and inefficient. A time-consuming administrative process will burden most those whose time is most valuable. That group may include those with limited childcare resources, but it also includes low-wage workers forced to take time off from work. Obviously, endangering one's employment by taking time off to comply with a public benefit program's burdensome administrative requirements is counterproductive for all concerned. Workers also may be more vulnerable to stigma if identified as recipients of means-tested benefits since they could face fairly immediate, concrete consequences: the loss of their employers' confidence and the opportunities that go with it. Those without jobs will not have this vulnerability and hence may be less likely to be deterred. ${ }^{106}$

Even when stigma does not deter destitute claimants, however, it may still have counterproductive consequences. Individuals who already feel beaten down may be demoralized further by being stigmatized. This could leave them even less likely to project the confidence that will help them become employed. Requiring claimants to make numerous job contacts and to obtain employers' verification of their failed applications can make them nuisances to local businesses and may persuade prospective employers that low-income people care more about documenting failed applications than doing what it takes to make successful ones.

Informal rationing systems also may raise serious equity concerns. On the simplest level, strategies to restrict the availability of information can be perceived as unfair. More broadly, rationing may have different, and often regressive, impacts across subgroups of claimants. Some of these strategies

106. Of course, unemployed claimants are likely to have personal pride and may react strongly to the prospect that their neighbors, landlord, or children's schools may discover that they are seeking public assistance-or any implication that they may be suspected of fraud. 
may have the greatest deterrent effects on some of the neediest families. For example, the burden of complying with many procedural requirements is likely to depend on the claimant's literacy, math ability, organizational and social skills, and childcare and transportation resources. ${ }^{107}$ Yet the claimants likely to be the weakest in those areas-and hence most burdened-also are likely to have the poorest job prospects and hence be the neediest. Similarly, the risk of fraud prosecution is likely to be greatest for illiterate claimants (who must communicate orally or through unreliable scribes), those with poor math abilities (who cannot readily recognize whether their benefit amount seems to have been adjusted for income they believe they have reported), and those with poor organizational and social skills. And a time limit may be less of a deterrent to a family with solid job prospects that is experiencing a modest reversal than it is for a much poorer family that cannot imagine that it will ever be able to increase its earnings much-and fears even harder times ahead. A family with more disposable income may be less burdened by a benefit being provided in kind since it has more cash expenses that the benefit can supplant. ${ }^{108} \mathrm{~A}$ family with less money also may simply lack the funds to make a required copayment even if the benefit of doing so would be quite substantial. ${ }^{109}$ More broadly, claimants with significant disabilities and those facing linguistic or literacy barriers may be disproportionately affected by many of these rationing systems-even though they also face severe barriers in the employment market.

Perhaps the most fundamental concern about choice-based rationing systems is whether the outcomes they produce really do represent claimants' and potential claimants' choices at all and, to the extent they do, whether those choices have the qualities that make them legitimate bases for allocating public resources. A low-income family that does not apply for a benefit because it does not know that the benefit exists has not made a

107. In Medicaid, where some beneficiaries may have difficulty getting to services, the failure to provide transportation long has been recognized as a formidable rationing device. See, e.g., Morgan v. Cohen, 665 F. Supp. 1164, $1169-75$ (E.D. Pa. 1987) (invalidating a Pennsylvania system for assuring Medicaid transportation upon finding that it tended to deny access to services to the most disabled beneficiaries).

108. For example, a $\$ 300$ food stamp allotment need not affect the purchasing habits of a family that is already spending $\$ 300$ on food; the family could simply purchase the same amount of food with the food stamps and spend the $\$ 300$ of cash that it frees up on any other household need. A poorer family that is spending less than $\$ 300$ on food may have its spending choices constrained.

109. This problem dogged the food stamp program for over a decade until the Food Stamp Act of 1977 eliminated the requirement that most recipients purchase a month's supply of food stamps. Pub. L. No. 95-113, sec. 1301, 91 Stat. 913, 958-79 (codified as amended at 7 U.S.C. $\S \S 2011-2027)$; see also 7 U.S.C. $\S 2016(b)$ (1976); H.R. REP. No. 95-464, at 170, 238-44 (1977). It remains an ongoing source of contention in Medicaid. See generally OFFICE OF TECH. ASSESSMENT, 103D CONG., BENEFIT DESIGN IN HEALTH CARE REFORM: BACKGROUND PAPERPATIENT COST-SHARING (1993) (describing research findings and controversy over cost-sharing requirements' impact on healthcare utilization). 
choice at all; neither has a low-income family that does not apply because it is wholly convinced, albeit wrongly, that it is ineligible. To say that the families made a choice not to try harder to learn about government benefit programs may be technically true, but normatively unpersuasive: The choice to seek out information is difficult to equate with a choice not to seek public benefits. A family that is denied public benefits due to a procedural default-whether as part of the application process or for failing to fulfill a behavioral requirement-may have made a conscious choice not to continue its pursuit of the benefit (or to pursue it only halfheartedly), or may sincerely have believed it was fully complying with the program's requirements. If the latter, it is difficult to argue that the family's failure to take additional steps to determine the adequacy of its compliance is the fair equivalent of a choice not to receive benefits.

Failures to participate that appear to result from claimants' choices may thus reflect decisions of third parties or simple random chance. Complex procedural requirements can give third parties the effective power to deny families' claims by refusing to provide required verification, by refusing to entertain an application for employment proffered in compliance with a job search requirement, by erroneously informing a potential claimant that she is ineligible for benefits, or even by stealing mail from the agency out of the claimant's mailbox. Effectively delegating control over claimants' eligibility to landlords or fast food managers seems to have all of the vices and few of the virtues of giving open-ended discretion to eligibility workers. Similarly, random chance, such as postal delays and misdeliveries, clerical errors or delays in processing papers that a claimant has submitted, or a claimant's mistake as to when an eligibility worker might be available to take a phone call, can result in procedural denials that cannot fairly be attributed to choice.

Even where potential claimants clearly did consciously choose to eschew benefits, questions can arise as to whether some of those choices were sufficiently voluntary to provide valid bases for denying a public benefit that may be crucial to the claimants' subsistence. Answering these questions requires having an empirical assessment of the nature of the choices a particular set of rules or practices imposes on potential claimants, which in turn requires an appreciation of the diverse range of potential claimants' capabilities and problems. ${ }^{110}$ It then requires a normative

110. The law evaluates the quality of choices in many other contexts: when criminal defendants or others waive constitutional rights; when deciding whether to enforce an alleged contract of adhesion; or when evaluating defenses of necessity, self-defense, incapacity, and the like. Typically, however, these are fact-intensive determinations. That process is largely unavailable here. To be sure, the facts of individual claimants' and potential claimants' choices do indeed vary: For example, the same actions could mean one thing for a claimant who fully understands her or his rights and options and quite another for one who is facing language, literacy, or other barriers. But many of the same factors that often impair claimants' ability to 
judgment as to what kinds of choices are both fair and good public policy. The reflexive and often covert manner in which informal rationing regimes typically have been imposed, however, has left little room for these sorts of reflections.

\section{HOW PRINCIPLES OF CHOICE AFFECT THE DESIGN OF PROGRAMS' SUBSTANTIVE EligibILITY RULES}

As developed in the preceding Part, the most important manifestation of choice principles in the new world of public benefits law is in the supplanting of formal eligibility rules with techniques of informal rationing. The critical assumptions underlying the regime of choice-based rationing, however, also have implications for the design of formal eligibility rules. In particular, the assumption of an active, willful claimant that is a foundation of choice-based rationing also suggests that incentives should be a central consideration in the design of eligibility rules. ${ }^{111}$

In certain respects, tightening eligibility rules can create incentives that advance some policymakers' goal of reducing receipt of means-tested benefits. A time limit is an obvious example: Having only a finite number of months of benefits available to a claimant in her or his lifetime gives that claimant an incentive to find alternative means of support whenever possible. In addition, the preference for choice-based rationing helps determine which eligibility rules will be tightened and which groups of claimants will bear the brunt of restrictions on eligibility. Those presumed to have the most alternatives to means-tested benefits, or to have entered their current predicament in part as a result of their own choices, become prime targets for reductions - even if those presumptions are baseless.

In other respects, however, taking incentives more seriously can lead to liberalizing rigid eligibility rules. Were the new regime to focus on incentives only when they result in reducing benefits, it could legitimately be accused of hypocrisy. To their credit, many states, as well as some federal policymakers, have moderated or cast aside some of the most entrenched restrictive eligibility rules upon recognizing the perverse incentives those rules created.

To be sure, the value of these liberalizations is diluted by the system's overall campaign to make receipt of benefits unattractive. Those efforts

make knowing and voluntary choices to decline benefits for which they are eligible also prevent the vast majority of those claimants from seeking adjudications that might free them from the consequences of a choice that was not truly voluntary.

111. For a cogent critique of the single-minded emphasis on incentives in public benefit programs, and a timely reminder that "incentives are not behaviors," see THEODORE R. MARMOR ET AL., AMERICA's Misunderstood Welfare State: Persistent Myths, ENDURING REALITIES $219-22$ (1990). 
reduce the significance of all substantive eligibility rules, both new and old. Nonetheless, these changes can help some families in serious need now. And, to the extent that the fairness of informal rationing can be improved over time, these reforms will become more significant. In the meantime, policymakers' adoption of incentive-based liberalizations can appropriately be held up as a measure of their sincerity in building a constructive new regime of public benefits law. As noted above, PRWORA's conservative authors did not, and knew they could not, sell the legislation as an indiscriminate purge of the rolls. The dogged retention of eligibility rules that discourage or punish claimants seeking employment can be criticized as exceeding the public's mandate for reform of public benefit programs.

This Part examines the influence that the increasing emphasis on choice has had on the design of substantive eligibility rules over the past decade. It argues that, in addition to criticizing the excesses of informal rationing, advocates and scholars should scrutinize formal eligibility rules for their fidelity to the new ideology of choice and incentives. Criticizing inconsistencies between informal rationing techniques that seek to reshape claimants' behavior and formal eligibility rules that implicitly assume that the same behavior is immutable may help compel changes in one system or the other-or call into question the basic good faith of the system.

Section A examines the ways in which the principal types of nonfinancial eligibility rules have been restructured to reflect claimants' actual or assumed choices. Although these changes give the appearance of enhancing claimants' self-determination and less arbitrary governmental control over who receives benefits, they may create serious inequities where claimants in fact lack genuine choices. As with informal rationing practices that rely upon spuriously imputed choices, these inequities can and should be exposed. Section B explores how the orientation toward choices has reshaped financial eligibility rules to facilitate and reward certain types of choices. The choice-based approach has brought liberals and conservatives together to relax the severity of means tests in some ways that would have been unthinkable only a few years before. Advocates should not allow the divisiveness of contemporary public benefits debates-or their ambivalence about the exaltation of choice-to deter them from taking advantage of these opportunities to form transitory alliances to address these significant problems.

\section{A. Nonfinancial Eligibility Rules}

\section{Requirements To "Earn" Eligibility}

Some of the politically strongest public benefit programs-Social Security, Medicare, veterans' benefits, and unemployment compensation- 
require claimants to have "earned" eligibility through their own work or the work of close relatives. To the extent that AFDC covered families with two able-bodied parents, it required one of those parents to have earned the family's eligibility with several quarters of work. ${ }^{12}$ Similarly, the food stamp program disqualifies many otherwise eligible college students but makes an exception for those who are working. ${ }^{13}$ And transitional medical assistance (TMA) is provided for up to one year to families whose earnings have put them above the state's income eligibility limit for family Medicaid. ${ }^{114}$ This policy clearly is intended as a reward for work effort: A family whose income rises because it obtained Social Security or other public benefits is ineligible for TMA. In none of these cases is an exception made for people who were unable to work due to economic conditions or a lack of marketable skills: Work is treated (somewhat fictitiously) as dependent entirely upon a claimant's choice to work.

The 1996 welfare law similarly allowed some of those subject to its nonfinancial eligibility rules to earn exemptions. Most of its limits on legal immigrants' eligibility for means-tested benefits required that the immigrant claim forty quarters of work under the Social Security system, either based on her own work or that of her spouse or parents. ${ }^{115}$ Childless adults whom PRWORA would otherwise limit to three months of food stamps in each thirty-six-month period are exempt if they are working at least twenty hours per week. ${ }^{116}$

Most prominently, the TANF statute gives states incentives to require most low-income families to earn means-tested cash assistance payments through compliance with work and other behavioral requirements. Many

112. See 42 U.S.C. $\$ 607$ (b) (1994), amended by Personal Responsibility and Work Opportunity Reconciliation Act of 1996, Pub. L. No. 104-193, § 103, 110 Stat. 2105, 2129.

113. See 7 U.S.C. $\S 2015(\mathrm{e})(4)(2000)$.

114. See 42 U.S.C. $\$ 1396 \mathrm{r}-6$. Receipt of TMA depends on both having received Medicaid for at least three recent months based on having income under this eligibility limit and on being employed. See id. $\S \S 1396 \mathrm{r}-6(\mathrm{a})(1), 1396 \mathrm{u}-1(\mathrm{~b})(1)(\mathrm{A}),(\mathrm{c})(2)$. Thus, this provision is a bit hard to categorize: Both current work effort and a recent paucity of earnings are required.

Also, in a somewhat similar vein, Medicaid recipients with disabilities can maintain coverage when they go to work if continuing Medicaid coverage is deemed essential to their ability to work or under various other conditions. See, e.g., id. \$§ 1396a(a)(10)(A)(ii)(XIII), (XV), $1396 \mathrm{~d}(\mathrm{q})$, (s), (v), 13960(g) (granting Medicaid eligibility to persons who would be unable to work without services that Medicaid covers and preventing persons returning to work from the disability rolls from losing Medicaid coverage immediately).

115. See 8 U.S.C. $\S \S 1183 \mathrm{a}(\mathrm{d}), 1612(\mathrm{a})(2)(\mathrm{C}),(\mathrm{b})(2)(\mathrm{C}), 1631(\mathrm{~b})$. Similarly, work in the U.S. armed forces provides an exception to many of these rules. See id. $\S \S 1612(\mathrm{a})(2)(\mathrm{B}),(\mathrm{b})(2)(\mathrm{B})$, $1613(b)(2)$.

116. 7 U.S.C. $\S 2015(\mathrm{o})(2)(\mathrm{A})$-(B). The lack of marketable skills does not allow a claimant who is unable to find half-time work to receive food stamps for more than three months. States may, but need not, seek waivers from the time limit for areas with "insufficient jobs." Id. $\S 2015(\mathrm{o})(4)$. Over forty states have obtained waivers for at least some areas, apparently reasoning that sufficiently severe local economic conditions prevent a claimant's failure to work from being fairly attributed to the claimant's choice. 
states also extend their time limits for claimants who are working or complying with work requirements.

This vision of choice has significant flaws. Not only does it ignore the plight of people who choose to work but are unable to find employment, but it also takes an unduly narrow view of what constitutes "work" for low-income parents (or, to put it another way, inappropriately assumes that work outside of the home is the only valid choice for them). Were the work of parenting considered a way to "earn" benefits, the condition of low-income families in this country would be considerably better. Some states' categorical rules for their TANF-funded programs now make parents' compliance with certain minimum standards of performance (e.g., having their children immunized) a necessary condition of eligibility, but except in the case of very young children, none makes parenting sufficient to satisfy categorical requirements. It should perhaps go without saying that the subjective judgments inherent in programs' definitions of what it means to "earn" a benefit implicate deeper problems with society's failure to value work traditionally done disproportionately by women. ${ }^{17}$ This suggests a limitation of the principle of choice. Low-income people are deemed independent and capable of making their own decisions for purposes of declining public benefits or committing acts deemed worthy of penalties. Yet in their more important capacity as parents, they are deemed incapable of making responsible decisions.

\section{Linkages to Receipt of Other Public Benefits}

Some programs tie eligibility to whether a claimant receives certain other benefits, either positively or negatively. Rules disqualifying recipients of one benefit from eligibility for another can be manipulated to induce some low-income people to decline to receive one benefit for which they may be eligible by offering another, less valuable one. In these cases, public policies that degrade the value of a nominally more generous benefit to the point that an inferior one seems preferable often go unnoticed. ${ }^{118}$

117. See, e.g., Beverly Leopold McDonald \& Rita Diehl, Women and Welfare, 14 CLEARINGHOUSE REV. 1036 (1981) (arguing that the most generous public benefit programs are those that primarily serve men); Jane C. Murphy, Legal Images of Motherhood: Conflicting Definitions from Welfare "Reform," Family, and Criminal Law, 83 CORNELL L. REV. 688, 732-41 (1998); Lucy A. Williams, Race, Rat Bites and Unfit Mothers: How Media Discourse Informs Welfare Legislation Debate, 22 FORDHAM URB. L.J. 1159 (1995) (describing the propensity of the media, politicians, and the public to jump to broad negative conclusions from anecdotal reports about low-income mothers, and to make policy accordingly).

118. An entirely separate kind of linkage between benefit programs is a rule that allows receipt of one benefit to satisfy some or all of the eligibility criteria for another. See, e.g., 42 U.S.C. $\$ 1758$ (b)(2)(C)(ii)(I)-(II) (granting automatic eligibility for free school meals to TANF and food stamp recipients); id. $\S 8624(\mathrm{~b})(2)(\mathrm{A})(\mathrm{i})$, (iii) (granting automatic eligibility for energy assistance). Where these linkages exist, a more rigorous regime of rationing in one program is 
In recent years, state and federal policymakers have applied this principle to conceal benefit reductions behind the principle of choice. States' TANF-funded programs offer applicants a lump-sum diversion payment in exchange for accepting an extended period of ineligibility for ongoing cash assistance. The lump sum generally is only a modest fraction of the value of the monthly benefits lost ${ }^{19}$ but may be appealing to a family in dire immediate need-or to one that does not relish ongoing involvement with the welfare office.

The State Children's Health Insurance Program (SCHIP), enacted in 1997, assures beneficiaries far less comprehensive benefit packages, higher cost-sharing, and less accessible application processes than Medicaid. ${ }^{120}$ Medicaid coverage thus is likely to be more beneficial to the poorest families, who have little other recourse for obtaining expensive healthcare and may be deterred by substantial cost-sharing requirements. ${ }^{121}$ To ensure that states' efforts to promote their separate SCHIP programs do not displace Medicaid, the SCHIP statute requires states to screen all applicants for possible eligibility. for Medicaid and to enroll them if they are eligible. ${ }^{122}$ Some states, however, have sought to stigmatize Medicaid as welfare, causing claimant families to seek to enroll their children in the cheaper but more respectable SCHIP programs.

The food stamp program's relationship with the Emergency Food Assistance Program (TEFAP) is not wholly analogous since the same household can receive benefits under both programs. Nonetheless, congressional Republicans have repeatedly trimmed funds from food stamps-making benefit cuts deeper in 1996 and increases smaller in 2002-to purchase commodities for TEFAP to distribute through emergency food programs. ${ }^{123}$ The value of the typical TEFAP benefit is far less than the food stamp allotment for all but the least needy households. Many emergency food providers, however, promote TEFAP as a

likely to reduce participation in others. These potentially unintended consequences provide an additional reason for concern about and close study of new informal rationing systems.

119. In states where the lump sum does not count against state time limits-it is not "assistance" under 45 C.F.R. $\$ 260.31$ and hence does not count against federal time limits-a calculation of the relative values of the two benefits becomes more complex.

120. Compare 42 U.S.C. $\$ 1397 \mathrm{bb}(\mathrm{b})$ (generally allowing states to set eligibility standards and procedures in SCHIP), with $\cdot$ id. $\$ 1396 \mathrm{a}$ (detailing claimants' entitlement to Medicaid benefits).

121. See KAISER COMM'N ON MEDICAID \& THE UNINSURED, THE HENRY J. KAISER FAMILY FOUND., HEALTH INSURANCE PREMIUMS AND COST-SHARING: THE IMPACT ON LOW-INCOME POPULATIONS (2003), http://www.kff.org/content/2003/4072/4072.pdf; LEIGHTON KU, CTR. ON Budget \& Policy Priorities, Charging the POOR MORE for Health Care: COST-SHARING IN MEDICAID 1 (2003), http://www.cbpp.org/5-7-03health.pdf.

122. 42 U.S.C. $\S 1397 \mathrm{bb}(\mathrm{b})(3)(B)$.

123. Compare, e.g., S. 1117, 104th Cong. $\$ \S 804-820$ (1995) (setting forth a Democratic proposal for few food stamp reductions and no new mandatory spending for TEFAP), with S. 1795, 104th Cong. $\S \S 1013-1038,1071$ (1996) (setting forth a Republican proposal for additional and deeper food stamp reductions and new spending on TEFAP). 
bureaucracy-free alternative to food stamps. The welter of behavioral and procedural requirements that federal and state governments have attached to the food stamp program in recent years makes that alternative appealing. In effect, TEFAP offers households a chance to buy their way out of the food stamp program's burdensome informal rationing procedures by making do with a less valuable TEFAP benefit. ${ }^{124}$

\section{B. Replacing Means-Testing with the Invisible Hand}

Traditionally, public benefit programs' financial rules have been regarded as one of the most objective aspects of eligibility determination. Those with less were eligible while those with more were not. Among those who were financially eligible, many programs provided greater benefits to those with the least. The analysis was largely static: How a claimant came to have the income or resources she or he did was largely irrelevant. Of all forms of state rationing of benefits, the major thrust of these rules-that benefits should follow objective need-was among the least controversial. ${ }^{125}$ Liberals and conservatives may have differed about how many people a program should serve, and hence about how high or low these standards ought to be, but the principle of looking at a claimant's current means was broadly accepted.

The income and resources a claimant possesses, however, reflect in significant part some choices that she or he has made. As means-tested programs have moved increasingly to managed choice ${ }^{126}$ as a rationing strategy, this aspect of choice has become increasingly difficult to ignore.

124. Republicans' preference for TEFAP certainly reflects to some extent their growing affection for private charities as delivery mechanisms for social services. Yet TEFAP is hardly a private charity: The federal government, not private donors, purchases the commodities TEFAP delivers.

The bias in favor of TEFAP is ironic since it denies the choice of what foods to purchase that food stamp recipients enjoy; choice in the capacity of a consumer, clearly, is not respected to the same degree that other types are. Similarly, the movement over the last decade to require Medicaid beneficiaries to enroll in managed care plans, occurring simultaneously with the blossoming of choice-based behavioral requirements and rationing systems, shows that low-income people's choices as consumers attract little respect.

125. Of course, there was plenty of controversy about the precision of those measures. E.g., Heckler v. Turner, 470 U.S. 184 (1985) (finding that Congress intended to calculate AFDC eligibility based on gross wages, not take-home pay); Shea v. Vialpando, 416 U.S. 251, 254 (1974) (prohibiting states from counting earnings not "actually available" to claimants under a prior AFDC statute); Hamilton v. Madigan, 961 F.2d 838 (9th Cir. 1992) (excluding relocation payments to homeless families from food stamp income calculations); New York v. Lyng, 829 F.2d 346 (2d Cir. 1987) (allowing the Department of Agriculture to count restaurant allowances to homeless families as income for the purposes of determining food stamp eligibility).

126. The term "managed choice" seems a fair moniker for this new regime. Claimants' choices about whether to seek government benefits are an inevitable part of any program's operations. What distinguishes this new approach from prior practice is the degree to which 


\section{Income Eligibility and Claimant Choice}

Prior to the 1990s, means-tested programs' recognition of choices varied considerably. The food stamp program offered a standard deduction, ${ }^{127}$ an earned income deduction of $20 \%,{ }^{128}$ and reduced benefits by only thirty cents for each additional dollar of income. ${ }^{129}$ Thus, net of food stamp benefit reductions, claimants retained the first hundred or so dollars that they earned plus $64 \%$ to $76 \%$ of the remainder. ${ }^{130}$

Through most of AFDC's history, on the other hand, its income rules did little to encourage employment. Initially, this was because AFDC was seen as a pension for widows who should be caring for their children rather than working outside the home. Even when AFDC decided that mothers should seek paid employment, it generally treated this as a moral obligation that claimants ought to honor without financial inducement. Those caught defying this obligation could be sanctioned, but the program had no reason to bribe claimants to fulfill their moral duties. Thus, for its first three decades, AFDC generally taxed earnings dollar for dollar. The earnings disregards introduced in the late 1960s were puny indeed: Claimants could retain the first thirty dollars they made plus only one-third of the remainder. In 1981, however, even these disregards were restricted to the first few months of employment. ${ }^{131}$

Medicaid retained the "thirty and one-third" disregards in 1981 and added a year of transitional medical assistance (TMA) later in the 1980s for claimants earning their way off of AFDC. ${ }^{132}$ Given the value of Medicaid benefits and the difficulty of replacing them on the private market, however, one nonetheless could argue that Medicaid punished claimants' decisions to seek and continue employment more severely than any other means-tested program.

The programs' passive approach to claimants' choices about working was inconsistent both with the vigorously pro-work ideology of welfare policy in the 1990s and with the broader trend toward replacing formal

officials at all levels of government seek to influence, or manage, those choices to achieve particular substantive results desired by the state.

127. 7 U.S.C. $\$ 2014(\mathrm{e})(1988)$ (amended 1990). This provision is still in effect today, in substantially the same form. See 7 U.S.C. $\S 2014(\mathrm{e})(2000)$.

128. Id. (1988).

129. Id. $\S 2017$ (a) (amended 1990). This provision is still in effect today in substantially the same form. See 7 U.S.C. $\$ 2017$ (a) (2000).

130. The amount claimants could retain depended somewhat on interactions with the excess shelter expense deduction. See 7 U.S.C. § 2014(e) (1988). For households with high shelter costs, this deduction increased the amount of income that the household could retain before its benefits began to be reduced but then increased the rate at which those reductions phased out its benefits.

131. See Omnibus Budget Reconciliation Act of 1981, Pub. L. No. 97-35, § 2301, 95 Stat. 357, 843-44 (formerly codified at 42 U.S.C. $\$ 602(a)(8)$ (1994) (repealed 1996)).

132. See Family Support Act of 1988, Pub. L. No. 100-485, § 303(a), 102 Stat. 2343, 2385-93 (codified as amended at 42 U.S.C. § 1396r-6 (2000)). 
rationing rules with techniques for managing claimants' choices. Connecticut provides an extreme example of the response. It adopted what amounted to a full disregard of earnings up to the poverty level and replaced means-testing with a twenty-one-month time limit. ${ }^{133}$ Thus, for all practical purposes its cash assistance program abolished its formal income test and allowed potential claimants to decide for themselves whether they would receive cash assistance. The short time limit, however, constrained those choices severely. A family could choose to receive a full cash assistance grant on top of poverty-level earnings, but in doing so it would use up a month of eligibility that it might need later on when it had no income at all.

Initial evaluations suggest that many families did not subordinate present need to protect their future eligibility and used up their twenty-one months while making significant earnings. ${ }^{134}$ The cause of these apparently imprudent choices is unclear. Some may reflect program administrators' failure to explain properly the tradeoffs being imposed on these families. Some of it may be inevitable adjustment difficulties surrounding a radically new system - a lag in claimants' understanding that financial eligibility had suddenly become far less important in Connecticut's program. Some of these choices may indicate that the current needs of families with wages at or below the poverty line are so great that these families are unlikely to be able to make what more affluent people would regard as economically sound choices. Ultimately Connecticut did allow a substantial number of extensions to the time limit, but these too were based on recipients' choices to comply scrupulously with state-designed work requirements. ${ }^{135}$ Thus, a fallback from formally unstructured choice coerced by severe consequences became a series of compliance choices closely structured by the state.

No other state replaced means-testing with managed choice as completely as Connecticut. Many other states, however, coupled strict time limits with liberal earnings disregards or exclusions of some part of child support collections from means tests. ${ }^{136}$ Only a small handful sought to protect claimants from a choice between meeting immediate needs for income supplementation and having a safety net available for future periods

133. See DAN BloOM ET Al., MANPOWER DEMONSTRATION RESEARCH CORP., JOBS FiRST: FINAL REPORT ON CONNECTICUT'S WELFARE REFORM INITIATIVE 2-4 (2002).

134. See id. at 60-62.

135. See id. at 68-71.

136. Compare State Policy Documentation Project, Findings in Brief: Time Limits, at http://www.spdp.org/tanf/timelimits/timelimitexpl.htm (last visited Nov. 11, 2003) (finding that twenty states have TANF time limits shorter than the federally prescribed sixty months), with State Policy Documentation Project, Financial Eligibility for TANF Cash Assistance, at http://www.spdp.org/tanf/financial/finansumm.htm (last visited Nov. 11, 2003) [hereinafter State Policy Documentation Project, Financial Eligibility for TANF] (finding that all but five states liberalized their treatment of earnings in calculating financial eligibility from AFDC rules). 
of joblessness. ${ }^{137}$ Thus, in the great majority of states, claimants' choices of whether to "bank" months on their time limit replaced means-testing. Indeed, attaching these unpleasant consequences to the receipt of benefits undoubtedly reduced the cost of more liberal income exclusions, and may have made these liberalizations politically viable. ${ }^{138}$

\section{Resource Eligibility and Claimant Choice}

Resource eligibility rules, too, have been revised heavily with an eye toward claimants' choices. Previously, rules that denied benefits to claimants with resources exceeding a certain amount generally did not purport to focus on any decision claimants might have made. Instead, the simple presence of the resource was enough to trigger the rule. Particularly as they applied to nonliquid assets such as motor vehicles, these rules focused less on what claimants might or might not be able to do ${ }^{139}$ and more on the resentment of taxpayers to paying for benefits for people with substantial assets. ${ }^{140}$

137. Illinois does not count months during which a parent has earnings for at least twenty hours per week toward a family's TANF time limit. Maine and Missouri apply similar policies to smaller subsets of their working families. See LIZ SCHOTT, CTR. ON BUDGET \& POLICY Priorities, State Choices on Time Limit Policies IN TANF-Funded Programs (1998), http://www.cbpp.org/9-1-98wel.htm. Michigan and Vermont do not time limit cash assistance. Liz SCHOtT, CTR. ON BUdGet \& POLICY PrIORITIES, WAyS That STATES CAN SERVE FAMILIES THAT REACH WELFARE TIME LIMITS 1 n.1 (2000), http://www.cbpp.org/6-21-00wel.pdf. In other states, however, this dilemma appears quite widespread: Over 800,000 families receiving TANF include a member working at least half-time, and another 750,000 families with such a worker are financially eligible for, but not receiving, TANF. KATHERIN ROSS PHILLIPS, EARNING BACK TIME: WHO WOULD BENEFIT FROM WORK-RELATED TIME LIMIT EXEMPTIONS? 4 (Urban Inst., Assessing the New Federalism Series No. B-50, 2002), http://www.urban.org/uploadedPDF/ 310569_b50.pdf.

138. In Medicaid and food stamps, without similar time limits, the same tradeoffs did not apply. To be sure, TMA and food stamp eligibility for many childless adults was time limited. See 7 U.S.C. $\S 2015(0)(2000)$; 42 U.S.C. $\S 1396 r-6$. But months of eligibility on the transitional Medicaid "clock" cannot be "banked" for future use, and the food stamp time limit-three months - arguably is too short to present a meaningful tradeoff between current and future use of benefits. Indiana did attempt to extend this principle of claimant choice to Medicaid by running beneficiaries' TANF clocks during months of Medicaid receipt; it abandoned this policy under HHS pressure.

On the other hand, neither program experienced the same sort of liberalization in the treatment of earned income. States raised Medicaid's income eligibility limits but generally did not do so for any particular type of income. The food stamp program changed accounting rules in ways that resulted in some wages being ignored for up to six months. See 7 U.S.C. $\S 2014(f)(1)$; 7 C.F.R. $\S 273.12(a)(1)(v i i)$, (f)(4) (2003). The program's basic eamed income deduction and benefit reduction rate did not change.

139. See, e.g., Alexander v. Glickman, 139 F.3d 733 (9th Cir. 1998) (denying food stamps to a claimant based on a vehicle that was concededly so heavily encumbered that the claimant could not obtain significant funds by selling it). But see David A. Super, 1990 Farm Bill's InaccessibleResource Provision Applies to Vehicles, 26 CLEARINGHOUSE REV. 1343 (1993) (arguing that Congress no longer wished to deny benefits to such households).

140. The House Agriculture Committee, for example, cited public resentment and criticism of presumed affluence among welfare recipients rather than any impact on a family's need for food 
Under the welfare reform demonstration projects of the early 1990 s and states' TANF and Medicaid programs later in the decade, attention shifted to the claimant's decisions. Where the claimant had substantial amounts of readily available cash, most states concluded that she or he ought to spend it on subsistence rather than seeking cash assistance. ${ }^{141}$ But states divided on whether possession of cash ought to disqualify a low-income family from receiving health coverage, particularly for its children. ${ }^{142}$ Presumably this difference reflects the difficulty of purchasing affordable individual health insurance policies.

For other assets, however, states widely shifted their focus to the decisions their eligibility rules were thrusting upon claimants. A rule denying subsistence benefits to a claimant based on her or his possession of a motor vehicle implicitly criticizes the claimant's failure to sell that vehicle or at least suggests that selling the vehicle is a preferable means of obtaining the funds to subsist. With vehicles essential to finding and keeping employment in much of the country, states no longer wanted to encourage low-income people to dispose of their cars. Thus, a great many states excluded many or all cars from their vehicle tests for cash assistance; ${ }^{143}$ even more did so for Medicaid. ${ }^{144}$ Beginning in July 1999,

as a reason for establishing the food stamp vehicle rule that rendered many low-wage working families ineligible because of the value of the vehicles they drive to work:

$[T]$ he Committee does not intend... to tolerate abuses of the kind that make the program subject to public criticism. If there is such a thing as a welfare Cadillac, there ought not to be. The Committee bill would treat Cadillacs and Rolls Royces and Bentleys or Mercedes Benzes or excessively expensive sports car[]s, even if used for a household member's employment because it transports its owner to work, as items leading to, almost conclusively, ineligibility. It is not necessary to drive to work in such cars .... However rural an area, a household does not have to have a new or slightly used luxury car to traverse the distances.

H.R. REP. NO. 95-464, at 89 (1977), reprinted in 1977 U.S.C.C.A.N. 1978, 2067. Although the Committee is obviously right that plain cars can carry one to work as well as expensive ones, that fact has little relevance to an impoverished family that happens to have a more expensive car. The Committee's fair market value test disqualified families that could not sell their cars for significant gain due to encumbrances.

141. See State Policy Documentation Project, Asset Limits as of December 1998 (1999), http://www.spdp.org/tanf/financial/asset.pdf (reporting that only Ohio does not have an asset test for TANF cash assistance and that all but three other states impose asset tests of between $\$ 1000$ and $\$ 5000$ on applicants for assistance).

142. See VERnON K. SMith ET AL., The HenRy J. Kaiser FAMILy Found., Eliminating THE MEDICAID ASSET TEST FOR FAMILIES: A REVIEW OF STATE EXPERIENCES 18 (2001), http://www.kff.org/content/2001/2239/2239.pdf (finding that thirteen states and the District of Columbia apply no asset test to families seeking Medicaid and that all but three of the remaining states have liberalized the asset tests they inherited from AFDC).

143. See State Policy Documentation Project, Financial Eligibility for TANF, supra note 136 (reporting that twenty-three states exclude the value of at least one car per family in determining eligibility for cash assistance, while twenty-seven states exclude part of the value of a car).

144. See SMITH ET AL., supra note 142, at 18-20 (finding that twenty-two states disregard the value of at least one vehicle per family while another nine states have no asset limit at all). 
first the Clinton Administration ${ }^{145}$ and then Congress ${ }^{146}$ took a series of actions to allow states to import the liberal vehicle policy from cash assistance and TANF-funded service programs into the food stamp program.

In addition, as conservatives came to see poverty as the result of a lack of thrift and savings (i.e., bad choices), it became increasingly difficult to justify resource policies that pushed claimants to choose consumption. While their forebears had won enactment of a statutory provision explicitly requiring the food stamp program to count individual retirement accounts (IRAs) as resources, ${ }^{147}$ conservatives now supported the 2002 Farm Bill, which allowed states to exclude retirement savings from financial eligibility determinations. ${ }^{148}$ Similarly, PRWORA and legislation enacted by the following Congress gave states broad options to establish "individual development accounts" (IDAs) that would not count as resources so long as the claimant did not spend the contents except for approved purposes, such as purchasing a home or paying for education. ${ }^{149}$

In cash assistance programs, however, all of these changes took place against the backdrop of time limits. Claimants with dependable cars might no longer be ineligible for assistance, but they nonetheless might be unwise to apply for benefits if they had any alternatives. Thus, although these resource exclusions generally enjoyed broad support across the political spectrum, they could operate as traps to unwary claimants or those with

145. See Food Stamp Program: Noncitizen Eligibility and Certification Provisions, 65 Fed. Reg. 10,856, 10,877-78 (proposed Feb. 29, 2000) (to have been codified at 7 C.F.R. pt. 273) (excluding vehicles that households would be unlikely to sell for a return exceeding half of the food stamp program's resource limits); Food Stamp Program: Noncitizen Eligibility and Certification Provisions, 65 Fed. Reg. 70,134, 70,170-71 (Nov. 21, 2000) (codified at 7 C.F.R. $\$ 273.8(\mathrm{e})-(\mathrm{f})(2003)$ ) (liberalizing the rules further for households with more than one vehicle); Letter from Susan Carr Gossman, Deputy Administrator, Food Stamp Program, to Regional Administrators-All Regions (July 14, 1999), http://www.fns.usda.gov/fsp/rules/Memo/ Support/99/raletter2.htm; see also CTR. ON BUDGET \& POLICY PRIORITIES, STATES' VeHICLE ASSET POLICIES IN THE FOOD STAMP PROGRAM (2003), at http://www.cbpp.org/7-30-01 fa.pdf (summarizing the current rules and states' take-up of options to liberalize vehicle asset policies).

146. See Act of Oct. 28, 2000, Pub. L. No. 106-387, § 847, 114 Stat. 1549, 1549A-66 (codified at 7 U.S.C.A. $\S 2014$ (g)(2)(D) (West Supp. 2003)) (allowing states to extend to the food stamp program any vehicle exclusions in their assistance programs operating under the TANF statute, including policies disregarding all vehicles); Food Stamp Reauthorization Act of 2002, Pub. L. No. 107-171, § 4107, 116 Stat. 134, 308 (codified at 7 U.S.C.A. $\$ 2014(\mathrm{~g})(5)-(6)$ ) (allowing states to exclude other kinds of resources).

147. Food Stamp Act of 1977, Pub. L. No. 95-113, sec. 1301, § 5(d)(8), 91 Stat. 913, 975 (codified at 7 U.S.C. $\$ 2014(\mathrm{~g})(2)(B)(v)(2000))$.

148. Food Stamp Reauthorization Act of $2002 \S 4107$ (codified at 7 U.S.C.A. $\S 2014(\mathrm{~g})(6)$ ).

149. Assets for Independence Act, Pub. L. No. 105-285, $\S \S 401-415$, 112 Stat. 2702, 2759-72 (1998) (codified at 42 U.S.C. $\$ 604$ note); Personal Responsibility and Work Opportunity Reconciliation Act of 1996, Pub. L. No. 104-193, $\S 103$ (a), 110 Stat. 2105, 2125-28 (codified at 42 U.S.C. $\$ 604(\mathrm{~h})$ ); see also CORP. FOR ENTER. DEV., 2002 FEDERAL IDA BRIEFING BOOK: HOW IDAS AFFECT ELIGIBILITY FOR FEDERAL PROGRAMS (2002), http://www.cbpp.org/ 10-29-02wel.pdf (explaining various legal statuses of IDAs and the prospects for excluding each type from financial eligibility calculations). 
unfounded optimism about their ability to subsist without cash assistance in the future.

\section{LAW AND ADVOCACY IN RESPONSE TO \\ CHOICE-BASED RATIONING STRATEGIES}

The tumultuous period culminating in PRWORA's enactment fundamentally transformed the way in which public benefits are rationed. It should not be surprising, therefore, that the nature of law and advocacy in this new world also has changed dramatically. The relatively straightforward sources of legal authority and advocacy techniques that prevailed in the pre-1996 regime characterized a formal system in which authority was centralized and policy transparent. These legalistic advocacy techniques' effectiveness had been waning for some time. The 1995 legal services restrictions and the 1996 welfare law accelerated and solidified the deterioration of the old advocacy regime, but it was already quite dilapidated.

To address the subtler and more diffuse problems, the new system of choice-based rationing requires a much more complex process of legal advocacy and change within these programs. Where, for example, policies discourage rather than deny claims for benefits, it could be difficult to establish standing to sue, much less establish the violation of one of the relatively few rules that still govern states' cash assistance programs. Similarly, few if any of the arguments for incentive-enhancing liberalizations of eligibility rules advanced in the preceding Part are judicially cognizable. Yet even where formal eligibility rules remain, as discussed in Part III, the ineffectiveness of the old, legalistic advocacy approaches strongly suggests that something new is needed.

To complicate matters further, the rise in informal rationing has coincided with broad changes in relationships within the ranks of programs' supporters and in the advocacy methods by which that support is expressed. In particular, the legal services organizations that formed the backbone of the community advocating for public benefits claimants from the mid-1960s to the mid-1990s were shrunken and hamstrung by appropriations restrictions enacted a year before PRWORA. ${ }^{150}$ A handful of members of that community "spun off" into independent organizations relying exclusively on nonfederal funding. For the most part, however, advocacy for fairer and more efficient programs must be carried out by a different group of people operating in a different set of forums.

Choice-based methods will not disappear any time soon from dominance in rationing public benefits, particularly cash assistance. The 
forces supporting them are too strong, and they provide too many practical benefits to a wide range of policymakers and administrators. As Part III demonstrated, the ideology of choice has begun to reshape longstanding substantive eligibility rules. Indeed, as shown in Part II, . properly constructed choice-based methods can actually provide better targeting of benefits than is practical through rigid eligibility rules alone. A wide range of choice-based techniques, however, is in use. Advocacy has an important role to play in discouraging methods that are particularly likely to produce putative choices that misrepresent the true desires and needs of claimants. Advocacy also can be vital to protecting groups of claimants especially vulnerable to coercion, such as racial minorities, persons with disabilities, and, ironically, low-wage workers. Finally, advocacy can be essential to ensuring that the theory of the active, volitional claimant is applied to provide improved supports for low-wage workers as described in Part III.

This Part examines the implications of the ideology of choice for advocacy on behalf of low-income people. The first Section considers the decline in traditional advocacy concepts-reliance on a few, formal sources for the applicable law, adversarial litigation and fair hearings for dispute resolution, and the attorney-client relationship. The legalistic approach was unable to avert the formation of the new regime and seems unlikely to prosper under it without significant modification. The second Section then sketches some of the alternative methods that have begun to emerge to fill the increasingly obvious gaps.

\section{A. The Declining Importance of Formal Modes of Legal Advocacy in the Choice-Based Public Benefits System}

The rule-based public benefit system arose largely in response to King v. Smith, ${ }^{151}$ which held that claimants could not be denied benefits on grounds not recognized in federal law, and Goldberg $v$. Kelly, ${ }^{152}$ which recognized continued receipt of means-tested benefits as a property interest protected by the Due Process Clause. The resulting system of legal advocacy revolved around a few basic principles. First and most obviously, the content of public benefit programs was set out in written rules that could be analyzed for legal and policy deficiencies. Second, violations of those rules in individual cases, or factual disputes, could be addressed through administrative fair hearings. Third, fundamental legal deficiencies with those rules-inconsistencies with federal or state regulations, statutes, or constitutions - could be addressed through litigation, commonly class actions filed in federal courts. And most importantly, advocacy would take 
place primarily through the attorney-client relationship. Today, all of these principles have eroded severely. The sources of this erosion are diverse. The rise of choice-based rationing, however, has exposed and accentuated deficiencies that were already present.

\section{The Proliferation of Sources of Public Benefits Law}

Studying public benefits law after PRWORA requires an expanded notion of what law is, how law changes, and how law relates to politics. Public benefits law is widely regarded as being heavily rule-based. For many reasons, that is decreasingly the case. On the global level, the rulemaking process federally and in many states has been unable to keep up with the process of policy change. Budgetary factors drive public benefits policy more immediately and directly than at any time in the past. State and federal legislators often finish their budget only shortly before-or, at times, somewhat after-the start of the fiscal year it is intended to govern. Even a highly accelerated administrative process could not produce rules before much of the fiscal year has passed, leaving savings unrealized or benefits the legislature meant to offer unclaimed. In many agencies, the levers of informal rationing may be easier to manipulate without undertaking rulemaking.

Moreover, as program policy becomes increasingly politicized, achieving consensus on even relatively simple choices becomes problematic. Avoiding official rulemaking narrows the range of actors aware of the policy being made and increases the chances of consensus. Simultaneously, it reduces the number of "chokepoints" at which a disaffected actor has the opportunity to block a pending policy. ${ }^{153}$ The process of policy development thus was guided in significant part by what agencies believed they could accomplish without promulgating regulations, within the terms of the Administrative Procedure Act's exemptions from informal rulemaking. ${ }^{154}$

153. This is particularly true at the federal level, where the 104th Congress deliberately sought to increase the number of such chokepoints in the hope of slowing down the regulatory process. See, e.g., Daniel Cohen \& Peter L. Strauss, Congressional Review of Agency Regulations, 49 ADMIN. L. REV. 95 (1997) (finding ambiguities in the congressional review procedures that are likely to complicate agencies' tasks even where Congress does not overturn their rules); Thomas O. Sargentich, The Small Business Regulatory Enforcement Fairness Act, 49 ADMIN. L. REV. 123 (1997) (describing new regulatory procedures as an effort to expand the range of persons who may impede agencies' rulemaking). One could argue that in the public benefits arena this initiative was somewhat self-defeating: It slowed the promulgation of the same policies that Congress imposed through PRWORA.

154. See 5 U.S.C. $\S 553($ a)-(b), (d). The most obvious exception-for public grants and benefits-was unavailable since HHS long ago waived that exception and the Food Stamp Act explicitly overrides it. See 7 U.S.C. $\S \S 2013(c), 2014(b)$. 
In addition, increasing emphasis on federalism has limited federal agencies' legal authority and political capacity to regulate states. ${ }^{155}$ One of the areas in which federal regulation remains most politically acceptable is financial accountability. Thus, substantive policy choices increasingly are buried in accounting guides. ${ }^{156}$ Beyond that, much policy guidance is provided through informal and largely invisible interactions between agencies' regional offices and states. The same phenomenon exists in many states.

In addition, rules have proven unsuitable to accomplishing either of two major opposite impulses in public benefit program policy. Most obviously, they are inconsistent with the desire to increase the scope of eligibility workers' discretion, to replace broadly drawn entitlements with arrangements in which a claimant must persuade an eligibility worker of his or her worthiness for benefits. Because rules must be interpreted, however, they also are inconsistent with desires for greater uniformity in some aspects of program administration. The demand for uniformity comes from at least three different sources. First, seeking uniformity and transparency in program administration is a longstanding progressive strategy for combating racial discrimination. Recent research suggests that discrimination remains a serious problem in public benefit programs. ${ }^{157}$ King $v$. Smith probably rejected Alabama's policy of denying AFDC to women with frequent male guests in part because of suspicions that it was being applied disproportionately against women of color. ${ }^{158}$ Similarly, the rationality required for state agencies to prevail at fair hearings under Goldberg v. Kelly offered some defense against racially biased program administration from a Court that was soon to demonstrate an unwillingness to do more. ${ }^{159}$ Second, conservatives have sought uniformity in applying work and other behavioral requirements because of suspicions that eligibility workers would exempt many claimants if empowered to do so. ${ }^{160}$ Finally, management concerns over improving the accuracy with which

155. The most striking example of this is 42 U.S.C. $\S 617$, added by PRWORA, which prohibits HHS from regulating states' conduct of their TANF programs without express statutory authority.

156. In tacit recognition of this fact, the Food and Nutrition Service has posted its Manual 310 , the Food Stamp Program Quality Control Review Handbook, on its website. FoOD \& NUTRITION SERV., U.S. DEP'T OF AGRIC., FOOD STAMP PROGRAM QUALITY CONTROL REVIEW HANDBOOK (2003), http://www.fns.usda.gov/fsp/qc/pdfs/310_Handbook_2003.pdf.

157. See, e.g., Gooden, supra note 76 (finding that black welfare recipients receive less transportation and education aid than white recipients).

158. See Dorothy K. NeWman et Al., Protest, Politics, and Prosperity: Black AMERICANS AND WHITE INSTITUTIONS, 1940-75, at 260 (1978).

159. See Jefferson v. Hackney, 406 U.S. 535, 546 (1972) (rejecting, for failure to show discriminatory intent, an equal protection challenge to lower benefit levels provided to categories of public recipients that were predominantly black and Hispanic than to categories primarily serving low-income whites).

160. See RECTOR, supra note 78 , at 5-6. 
eligibility workers execute policy increases the pressure for uniformity. Although most visible in the food stamp quality control (QC) system, this phenomenon operates much more widely. ${ }^{161}$

As a result, on many important subjects, state agencies do not make formal policy at all. Where policy is to be made, it often is through the programming of automated systems that are assumed to be less prone than humans to bias, sentiment, interpretation, or error.

Paradoxically, the importance of states' rules also is eroded by the increase in the sheer number of rules. Eligibility workers, supervisors, and even many state administrators cannot possibly remain conversant with all of the contents of their multivolume policy manuals. In many agencies, caseloads deny eligibility workers the opportunity to look up and analyze the rules applicable to each problem they encounter. In addition, many agencies have such high rates of turnover that they must limit the amount of time they invest in training eligibility workers. ${ }^{162}$ As a result, eligibility workers may not even have heard of the formal policy applicable to many problems. Instead, eligibility workers will familiarize themselves with a few areas of policy they believe are most important, either because of recurrent problems or because of superiors' apparent priorities.

Eligibility workers, of course, do not reanalyze every problem de novo. Although not charting their courses on the basis of rules or applying anything resembling stare decisis, most will naturally tend to reach similar conclusions when confronted with similar facts. Workers who have not encountered a particular problem before will consult more experienced peers. The result is a method of elaborating policy that resembles a common law process of reasoning from case to case far more than a rule-based system. ${ }^{163}$ This means that merely changing a program's rules is unlikely to change its operation on the local level. Assumptions that positive law more or less dictates agencies' operational behavior are plausible only where the private entities with which they interact know the positive law and have the resources to enforce it if necessary. The vast majority of claimants for public benefits neither know their rights under agency rules nor have the means to enforce them. Indeed, most claimants' primary sources of information about agencies' rules are eligibility workers

161. See Diller, supra note 36, at 1202-06.

162. If tax preparation firms and similar businesses are paying several thousands of dollars a year more than the welfare department for less demanding work, the agency cannot expect to retain eligibility workers for long. The higher the turnover an agency has, the higher the total number of weeks of productive work it loses while training new eligibility workers. If a typical worker will only stay a year, training new workers for three months each means that about one quarter of the agency's workforce will be in training at any given time. A logical response might be to adopt more competitive pay levels, but that often is beyond agency executives' power.

163. Put another way, the system operates on the strength of orders far more than rules. See NLRB v. Wyman-Gordon Co., 394 U.S. 759, 765 (1969) (plurality opinion) (allowing an agency to act through orders rather than by promulgating rules). 
and other claimants, both of whom are likely to reflect the "common law" of practice in other claimants' cases far more directly than they do the agencies' written policies.

The inability of eligibility workers and lower-level supervisors to keep track of, much less comply with, an agency's plethora of rules and directives offers new opportunities to shield potentially controversial policies from political scrutiny. Faced with demands for two operationally incompatible policies-such as stringent work requirements covering the overwhelming majority of the caseload and protections for all those who would be likely to suffer severe hardship - state officials can promulgate rules that implement both policies and then rely on informal signaling methods to communicate to line employees which of the two they will enforce more stringently. Few researchers, journalists, or even advocates will look beyond a formally satisfactory policy to see if it is being overridden in practice by another. Under this approach, discretion lies not on the face of the rules but in the choice of which rules to follow.

Oddly enough, then, as policymakers increasingly reject the premises of the rule-based system, they are demolishing it as much by producing an overload of new rules as by repealing old ones. Thus, any attempt to separate law from practice in the public benefits context is hopeless folly. In this atmosphere, practices that induce real or apparent choices not to participate in public benefit programs can flourish with little legal or policy scrutiny.

\section{The Limitations of Fair Hearings as Responses to Choice-Based Rationing Techniques}

Another cornerstone of legal advocacy in the pre-1996 public benefits system was the administrative fair hearing. Some scholars overestimate the importance of the fair hearing. ${ }^{164}$ Long before public benefit programs' structure began to change in the 1990 s, fair hearings had been marginalized in most states' program administration. The best, and often the only, national data are from the food stamp program. Food stamp rules provide more specific standards for eligibility and state agencies' behavior than the rules of any other state-administered public benefit program. Thus, one might expect the fair hearing process to offer claimants more leverage in

164. See, e.g., David J. Kennedy, Due Process in a Privatized Welfare System, 64 BRooK. L. REV. 231 (1998); Melissa Kwaterski Scanlan, The End of Welfare and Constitutional Protections for the Poor: A Case Study of the Wisconsin Works Program and Due Process Rights, 13 BERKELEY WoMEN's L.J. 153 (1998); Rebecca E. Zietlow, Two Wrongs Don't Add Up to Rights. The Importance of Preserving Due Process in Light of Recent Welfare Reform Measures, 45 AM. U. L. REV. 1111 (1996). 
the food stamp program than in other programs granting states greater discretion. ${ }^{165}$

Although New York is a significant outlier, ${ }^{166}$ in most states the overwhelming majority of claimants who requested and pursued fair hearings received nothing for their efforts. ${ }^{167}$ Perhaps even more significantly, extremely few claimants even request fair hearings. Given that the number of fair hearings held in a year equals only $0.5 \%$ of the average monthly number of families receiving food stamps, ${ }^{168}$ such hearings seem unlikely to have a major influence on programs' operations. Even an eligibility worker with the relatively high caseload of two hundred households is likely to be asked to attend a fair hearing only once a year and may lose one only once every three years. Since no adverse consequences generally attach to an eligibility worker for losing a hearing, this process can hardly bear much of a deterrent effect.

As weak as the fair hearing system was under the old regime, however, the shift to choice-based rationing reduces its efficacy even further. Where the claimant's "choice". not to receive a benefit resulted from her not knowing that the benefit was available, she is also unlikely to know about fair hearings or about any issue she might raise at one. Similarly, where the claimant knows about the benefit but does not understand how to obtain it, she may not know how to request a fair hearing.

Even if a hearing is held, the state's role in events leading to the claimant's failure to receive the benefit may be relatively invisible and hence difficult to criticize under the program's rules. On the other hand, the claimant will have to struggle to show that her actions or inactions did not either disqualify her from receiving the benefit or waive or forfeit her rights to that benefit. ${ }^{169}$ At best, the hearing may be reduced to a credibility

165. In addition, states report that $3.57 \%$ of the denials and terminations they examined as part of the food stamp quality control system were erroneous. U.S. DEP'T OF AGRIC., FOOD STAMP PROgRam Quality CONTROL ANNUAL REPORT, FisCal YEAR 2000, at 19 (2000). Moreover, underissuances to food stamp recipients equal $2.4 \%$ of the total value of all benefits issued. Id. at 15 . Thus, many food stamp claimants appear to have valid claims that would allow them to prevail at hearings.

166. Anecdotal evidence suggests that claimants' relative success in fair hearings in New York, particularly in New York City, derives from the habit of many eligibility workers not to take the time required to travel to the site where hearings are held. Thus, agency staffs' aversion to dealing with their own bureaucracy causes many claimants to win by default.

167. See STATE ADMIN. BRANCH, U.S. DEP'T OF AGRIC., FOOD STAMP PROGRAM STATE ACTIVITY REPORT FISCAL YEAR 2001, at 22 (2002).

168. Id. at 6, 22.

169. The distinction between waiver and forfeiture--between affirmatively surrendering a right and simply failing to assert it-is very important in criminal procedure. See, e.g., United States v. Olano, 507 U.S. 725, 733 (1993) (distinguishing between objections passively forfeited, which are subject to review but only under the deferential "plain error" standard, and affirmatively waived rights, which may not form the basis of an appeal at all). Waivers of important rights must be "knowing and voluntary," which requires the individual being held to the waiver to be aware not just of the waiver but also of the relevant facts and of the waiver's likely consequences. Brady v. United States, 397 U.S. 742, 748 (1970); United States v. Ready, 82 F.3d 551, 556-57 (2d Cir. 
determination about whether something the eligibility worker said was a suggestion or a mandate; these sorts of credibility determinations tend to go badly for claimants.

\section{The Demise of Public Benefits Litigation}

The mainstay of liberal policy change in public benefit programs in the three decades preceding PRWORA was the affirmative class action lawsuit. Litigation requires an injured claimant who seeks legal help, an attorney willing to bring the case, the absence of a lethal procedural defense, and a claim with substantive merit. Each of these conditions can be a significant obstacle to litigation challenging post-1996 choice-based rationing.

The basis on which a claimant is denied benefits is likely to have a strong influence on whether she or he seeks advocacy help. Behavioral requirements are among the most likely to be understood by, and to offend, the claimants they disadvantage. When an eligibility worker tells a claimant that she is ineligible because of some specific action or omission, she often will feel either that the eligibility worker got his facts wrong or that the requirement is unfair. By contrast, programs' financial formulae and procedural requirements often are relatively opaque to claimants. Without the formula the agency applied, the data about her circumstances that the agency relied upon, and a fair amount of mathematical sophistication and confidence, claimants cannot evaluate financial eligibility determinations independently. Similarly, without a clear notion of what was required, many claimants may fear looking foolish challenging an assertion that they defaulted on their procedural obligations. At most, they may complain that they were unaware of those rules at the relevant time, an argument that rarely prevails. ${ }^{170}$

As a result, claimants are far more likely to complain to potential legal representatives about behavioral eligibility restrictions than financial or procedural ones. Thus, an agency relying on sanctions for noncompliance with behavior requirements is relatively likely to attract advocacy intervention, while one that rations benefits informally with procedural obstacles is not. Unsuccessful claimants might not approach legal services

1996). Although claimants deterred from receiving public benefits through informal rationing often will not meet the standard for knowing and voluntary waivers of rights, programs generally require claimants to submit an application for benefits. A claimant who did not apply is not eligible for benefits, regardless of why she did not do so. This, then, is effectively a forfeiture. Similarly, because claimants for public benefits generally bear the burden of proof in establishing eligibility, those who fail to perform all of the tasks the program's rules require generally are treated as having forfeited their rights to those benefits without regard to whether they met the standards for knowing and voluntary waiver.

170. See, e.g., Atkins v. Parker, 472 U.S. 115, 130-31 (1985) (holding that food stamp recipients have no constitutional right to notice of a change in federal law prior to the reduction in their food stamps). 
programs and similar agencies when denied benefits on procedural grounds because they might assume the problem is insoluble.

This would seem to suggest that states building informal rationing systems around behavioral requirements might be opening themselves increasingly to litigation. This might well have been true but for three key changes. First, the elimination of the entitlement to cash assistance in the Social Security Act and many state laws was widely understood as a rejection of public benefits litigation. To the extent that judges share that understanding, they may be particularly eager to find procedural or substantive grounds to dismiss claimants' cases. Moreover, to the extent that states can change their rules and practices more rapidly and inexpensively than claimants can challenge those rules and practices, the rewards for winning a challenge against an unlawful policy are greatly reduced.

Second, prior to enacting PRWORA the 104th Congress sharply reduced legal services funding and restricted the remaining legal services advocates' ability to advocate on issues relating to "welfare reform."171

Third, new behavioral conditions have been implemented in tandem with other changes in tone and procedure that have confused many claimants and discouraged them from investigating possible legal rights. If one believes one is unlikely to have any enforceable legal rights, one is less likely to take the time to go to a legal services office. Also, if one believes one's receipt of public benefits would be brief or costly in any event, one has less incentive to question whether one is getting somewhat fewer months than might otherwise be allowed. Finally, if one believes that one's eligibility worker holds virtually absolute control over one's ability to receive desperately needed public benefits, one may be reluctant to risk alienating her or him by attempting to file what appears to be a futile lawsuit.

Even assuming claimants seek out attorneys to file litigation challenging a choice-based rationing technique, the probabilistic impact of those techniques ${ }^{172}$ is likely to pose difficult analytical problems to courts, forcing them to adopt a very new role. The traditional role of the court in public benefits law has been to interpret formal rules: The statute or regulation speaks, and the court ensures that the administering agency obeys. The claimant is eligible, or she is not. The rules of standing reinforce this mechanistic vision of law: The Supreme Court has taken a dim view of cases brought on probabilistic theories. The fact that a given policy makes it more likely that a hospital will turn away a low-income patient ${ }^{173}$ or that a

171. See infra note 178 and accompanying text.

172. See supra Subsection II.C.3.

173. See Simon v. E. Ky. Welfare Rights Org., 426 U.S. 26, $42-43$ (1976). 
police officer will injure a suspect ${ }^{174}$ is insufficient to create a cognizable case or controversy. ${ }^{175}$ Thus, cases asking courts to determine that a particular policy reduced, while not eliminating, the likelihood that concededly eligible claimants would receive benefits calls on courts to depart significantly from their traditional and accepted roles.

The difficulty of litigating these policies may mean that no advocacy is done at all. Lawyers' habit of analyzing problems in terms of their litigation potential may cause them unconsciously to adopt the mechanistic outlook of the standing rules. This can cause them to miss numerous problems that indisputably make a difference in practice. A regime of employee evaluation that increases by half the likelihood that a claimant's application will be denied may not be actionable, ${ }^{176}$ but it reduces the number of claims that will be allowed just as reliably as tightening financial eligibility limits would.

\section{The Decline of the Attorney-Client Relationship as the Paradigm for Public Benefits Advocacy}

Rightly or wrongly, scholars and lawyers conventionally tended to chart change in AFDC in terms of litigation around formal eligibility requirements. ${ }^{177}$ The process thus could be understood in terms of an adversary process built upon a more or less traditional attorney-client relationship.

PRWORA's elimination of most federal rights to family cash assistance obviously has extinguished most such litigation. Yet even in Medicaid, food stamps, and other means-tested programs where claimants retain more substantial federal statutory rights, litigation has declined sharply. The fading of litigation has resulted in part from Congress's action in 1995 to incapacitate federally funded legal services programs from bringing class actions and lawsuits challenging the vaguely defined concept of "welfare reform" or receiving attorneys' fees to sustain their work. ${ }^{178}$ As Congress

174. See City of Los Angeles v. Lyons, 461 U.S. 95, 105-06 (1983).

175. Similarly, many conditions that make a decisionmaker much more or less likely to rule in a particular manner generally do not suffice to establish a cognizable claim of bias under the Due Process Clause. See, e.g., Withrow v. Larkin, 421 U.S. 35, 55 (1975) (rejecting a per se rule that a board that initiates an investigation may not adjudicate the results). Accordingly, lawyers do not tend to "spot" these issues, as real as they may be in practice.

176. See, e.g., Stieberger v. Heckler, 615 F. Supp. 1315 (S.D.N.Y. 1985) (rejecting challenges to a review procedure that subjected Social Security administrative law judges with high rates of allowances to more intensive scrutiny), vacated on other grounds sub nom. Stieberger v. Bowen, 801 F.2d 29 (2d Cir. 1986).

177. This author believes that, even with respect to AFDC, this approach is problematic. See David A. Super, Entitlement, Counter-Entitlement, and Disentitlement: The Substantive Importance of Programmatic Structure (2003) (unpublished manuscript, on file with author).

178. See supra note 17 and accompanying text; see also, e.g., 45 C.F.R. $\S \S 1610.3,1612.3$, $1617.3,1626.3,1639.3,1642.3$ (2003). The Supreme Court struck down the restriction on legal 
cut and restricted legal services programs' funding, other organizations and funders perceived a gap and sought to step in. Many of these advocates were not lawyers and did not see the need to intervene through litigation.

The shift away from litigation also resulted in part from changes in what are the most important issues in these programs. With the Supreme Court's emphatic rejection of constitutional claims to welfare benefits in the early $1970 \mathrm{~s},{ }^{179}$ it became clear that federal or state legislatures were the only potential entities that would liberalize basic eligibility rules, particularly numeric rules such as income and resource eligibility levels. To be sure, litigation to enforce compliance with existing standards of performance has been important. ${ }^{180}$ No longer, however, is it the exclusive or even primary vehicle for enforcing those standards. ${ }^{181}$

In addition, the dominance of litigation in the three decades prior to PRWORA can be traced in significant part to the default of other means of change. Through much of that period, the political process was hopelessly deadlocked on major public benefits issues, particularly those surrounding AFDC. Thus, litigation results that much of the public, or even majorities in Congress, likely would have rejected could stand for many years because significant welfare legislation could not move. With the passage of PRWORA, this obstruction in the political process was decisively broken. It no longer serves any great purpose for lawyers to devise clever reinterpretations of statutes or regulations if Congress or a state legislature is likely to pass a "technical correction" of the language in question before the case even goes to judgment. Thus, to have much value a litigation theory must be sustainable both legally and politically, with the standard of review on the latter criterion now markedly more stringent.

The rise in informal, choice-based rationing further reduced the importance of litigation as a means of expanding public benefit programs. Many of these policies, though debatable on policy grounds, are fairly

services' participation in matters involving "welfare reform." Legal Servs. Corp. v. Velazquez, 531 U.S. 533 (2001). Nonetheless, the tools that LSC-funded advocates can use to influence the policies of state public benefit programs remain extremely limited.

179. See, e.g., Jefferson v. Hackney, 406 U.S. 535, 549-50 (1972) (upholding state grant levels that were lower for families with children than for aged, blind, and disabled persons against a challenge noting that recipients of welfare were far more likely to be people of color); Dandridge v. Williams, 397 U.S. 471, 485 (1970) (holding that classifications in welfare programs ordinarily need only pass a "reasonable basis" standard of review).

180. See, e.g., Robertson v. Jackson, 972 F.2d 529 (4th Cir. 1992) (untimely processing of food stamp applications); Alexander v. Hill, 707 F.2d 780 (4th Cir. 1983) (untimely processing of Medicaid applications); Southside Welfare Rights Org. v. Stangler, 156 F.R.D. 187 (W.D. Mo. 1993) (untimely processing of food stamp applications); Harley v. Lyng, 653 F. Supp. 266 (E.D. Pa. 1986) (same).

181. See, e.g., FoOd \& Nutrition SERV., U.S. DeP'T of AGRIC., NEW York PRogram ACCESS REVIEW NOVEMBER-DECEMBER 1998 (1999) (requiring correction of many of the same kinds of violations of applicants' rights that have prompted litigation in prior years). 
plainly legal. Even where a legal question exists, ${ }^{182}$ only rarely will an attorney willing and able to file such a case encounter an individual who has a claim that can survive the many procedural defenses available to program administrators. ${ }^{183}$ Any case that survives these procedural hurdles may founder on the difficulty of proving the extent of the alleged practice, establishing that it really did prevent claimants from obtaining benefits, and demonstrating that claimants did not waive or abandon their claims at some point.

Several important consequences flow from this partial replacement of the traditional attorney-client model of pursuing change in public benefits law. First, and most obviously, transporting these debates from the courtroom to legislative chambers or agencies' conference rooms changes the nature of the evidence and arguments that may be brought to bear. However artificial it may have been to try to separate public benefits law from public benefits policy prior to 1996, today it is simply absurd. An advocate who is not fluent in the language of incentives will accomplish little.

Second, the process of accommodating multiple interests becomes much more complex. This is particularly important because informal rationing often has divergent impacts on various groups of claimants. In litigation, ethical rules prevent any one attorney from representing multiple parties with adverse interests. When more affluent interest groups engage lobbyists, they observe similar principles: No one who can afford to choose is likely to want a lobbyist who is working for competing interests. By contrast, only one or a small handful of groups is likely to be advocating the liberalization of a program before Congress or federal administrators, or on the state level. When an adversity arises between the interests of various subpopulations of claimants, these advocates must resolve them internally. They must decide, for example, whether to increase the chances that a given liberalization will be adopted by agreeing to exempt an unpopular group of

182. For example, 7 C.F.R. $\S 273.2$ (c)(2) requires a food stamp office not just to allow potential claimants to apply but requires it to "encourage" them to do so if they express an interest in receiving food stamps or concerns about having sufficient food. This could give discouraged potential applicants a legal claim even if they cannot show that they actually have been prohibited from applying.

183. For example, if the individual has not yet been denied benefits, she or he is unlikely to have standing. $C f$. cases cited supra notes 173-174. If she or he has been denied benefits in the past but does not have a claim for benefits for the current period, the Eleventh Amendment may prevent the claimant from invoking the jurisdiction of the federal courts. See Green v. Mansour, 474 U.S. $64,68-73$ (1985). Counsel will have an ethical duty to seek to overcome the procedural barriers keeping the prospective plaintiff from receiving benefits; upon doing so, she or he may either lack standing or, if the case already has been filed, be vulnerable to dismissal for mootness. Alternatively, upon receipt of a demand letter or the filing of the suit, the defendants may choose to provide benefits to the claimant to create standing or mootness problems. These obstacles to decisions on the merits are far less likely in litigation over an explicit eligibility rule that defendants assert is valid. 
claimants. If a limited fund is set aside for liberalization in a program, these advocates must decide how to seek to have it spent. Thus, although the process by which these groups interact with their opponents is very much adversarial, ${ }^{184}$ the process by which they resolve competing interests within the claimant population does not conform to traditional models of the attorney-client relationship. This phenomenon has become increasingly significant as debates about public benefits policy have been characterized more frequently by attempts to differentiate between the "worthy" and "unworthy" poor through purported tests of desire and willingness to "earn" benefits. ${ }^{185}$ Indeed, conflicts can arise over whether to advocate formal or informal rationing. Some advocacy groups may prefer a more stringent regime of informal rationing to reductions in eligibility, because the former may seem more readily reversible in the future-or a less obvious sign of defeat to the groups' funders or other constituents.

Finally, the partial abrogation of the attorney-client model for advocacy on behalf of the claimants' interests for public benefits has led to critical information issues. In conventional attorney-client relationships, the attorney learns of the client's needs, desires, and problems primarily from the client. ${ }^{186}$ The new, nonattorney advocacy groups that lack relationships with clients must develop alternative ways of understanding how programs affect claimants. The complexity and frequent invisibility of informal rationing makes this particularly crucial. Although desirable, simply talking to actual claimants is no solution either. These advocates obviously cannot talk to all or even a significant fraction of claimants and potential claimants for these benefits. They inevitably must consider how well the views and problems of the claimants they meet represent those of others. ${ }^{187}$ Thus, qualitative and quantitative social science research becomes increasingly

184. A naive model of consensus policymaking, in which public-spirited individuals try to balance all competing interests, clearly would not capture the process. All participants in these debates conceive of themselves as part of an adversarial process. Groups supporting or opposing programs talk of one another as opponents, they respond to one another's writings, and they view results as victories or defeats depending on the degree to which a program is strengthened or weakened.

185. See, e.g., KATZ, supra note 5, at 274-77; PIVEN \& ClowARD, supra note 5, at 80-82; McDonald \& Diehl, supra note 117, at 1037; Williams, supra note 117, at 1195-97.

186. This phenomenon has a limited parallel in attorneys' representation of mentally incompetent clients. See, e.g., Jan Ellen Rein, Ethics and the Questionably Competent Client: What the Model Rules Say and Don't Say, 9 STAN. L. \& POL'Y REV. 241 (1998). Although this can be an issue in class action litigation, including that surrounding public benefit programs, there it is governed by somewhat more formalized principles. See, e.g., Stephen Ellmann, ClientCenteredness Multiplied: Individual Autonomy and Collective Mobilization in Public Interest Lawyers' Representation of Groups, 78 VA. L. REV. 1103 (1992); Nancy Morawetz, Bargaining, Class Representation, and Fairness, 54 OHIO ST. L.J. 1 (1993); Deborah L. Rhode, Class Conflicts in Class Actions, 34 STAN. L. REV. 1183 (1982).

187. This is a particularly serious problem in connection with claimants and potential claimants whose ability to contact social welfare advocacy groups is limited by disability or work schedules. 
crucial in shaping the direction of advocacy efforts. Yet research may be more valuable in executing a predetermined strategy rather than in identifying a problem in the first place.

\section{B. Advocacy in the New Public Benefits Environment}

The great liberal dream of the 1960s - that somehow, with the right legal theory and the right court, the law could become a great engine of social reform rolling over the political process on behalf of low-income people $^{188}$ - clearly has ceased to be credible. The myth that the law could so dominate the political process endured as long as it did because the political process spent so much of the three decades prior to PRWORA in near paralysis. With much more of public benefits policy now being addressed within the political domain, the role of the law must inevitably shrink.

On the other hand, the contrary conclusion-that law has become irrelevant to social welfare law-is also indefensible. Effective legal advocacy can achieve favorable results on the plethora of issues too complex or too vexing to gain broad public attention. Even if one supposes, for example, that the public supported a block grant mechanism for expanding children's health insurance coverage, it surely did not have any notion of how that block grant should interact with the existing Medicaid program. Foresighted legal advocacy established the screen-and-enroll requirement and antisupplanting rules that preserved Medicaid's vitality. ${ }^{189}$ Similarly, even if one believes that the public supports calibrating food stamp benefits by need-or, more probably, supports a funding level that makes such calibration necessary-it cannot have any meaningful preferences as to whether horizontal and temporal targeting requires greater precision. ${ }^{190}$

Law also sets many of the incentives that drive agencies' behavior. Some states, local offices, and eligibility workers will defy these incentives out of passion or thoughtlessness. Perfect compliance, however, is not a realistic standard. Even in an era when explicit mandates were far more common, numerous violations went unnoticed or unlitigated by advocates or were insufficiently striking to prompt judicial intervention. ${ }^{191} \mathrm{~A}$

188. See, e.g., Martha F. Davis, Brutal NeED: LAWYERS AND the Welfare RightS MOVEMENT, 1960-1973, at 119-45 (1993) (describing efforts to design a systematic weifare litigation strategy relying on legal services lawyers); PIVEN \& CLOWARD, supra note 87, at 301-69 (describing the close links between the welfare rights and legal services movements in the late 1960 s and early 1970 s).

189. See 42 U.S.C. $\S 1397 \mathrm{cc}(\mathrm{b})(2)$ (2000) (preventing states from using SCHIP block grant funds to supplant their healthcare costs for their own employees).

190. See Super, supra note 64 (manuscript at 30-31).

191. But see Withrow v. Concannon, 942 F.2d 1385, 1388 (9th Cir. 1991) (requiring full, not merely substantial, compliance with federal regulations on timeliness). 
thoughtful system of incentives, designed with a subtle understanding of states' choices and constraints, can affect behavior as well as most mandates. Just as the law of contract has produced a viable system of incentives without judges frequently invoking specific performance, so too a careful application of the law can shape much of the most important behavior in public benefit programs.

In addition, law is the starting point for the complex patterns of signaling that direct states' and local offices' operations of a program. Eligibility workers do not read statutes and may not even have routine access to regulations. Yet those regulations provide the basis for data fields, refresher trainings, performance reviews, and other signs of higher agencies' priorities. ${ }^{192}$ HHS's Centers for Medicare \& Medicaid Services (CMS) and the USDA conducted reviews of access to Medicaid and food stamps in 1999 and 2000 not so much to obtain specific answers as to signal with their questions the importance of those issues. ${ }^{193}$ States' compliance with federal rules protecting claimants' access to food stamps is far from immaculate. Yet most states likely would have continued to adhere to many of those procedures for some years even if those rules had been repealed, as the USDA proposed in 2000. Nonetheless, the decision of the USDA's Food and Nutrition Service (FNS) ${ }^{194}$ to preserve and expand claimants' rights sent states a powerful message that access deserved more weight in their decisionmaking.

Finally, after securing a system of incentives and signals that channels most states' behavior in desirable directions, the law provides a valuable means for bringing the few remaining deviant states into line. The courts cannot force fifty states and innumerable local offices to change, and they are unlikely to try. They can, however, bring an occasional outlier into line. ${ }^{195}$

192. Statutes and regulations should be designed with an understanding that they will have to be translated in this manner to have a significant effect. Legal principles that are excessively complex, or that require information not readily available to states' eligibility workers and automated systems, are likely to become garbled in application no matter how the original statute or regulation was drafted.

193. See Super, supra note 64 (manuscript at 53); Letter from Timothy M. Westmoreland, Director of the Center for Medical Assistance, Health Care Financing Administration, to State Medicaid Directors (Apr. 7, 2000), http://www.cms.hhs.gov/states/letters/smd40700.asp.

194. FNS is the agency within the USDA charged with operating the food stamp program. 7 C.F.R. $\$ 271.3(2003)$.

195. See, e.g., Reynolds v. Giuliani, 35 F. Supp. 2d 331, 347-48 (S.D.N.Y. 1999) (imposing extensive remedies for New York City's interference with low-income claimants' ability to apply for food stamps and Medicaid). 


\section{A Nonadversarial Alternative to Fair Hearings}

Whatever the weaknesses of the actual fair hearing system, the concerns that gave rise to administrative review procedures even before Goldberg remain valid. Indeed, the decreased visibility of agencies' actions to influence claimants' decisions may make external review even more important.

It therefore is worth examining the fair hearing process to find what elements can be salvaged in a reconstituted form of external review. The aspect of the fair hearing system that has failed most conspicuously is its reliance on an adversarial process. Claimants do not request the hearings when they have been mistreated, and they generally flounder when they do get to a hearing. Many of the same benefits could be obtained, however, by trying to replicate as much of the fair hearing, as possible through an inquisitorial rather than adversarial system.

One example is the customer service reviews the Tennessee Department of Human Services has established for cases prior to closure. ${ }^{196}$ Except where the basis for closure is financial eligibility-one of the remaining objective formal eligibility rules - all cases must be sent to impartial experts for review. Where the case file does not support the eligibility worker's proposed action, the termination is disallowed and the file is returned for further work. Where the basis of closure is failure to comply with a behavioral requirement, the customer service reviewer tries to contact the claimant to try to induce compliance. Since Tennessee established this system, customer service reviewers have been able to reach about half of all recipients proposed for termination and have been able to achieve compliance-avoiding a termination-for two-thirds of them. File reviews also have resulted in vacating one-third of all terminations in cases where reviewers did not reach the claimant. ${ }^{197}$

This overall success rate of about fifty percent towers over the achievements of the fair hearing system. It does not require initiation by the recipient family, representation, or eligibility workers to take time out of their days to attend hearings. The customer service reviewers have access to, and can become expert in, the full range of the agency's policies, including those that are embedded in automated systems or otherwise unavailable to claimants or even most advocates. This system also allows

196. See Russ Overby, Tenn. Justice Ctr., Customer Service Review: Tennessee's Review Process Before Welfare Reform Cases Are Closed, http://www.tnjustice.org/Links/Customer.html (last visited Nov. 18, 2003).

197. These results are compiled from weekly reports of the Tennessee Department of Human Services on welfare case closures, covering the period of January 2002 to October 2003. See, e.g., Office of Research \& Pub. Serv., Coll. of Soc. Work, Tennessee Department of Human Services: Customer Service Review Weekly Report 3 (Oct. 17, 2003) (unpublished manuscript, on file with author). 
for a new category of successful outcomes: cases in which the eligibility worker's actions technically were valid but where offering accommodations can achieve compliance. These accommodations can be as simple as a clearer explanation of the requirement and a second chance to comply. This latter possibility provides a basis for promoting this approach in the new regime of public benefits law: The reviewers' intervention can improve the quality of claimants' choices.

Although no other state has fully emulated Tennessee's system, simpler, if less effective, means exist for achieving independent nonadversarial reviews of eligibility workers' decisions. The food stamp quality control system long has required states to review a sample of the cases they deny or terminate ${ }^{198}$ and to implement corrective action for significant deficiencies. ${ }^{199}$ In 2000 , the USDA required its regional offices to review a subsample of the cases states examined in these "negative action reviews."

A standard due process lawsuit in the Goldberg mold is unlikely to result in a requirement that states institute customer service reviews or similar mechanisms. On the other hand, states may find such devices help them meet other goals or obligations, such as the accommodation of persons with disabilities. ${ }^{200}$ The establishment of these reviews also might be a mutually advantageous way of settling a more traditional due process case. ${ }^{201}$

\section{Managing Program Administrators' Incentives}

If incentives rather than mandates are becoming the primary language for influencing claimants' participation in public benefit programs, the same is increasingly true for influencing the practices of state and local administrative agencies. Advocates of more relaxed informal rationing regimes therefore must understand what motivates state administrators and the staffs of local offices if they are to have any hope of change.

Fortunately, in several key areas the interests of administrators and claimants coincide. ${ }^{202}$ First, both struggle with information costs: The more

198. 7 C.F.R. $\S 275.13$

199. Id. $\$ 275.16(\mathrm{~b})(3)$.

200. See Cary LaCheen, Using Title II of the Americans with Disabilities Act on Behalf of Clients in TANF Programs, 8 GEO. J. ON POVERTY L. \& POL'Y I (2001).

201. See, e.g., Weston v. Cassata, 37 P.3d 469, 474-75 (Colo. Ct. App. 2001), cert. denied, 536 U.S. 923 (2002) (finding that, notwithstanding language in federal and state statutes disavowing any entitlement to cash assistance, the state's eligibility rules were sufficiently objective to create a property interest in continued benefits). In other words, even if a court might be more inclined to order a traditional fair hearing structure, both parties might find that a nonadversarial customer service review structure served their interests better.

202. This discussion focuses primarily on state administrators because they more frequently can control their agencies' positions in national policy debates. Many of the same considerations 
information and verification administrators are required to obtain from claimants, the more burdensome the process becomes for both and the greater the risk of errors for each. Thus, Medicaid and food stamp options to reduce information demands on claimants proved hugely popular among states. Were it not for the strong political desire to reduce cash assistance roles without adopting formally restrictive eligibility policies, state administrators likely would disdain many parts of states' informal rationing regimes for cash assistance benefits.

Second, both generally prefer systems that work and become frustrated when they do not. ${ }^{203}$ Claimants learn about public benefit programs significantly from their own experiences and those of friends and relatives. A broken, erratically performing system will be harder to understand and predict through these means. New eligibility workers learn policy from one another; a chaotic system in which eligibility workers simultaneously pursue several inconsistent policies will be far more difficult for new workers to decipher.

Third, and related, simplicity generally benefits both claimants and administrators. The channels that both claimants and eligibility workers rely upon to learn about programs' rules are ill-equipped to convey intricacies. The value of any special rule-a benefit tailored to address an unusual need, an exception to a burdensome requirement, or the like-must be discounted for the substantial number of potential beneficiaries who will not learn about or understand it and for those whose eligibility workers will fail to implement it properly. Some complexities, to be sure, are worth it: for example, the medically needy eligibility category that makes major surgery available to some uninsured people above Medicaid's regular

motivate federal civil servants as well, but political appointees more routinely override their preferences in adopting administration policy.

203. Whatever the merits of the 1960s welfare rights strategy to provoke a crisis of public welfare administration, see PIVEN \& CLOWARD, supra note 87, at 264-362, broken systems today clearly do not lead to anything positive for claimants. The political process is not about to respond to any such failures with new infusions of resources, much less federalization of programs, see id., and claimants tend to be the first victims of chaotic or inept administration. For example, during the mid-1980s, Pennsylvania both abandoned expedited issuance of food stamps and ran up one of the highest QC error rates in the country. See Harley v. Lyng, 653 F. Supp. 266, 270-73 (E.D. Pa. 1986); STATISTICAL SUPPORT SECTION, U.S. DEP'T OF AGRIC., FOOD STAMP QUALITY CONTROL ANNUAL REPORT FISCAL YEAR 1987, at 12-13 (1988). Over the last several years, California has had both one of the lowest participation rates and a persistently high error rate. ALLEN L. SCHIRM \& LAURA A. CASTNER, U.S. DEP'T OF AGRIC., REACHING THOSE IN NEED: STATE FOOD STAMP PARTICIPATION RATES IN 2000, at 2 (2002), http://www.fns.usda.gov/oane/MENU/Published/ FSP/FILES/Participation/Reaching2000.pdf; U.S. DEP'T OF AGRIC., supra note 165, at 13. New York in the late $1990 \mathrm{~s}$ managed both to raise numerous unlawful access barriers to eligible households and to maintain an extremely high QC error rate. See Reynolds v. Giuliani, 35 F. Supp. 2d 331, $341-47$ (S.D.N.Y. 1999); U.S. DEP'T OF AGRIC., supra note 165, at 13. Georgia and Michigan had high error rates throughout the 1990 s and proceeded to blame the overissuances on claimant fraud. The result was thousands of disqualifications without hearings. See STATE ADMIN. BRANCH, supra note 167, at 24, 26; U.S. DEP'T OF AGRIC., supra note 165 , at 13 . 
income guidelines, or the food stamp shelter deduction that mitigates the choice between heating and eating that many low-income people face. ${ }^{204}$ Conversely, because the participation effects of simplification are difficult to quantify, budget analysts likely underestimate the benefit of the kinds of changes made in Medicaid and food stamps in the years following PRWORA. Whatever state administrators' personal ideological preferences may be, their self-interest is likely to drive them to support simple policies and oppose confusing and error-prone ones. ${ }^{205}$ Thus, many types of informal rationing systems may appeal to senior policymakers much more than they appeal to program managers.

Finally, program administrators and the vast majority of claimants share an interest in developing other, better sources of income for the claimants. For the administrators, this has emerged in the post-PRWORA world as a significant criterion upon which their success is measured. ${ }^{206}$ For claimants, it represents the reality that public benefits provide grossly inadequate resources to support a family and are dispensed in a manner that offers little security. ${ }^{207}$ To be sure, administrators and claimants often have very different ideas about how the goal of employment should be pursued: Few claimants presumably favor sanctions for violating work requirements or policies that increase the effective cost of receiving assistance. Nonetheless, this commonality of purpose can provide the basis for advocacy strategies, including many of those that helped transform Medicaid and the food stamp program over the last several years.

In other respects, to be sure, state administrators' interests are distinctly their own. Even here, however, these interests generally are not antithetical to those of claimants and thus provide leverage to advance claimants' positions. First, because the quality of their performance is so difficult to measure, administrators are extremely sensitive to systems of rewards and

204. See Dorothy Rosenbaum et al., CTR. ON Budget \& Policy Priorities, The Food STAMP SHELTER DEDUCTION: HelPING HouseholdS WITH High HOUSING BuRdens MEET THEIR FOOD NEEDS 1-2 (2002).

205. Just as John Kenneth Galbraith noted that the foremost objective of corporate managers is to ensure a sufficient level of return to maintain their autonomy, JOHN KENNETH GALBRAITH, THE NEW INDUSTRIAL STATE 166-71 (1967), so too human services managers' prime objective must be to avoid criticism that could threaten their tenure. Complex rules that administrators' staffs may fail to implement correctly pose a much greater risk of critical evaluations. Except on those rare occasions when political passions are most inflamed, ideological missteps or even unanticipated spending do not pose similar risks. Just as "[1] oss can destroy the technostructure; high revenues accrue to others," id. at 168 (footnote omitted), accusations of mismanagement can lead to the decapitation and dismemberment of an agency; credit for achieving ideological purity will be seized by political superiors.

206. House-passed legislation reauthorizing the TANF block grant would offer states bonuses on top of their block grants if they achieved substantial improvements in the employment status of former welfare recipients. Personal Responsibility, Work, and Family Promotion Act of 2003, H.R. 4, 108th Cong. § 105 (2003).

207. See EDIN \& LEIN, supra note 37 , at 77 (finding an overwhelming preference for work among single mothers receiving cash assistance). 
penalties even if very modest amounts of money are at stake. Thus, in the 2002 food stamp reauthorization bill, state administrators favored the financially less advantageous House version of QC sanction reform because the Senate bill contained a procedure for branding states "seriously negligent." 208 Conversely, when CMS and claimants' advocacy groups circulated scorecards of the simplicity of states' Medicaid enrollment processes, many states appeared to respond in hopes of improving their grades. $^{209}$

Second, state administrators do not necessarily seek to maximize revenues or minimize outlays. Although human services agencies have budgets, experienced state administrators recognize that factors beyond their control-small economic changes, modest natural disasters, and the like-can affect their ability to meet those budgets more than their policy decisions do. Thus, CMS's $\$ 500$ million fund at a generous match and the several million dollars FNS made available without a state match could not induce many states to make delinking a priority or to create work slots for claimants reaching the food stamp time limit. ${ }^{210}$ Their budgets already were flush and they had other priorities. Conversely, the cost of expanding Medicaid rolls did not seem to disturb state administrators until the recent state budget crises because the administrators were focused on the nonfiscal goal of reducing the incidence of uninsuredness. Yet monetary incentives can have some effects. Creating a dedicated funding stream for a particular entity within a state government can help empower that entity to set its own course: FNS did this by giving antifraud units thirty-five percent of the value of food stamps they can get designated as trafficked. ${ }^{211}$ Funds sufficient to provide substantial incentives can be difficult to obtain, but not impossible to provide.

Third, state administrators tend to value stability. Continuity is much easier to manage than change and creates far less risk of embarrassing misfires. Change forces administrators to expend capital within their agencies to obtain scarce resources such as the time of computer programmers, policywriters, and staff trainers. Unless the benefits of a new policy clearly outweigh those costs and risks, state administrators are likely to be leery. Thus, absent acute distress, most administrators tend to prefer a bad familiar policy to a new, better one. This certainly was evident in states' resistance to delinking Medicaid from cash assistance, as well as the

208. Agriculture, Conservation, and Rural Enhancement Act of 2001, S. 1731, 107th Cong. $\S 430(2002)$.

209. See Donna CoHen Ross \& laura Cox, Ctr. ON Budget \& Policy Priorities, MAKING IT SIMPLE: MEDICAID FOR CHILDREN AND CHIP INCOME ELIGIBILITY GUIDELINES AND ENROLLMENT PROCEDURES: FINDINGS FROM A 50-STATE SURVEY, at v, 22-34 (2000) (listing states that have not adopted specified Medicaid simplification options).

210. See Super, supra note 64 (manuscript at 42-43).

211. See 7 C.F.R. § 273.18(a) (2003). 
low take-up rate of a transitional food stamp option for recipients leaving TANF, ${ }^{212}$ despite states' expressed philosophical support for the concept. ${ }^{213}$ State administrators tend to be suspicious of ideologues, who demand rapid change without considering the bureaucratic costs, who tend to be impatient with logistical obstacles to achieving that change, and whose policies may be unacceptable to their successors, leading to further demands for change. At times when advocates are seeking radical changes in states' programs, this administrative conservatism has been intensely frustrating. Certainly it has caused successful plaintiffs in public benefits litigation great frustration as they have sought rapid implementation of their judgments. Yet in eras like the one following 1996, when programs are reeling under ideological attack, this reflexive institutional caution should be most welcome.

Savvy administrators understand, however, that some change is inevitable and even desirable. Thus, successful advocacy depends on convincing administrators that a proposed new policy will require relatively few resources to implement, that once implemented it can legally and politically be left in place with minimal adjustments for years to come, that it will bring concrete benefits to the agency (as opposed to the claimants the agency serves), that the state will have enough time to implement it, and, if possible, that some change in the given area is likely to be inevitable. Self-declaration of income and passive redeterminations in Medicaid, as well as quarterly and semiannual reporting in food stamps, were successfully sold to states because they offered concrete benefits to the agencies: less staff time spent determining eligibility and, in the case of food stamps, fewer errors. The Medicaid changes also looked relatively sustainable since the trend was for CMS to exercise progressively less control over the states. States avoided implementing an option to provide transitional food stamps that the Clinton Administration created in its closing days while the Bush Administration's willingness to sustain it remained in doubt, and continued to keep their distance when Congress began considering legislation that could change the requirements on implementing states. ${ }^{214}$ The USDA likely blunted states' resentment of the new mandate to liberalize access to food stamps by giving them over six months to implement it. ${ }^{215}$

212. See id. $\S 273.12(f)(4)$ (viii).

213. The leading association of state welfare administrators, the American Public Human Services Association, recommended creating a transitional food stamp option for the states. See

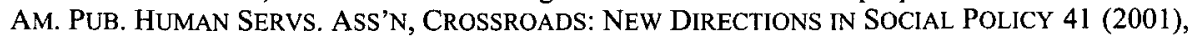
http://www.aphsa.org/reauthor/crossroads.pdf.

214. See FoOD \& NUTRITION SERV, U.S. DEP'T OF AGRIC., FOOD STAMP PROGRAM: STATE OPTIONS REPORT 4 (2003).

215. See Food Stamp Program: Noncitizen Eligibility and Certification Provisions, 65 Fed. Reg. 70,134, 70,134 (Nov. 21, 2000); see also Solis v. Saenz, 60 Fed. Appx. 117 (9th Cir. 2003) (unpublished opinion) (rejecting a challenge to the USDA's authority to give states this discretion). 
Finally, state administrators tend to be strikingly responsive to clearly articulated goals and concepts even when they are not backed with enforcement mechanisms. This tendency results in part from administrators' aversion to criticism. In addition, seasoned administrators have learned that policies that start out as trends or preferences often mutate into mandates on relatively short notice. If administrators believe that adopting a policy is inevitable, they may prefer to get started with the task rather than risk being given insufficient time once a mandate appears. More generally, training eligibility workers to exercise open-ended discretion, much less programming computers to account for such discretion, is far more difficult than giving an agency a clear direction in which it is expected to move. As important as the specific policies CMS and the USDA adopted may have been, arguably even more important were their signals that access was now a major priority. Even though the pace of food stamp reform has slowed considerably under the Bush Administration, its ratification of the Clinton Administration's major rulemakings ${ }^{216}$ and continuation of access reviews sent a message to states that access remained a federal priority. By contrast, apart from any specific policy changes, states' expressions of anxiety over Medicaid costs likely are affecting the way eligibility workers treat Medicaid claimants.

\section{The Value of Incentive-Based Public Benefits Advocacy}

One objection to the approach to legal advocacy described in the immediately preceding pages is that, even when it works, the resulting policies often exist in relatively ethereal form. Superficially, the Bush Administration could have wiped away the vast majority of these initiatives, some by issuing simple guidance, others by freezing rulemakings that had not taken effect when it came to office, and others by going through simple new informal rulemaking proceedings to repeal those rules already in effect. Had the Medicaid and food stamp agendas pursued during the last four years of the Clinton Administration been, or been perceived as being, simple benefit maximization for claimants, it might well have done so. Indeed, a visionless agenda seeking only to increase benefits willy-nilly for claimants might well have aroused such cynicism among career officials in CMS, the USDA, and OMB that they might have taken the initiative in starting that rollback as soon as the new administration arrived. Yet with only two significant exceptions, that did not happen. In both of the exceptions-some relatively technical changes in SCHIP regulations and some much larger changes in a Medicaid managed care rule-states were in vehement opposition and the Clinton initiatives did not

216. See Super, supra note 64 (manuscript at 53,57 ). 
appear central to the visions of reducing uninsuredness and helping lowwage workers.

Whatever stability these programs and particular policies will prove to have comes in large part from the interplay between their strategic vision and the technical details of the changes made. The broad appeal of the vision makes the specific initiatives defensible even though most are too technical to explain readily to the public. The impact of the particular initiatives, in turn, lends credibility to the strategic vision and avoids the cynicism that can prove lethal to public programs undertaken in the name of idealism.

To dismantle the Medicaid and food stamp initiatives of its predecessors credibly, the Bush Administration would need to do much more than cancel particular policies. It also would have to articulate an alternative vision that could compete with what they had implemented and offer enough new specific policies to make itself look serious about that alternative vision. For a busy administration with an extensive agenda, that prospect apparently had little appeal. Indeed, the vision of supporting the working poor won significant adherents among Bush political appointees, particularly, although not exclusively, ${ }^{217}$ within the USDA. Because they are compatible with the contemporary political environment, these policies are likely to survive unless and until that environment significantly changes. No judgment in nonconstitutional litigation today can plausibly claim any greater assurances of durability.

Nor does the diminished importance of the traditional attorney-client relationship in shaping public benefits advocacy necessarily portend the derogation of claimants' ability to articulate their own interests or a return to a world in which only paternalistic visions, be they liberal or conservative, shaped public benefit programs. First, the primacy of the attorney-client relationship was not as empowering as it might have seemed given the vast discretion attorneys had in allocating the scarce supply of free representation. Although an attorney may be faithfully pursuing the expressed wishes of his client, he may have preordained the course of the representation when he decided which claimants he would represent in class litigation or in a legislative or rulemaking process.

More importantly, advocacy in the post-PRWORA era generally takes place in forums that are more accessible to claimants and their organizations. Little of the important work in transforming Medicaid and the food stamp program required a bar card. Development of an effective advocacy strategy requires a nuanced feel for the legal constraints on

217. See, e.g., HASKINS, supra note 84 , at 37-44 (arguing for the importance of Medicaid and food stamps as supports for low-wage workers). Haskins subsequently became a high-level White House advisor on welfare policy. 
agencies' discretion, strong lawyers, and a sensitive understanding of the implicit limits on that discretion that the political process imposes. But it also requires a sophisticated appreciation of the way local human services offices operate and the kinds of obstacles that they place in the way of claimants, intentionally or otherwise. Claimants have natural, hard-won expertise in this latter field that can make them invaluable coalition partners for attorneys and other advocates of human services programs.

Building effective coalitions between lawyers, other professionals, and claimants, to be sure, will require more trust and open communication than sometimes has been present between claimants and lawyers. Lawyers are likely to resist investing great resources in an agenda that is patently beyond what is legally or politically sustainable. Claimants, in turn, are unlikely to see much point in pursuing proposals that they know are certain to be mangled in implementation. Similarly, just as lawyers wishing to become effective in the new environment must move beyond litigation and traditional deterministic legal analysis, so too claimants and their organizations are likely to need to diversify their advocacy arsenals beyond, while not completely abandoning, traditional confrontational tactics of demonstrations and sit-ins.

Saul Alinsky urged organizers " $[w]$ herever possible go outside of the experience of the enemy. Here you want to cause confusion, fear, and retreat." ${ }^{218}$ When fighting program administrators in court, before higher executive or legislative authorities, or in the media, that remains sound advice. In the current environment, however, advocates often must be resourceful in framing their agendas within the experience of federal and state administrators. Those officials frequently are cast as adjudicators on proposals that no other policymakers are likely to address. More broadly, their allegiances are increasingly critical in deciding battles between those who would dismantle means-tested public benefit programs and those who see those programs as having a vital role to play. PRWORA provides a stark example of how much those programs can be damaged when state administrators have been so thoroughly alienated that they are willing to help legitimize the attacks of the programs' ideological opponents. The transformation of Medicaid and the food stamp program in the years since PRWORA, on the other hand, provides a hopeful demonstration that the programs can regain state administrators' loyalties. Indeed, not only did that reconciliation not come at a high cost to claimants, but many of the policies that were most important to states also helped claimants.

Finding ways to seduce federal and state administrators to supporting policies that will strengthen programs and improve their ability to serve

218. SAUl D. ALINSKY, RULES fOR RADICALS: A PRACTICAL PRIMER FOR REALISTIC RADICALS 127 (1971). 
low-income people is a complex process, far more so than filing a simple lawsuit or writing a legislative point paper. The skills required to engage in this form of advocacy include but go far beyond those in which lawyers traditionally are trained. The results are difficult to predict and, even when favorable, generally lack the satisfying sense of progress that comes from a court's judgment or an enacted statute. But with the stakes as high as they are, those concerned about the well-being of low-income people can ill afford to eschew these forums.

\section{CONCLUSION}

In 1949, Senator Robert A. Taft, one of the leading conservative Republicans of his generation, declared:

I believe that the American people feel that with the high production of which we are now capable, there is enough left over to prevent extreme hardship and maintain a minimum standard floor under subsistence, education, medical care and housing, to give to all a minimum standard of decent living and to all children a fair opportunity to get a start in life. ${ }^{219}$

Although the 1996 welfare law reflected a widespread rejection of the method by which that aid was being provided, Senator Taft's sentiments appear still to be widely shared by the American public. ${ }^{220}$ Honoring those charitable impulses while fulfilling promises of sharp reductions in welfare caseloads presented state and local policymakers with a serious dilemma that the traditional rule-based systems for rationing benefits could not answer. Choice-based rationing strategies offered a way to resolve this challenge that fit comfortably within contemporary market-oriented ideology.

The time when the generosity and antipoverty effectiveness of public benefit programs could be understood by considering those programs' formal rules is past. Substantial numbers of low-income people long have foregone benefits for which they were legally eligible, but state and local officials' increasingly varied and energetic efforts to influence those choices of claimants, or to induce procedural defaults that can be taken as proxies for choices, have reduced the importance of eligibility policy

219. REPORT OF THE NATIONAL ADVISORY COMMISSION ON CIVIL DISORDERS 256 (1968).

220. Even conservative critics of means-tested benefits seem to concede this point. See Hearing, supra note 85 . The consistent choice of the conservative 104th Congress to avoid extracting significant savings from AFDC when converting its funding to a block grant, and PRWORA's sponsors' propensity to assert that the government would continue to help low-income people avoid destitution, see, e.g., supra note 2, suggest that they, too, believe that Senator Taft's benevolent sentiments continue to hold wide sway. 
significantly. The longer scholarly and public attention remains singlemindedly fixated on formal rationing methods, the more informal rationing methods will become entrenched without undergoing serious examination.

Although expanding claimants' choices can offer greater autonomy and independence, the growth of informal rationing also creates the risks of false or coerced choices and of illicit rationing agendas that could not have won acceptance as the basis for substantive eligibility rules. Identifying and quantifying the effects of practices that influence claimants' choices concerning public benefit programs requires new analytical tools and far more effort than appraising programs' eligibility rules. The time clearly has passed when much could be accomplished with a simple appeal against bureaucratic denials of benefits to eligible claimants. ${ }^{221}$

The costs of failing to rise to this challenge, however, are high. Choicebased rationing policies often are designed so carelessly that, far from improving the rationality with which benefits are distributed, they disadvantage some of those most in need of assistance. The regressivity of some informal rationing devices may exceed some of the most insensitive changes in formal eligibility rules. Their shadowy nature subverts public accountability both as to the goals of these programs and as to their effectiveness in meeting those goals. Appeals to public opinion to increase the generosity of assistance offered to low-income people will have great difficulty succeeding as long as the public believes that its existing programs are as generous as their eligibility rules would suggest.

On the other hand, the advantages this regime has over its historical predecessors should not be neglected. Despite the 1996 welfare law, it espouses a far stronger commitment to meeting need and preventing hardship than guided programs of the past. One of its great shortcomings is the vast discretion that local officials and individual eligibility workers have to exacerbate or moderate the deterrents to receipt of benefits: That authority can be wielded in a racially discriminatory manner or to subjugate claimants to the whims of agencies' staffs. It seems unlikely, however, that the extent of racism or paternalism that arises under this regime can match that suffered by low-income claimants in the poorhouse period or the first three decades of the AFDC program. Indeed, even during the legalistic era, a determinedly bigoted or arrogant eligibility worker had considerable opportunities to make the public benefits system more burdensome and repellent with little practical risk of being called to account.

221. See, e.g., Hunger Prevention Act of 1988, Pub. L. No. 100-435, $\S$ 201-220, 102 Stat. $1645,1655-60$ (codified as amended in scattered sections of 7 and 42 U.S.C.) (seeking explicitly to remove barriers to access to the food stamp program); Dehavenon, supra note 102, at 250-54 (insisting that welfare programs" eligibility processes should be improved "[u]nless our society is one consumed by hostility toward the poor"). 
Although the personal choice regime in the aggregate is certainly less generous philosophically and practically than its immediate predecessor, the ideology of choice provides the basis for correcting some central, highly counterproductive eligibility restrictions that had proven immune to attack during the legalistic period. Moreover, in some respects the new regime may be more susceptible to positive change than its predecessor. Limiting or ending policies that degrade the value of benefits will allow more to be done for low-income families without requiring any expansion of public resources, an important opportunity at a time of economic stagnation and shaky public finances. Indeed, since so much of the constraint on the availability of benefits results from administrative actions, programs can be liberalized much more without going through the legislative process than was typically true under the legalistic regime. The difficulty of extracting new money for program expansion or rationalization proved a major shortcoming of the prior system.

Expanding low-income people's choices in relation to public benefit programs is a laudable goal. Scholars and advocates should not seek to eliminate choice-based systems as a class. They should, however, make these systems more transparent to claimants and the general public, and should do so while also seeking to identify and expose both those programs that waste the resources of agencies and claimants alike and those that disproportionately burden the most vulnerable claimants. Some of this quest requires new empirical work, but a great deal can be accomplished by applying rigorous analysis to the results of little-noticed studies already in the public domain. ${ }^{222}$ With careful analysis of these systems' effects on claimants, choice-based programs may come to contribute to a humane public welfare policy rather than subvert it, as such policies too often do today.

222. See, e.g., VIVIAN GABOR \& CHRISTOPHER BOTSKo, CHANGES IN CLIENT SERVICE IN THE FOOD STAMP PROGRAM AFTER WELFARE REFORM: A SYNTHESIS OF CASE STUDIES IN EIGHT STATES 18-19 (Office of Analysis, Nutrition \& Evaluation, U.S. Dep't of Agric., Food Stamp Program Report No. FSP-01-CSCFP, 2001), http://www.fns.usda.gov/oane/MENU/ Published/FSP/FILES/ProgramOperations/ClientServices.pdf (describing numerous practices that impede access to food stamps and likely violate the right to apply for food stamps, as set out in 7 C.F.R. $\$ 273.2(\mathrm{c})(2)$, and the limitations on the verification process, prescribed in 7 C.F.R. $\S 273.2(\mathrm{~d})(1),(\mathrm{f})(4)-(5))$. 
$* * *$

Imaged with the Permission of Yale Law Journal 